\title{
Deep sea without limits-four new closely related species of Emertonia Wilson, 1932 (Copepoda: Harpacticoida: Paramesochridae) show characters with a world- wide distribution
}

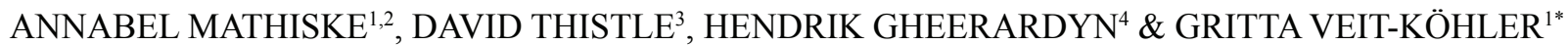 \\ ${ }^{1}$ Senckenberg am Meer, German Centre for Marine Biodiversity Research DZMB, Südstrand 44, D-26382 Wilhelmshaven, Germany. \\ ${ }^{2}$ Carl von Ossietzky University Oldenburg, Department of Biology and Environmental Science, Marine Biodiversity, D-26111 Oldenburg, \\ Germany. |" amathiske@gmail.com; ㄴttps://orcid.org/0000-0003-2929-2644 \\ ${ }^{3}$ Florida State University, Department of Earth, Ocean and Atmospheric Sciences, Tallahassee, FL, USA. \\ ”"dthistle@fsu.edu; @ ittps://orcid.org/0000-0002-8436-6987 \\ ${ }^{4}$ Eurofins Aquasense, Korringaweg 7, 4401 NT Yerseke, The Netherlands. \\ " hendrik.gheerardyn@gmail.com; ๑ https://orcid.org/0000-0003-4239-8662 \\ ${ }^{*}$ Corresponding author. =" gveit-koehler@senckenberg.de; 이ttps://orcid.org/0000-0002-3453-898X
}

\begin{abstract}
The large-scale dispersal of deep-sea harpacticoid copepods is an increasing focus for ecological studies. A fundamental prerequisite for monitoring and explaining their geographical distribution is precise descriptions of their morphology. Four new, closely related species of the family Paramesochridae (Copepoda, Harpacticoida) were found in the deep sea of the Pacific (San Diego Trough and off Chile), the Atlantic Ocean (Porcupine Abyssal Plain and Angola Basin), and the Atlantic and Indian Ocean sectors of the Southern Ocean (Weddell Sea and off Crozet Island). The discovery of Emertonia berndi sp. nov., E. hessleri sp. nov., E. ilse sp. nov., and E. serrata sp. nov. increases the number of known deep-sea species in this genus to ten. The new species are placed in Emertonia Wilson, 1932 because of their one-segmented endopods on the second and third swimming legs. The presence of a two-segmented endopod on the fourth swimming leg allocates them to the "andeep-group" within this genus. The four species can be distinguished from their congeners by the strongly serrated spines on the exopods of their swimming legs and an outwardly directed flexible seta on the exopod of the fifth leg. It is conveivable that these two specific characters evolved only once in the genus Emertonia. Their apparently cosmopolitan distribution covers thousands of kilometres and spans all major oceans. This biogeographical pattern may be explained by resuspension events followed by passive transport by benthic currents. Discrepancies in their dispersal ranges may be a result of changing geological and oceanographic boundaries.
\end{abstract}

Key words: distribution range, Kliopsyllus, meiobenthic copepods, Paramesochridae, species description, systematics, DIVA-1, PUCK, SYSTCO, D.S.V. Alvin, CROZEX

\section{Introduction}

World-wide projects such as the 'Census of the Diversity of Abyssal Marine Life' (CeDAMar) within the framework of the international 'Census of Marine Life' (CoML) resulted in an increase of the number of deep-sea expeditions dedicated to taxonomy and biogeography. This has generated more attention to taxonomic studies on deep-sea copepods and consequently the number of species descriptions has risen significantly (e.g. Seifried \& Martínez Arbizu 2008; Menzel \& George 2009; Vasconcelos et al. 2009; Veit-Köhler \& Drewes 2009; Pointner et al. 2013). Reliable descriptions are needed for carrying out biogeographical studies on deep-sea copepods. In recent years several studies of large-scale harpacticoid distribution patterns were published (Gheerardyn \& Veit-Köhler 2009; Chertoprud et al. 2010; Veit-Köhler et al. 2010; Menzel et al. 2011; Easton \& Thistle 2016).

The four new species presented here live in typical deep-sea habitats such as troughs, abyssal plains and off continental margins. They were collected from one or more of the following localities: Pacific Ocean-San Diego Trough off California (1,050 m depth), at the continental margin of Chile off Antofagasta, Concepción and Chiloé 
(890-2,060 m); Atlantic Ocean-Porcupine Abyssal Plain (4,843 m) and Angola Basin (5,389 m); Atlantic and Indian Sector of the Southern Ocean-Southern Polar Front and Crozet Plateau (2,964 and 4,197 m depth, respectively). All four species belong to the genus Emertonia Wilson, 1932 in the family Paramesochridae. Members of this family typically have a cylindrical body shape and a small rostrum but a varying segmentation in the endopods of the swimming legs (Boxshall \& Halsey 2004). For instance, Emertonia can readily be distinguished from the other genera of the subfamily Paramesochrinae by their one-segmented endopods on the second and third swimming legs which bear one apical seta (Veit-Köhler 2004). Back \& Lee (2017) amended the diagnosis of Emertonia and established five groups within the genus. All four new species belong to the "andeep-group", which is characterized by a two-segmented endopod on the fourth swimming leg.

Including the above, ten Emertonia species have been described from deep-sea habitats so far. The other most recently described deep-sea species are the widely distributed and eurybathic E. clausi Pointner \& Veit-Köhler in Pointner et al., 2013 from the Pacific Nodule Province and the Atlantic Ocean (Angola Basin, Guinea Basin, Great Meteor Seamount) and E. ingridae Pointner \& Veit-Köhler in Pointner et al., 2013 from the Guinea Basin (Pointner et al. 2013).

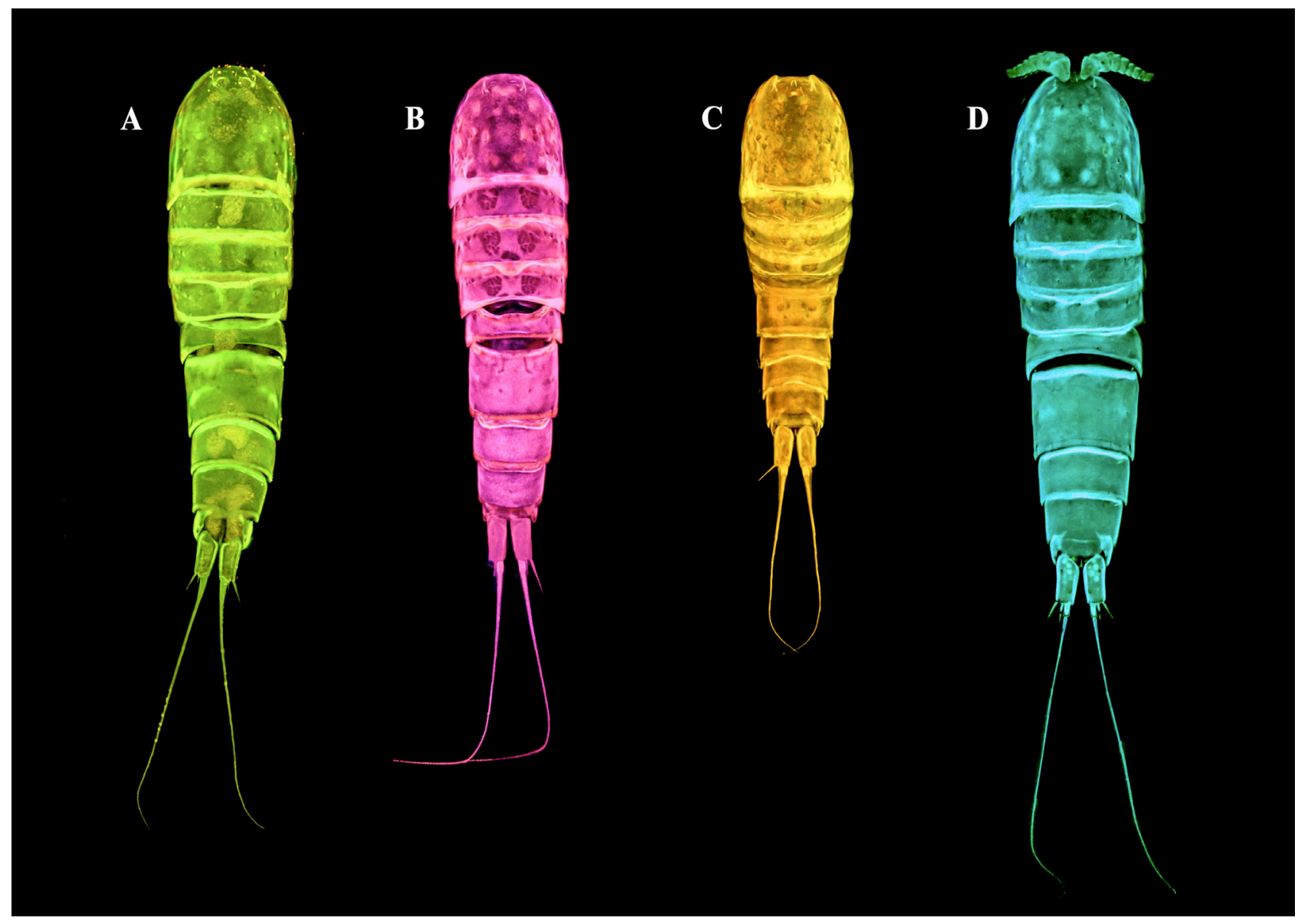

FIGURE 1. Dorsal view of the habitus of the four new Emertonia species. A, E. serrata sp. nov. (female holotype, 0.24 mm); B, E. ilse sp. nov. (female holotype, $0.23 \mathrm{~mm}$ ); C, E. hessleri sp. nov. (male allotype, $0.19 \mathrm{~mm}$ ); D, E. berndi sp. nov. (female holotype, $0.25 \mathrm{~mm}$ ). Images taken with confocal laser scanning microscope.

\section{Material and methods}

Specimens of Emertonia berndi sp. nov., E. hessleri sp. nov., E. ilse sp. nov., and E. serrata sp. nov. were collected from stations in the Pacific, the Atlantic and the Southern Ocean (Fig. 2; Table 1).

Meiofauna samples, containing specimens of the new species (Fig. 2), were taken in the Atlantic Ocean during expeditions on board the RRS Discovery to the Porcupine Abyssal Plain (PAP, 1997; sampling information in Kalogeropoulou et al. 2010), RV Meteor M48.1 to the Angola Basin (DIVA-1, 2000; more data in Rose et al. 2005), 
RV Polarstern PS71 to the Southern Ocean (SYSTCO, 2007-2008; for details see Veit-Köhler et al. 2013). From the Indian sector of the Southern Ocean samples were collected during the RRS Discovery cruise 300 to the Crozet Plateau (CROZEX, 2005-2006; cruise report by Wolff 2006). In the Pacific Ocean sampling was carried out with D.S.V. Alvin from board of the RV Atlantis II in the San Diego Trough (ALVIN, 1987; information on sampling in Thistle \& Eckman 1990), and on board RV Sonne cruise SO 156 (PUCK, 2001; specimens collected at stations below the oxygen minimun zone as described by Veit-Köhler et al. 2009).

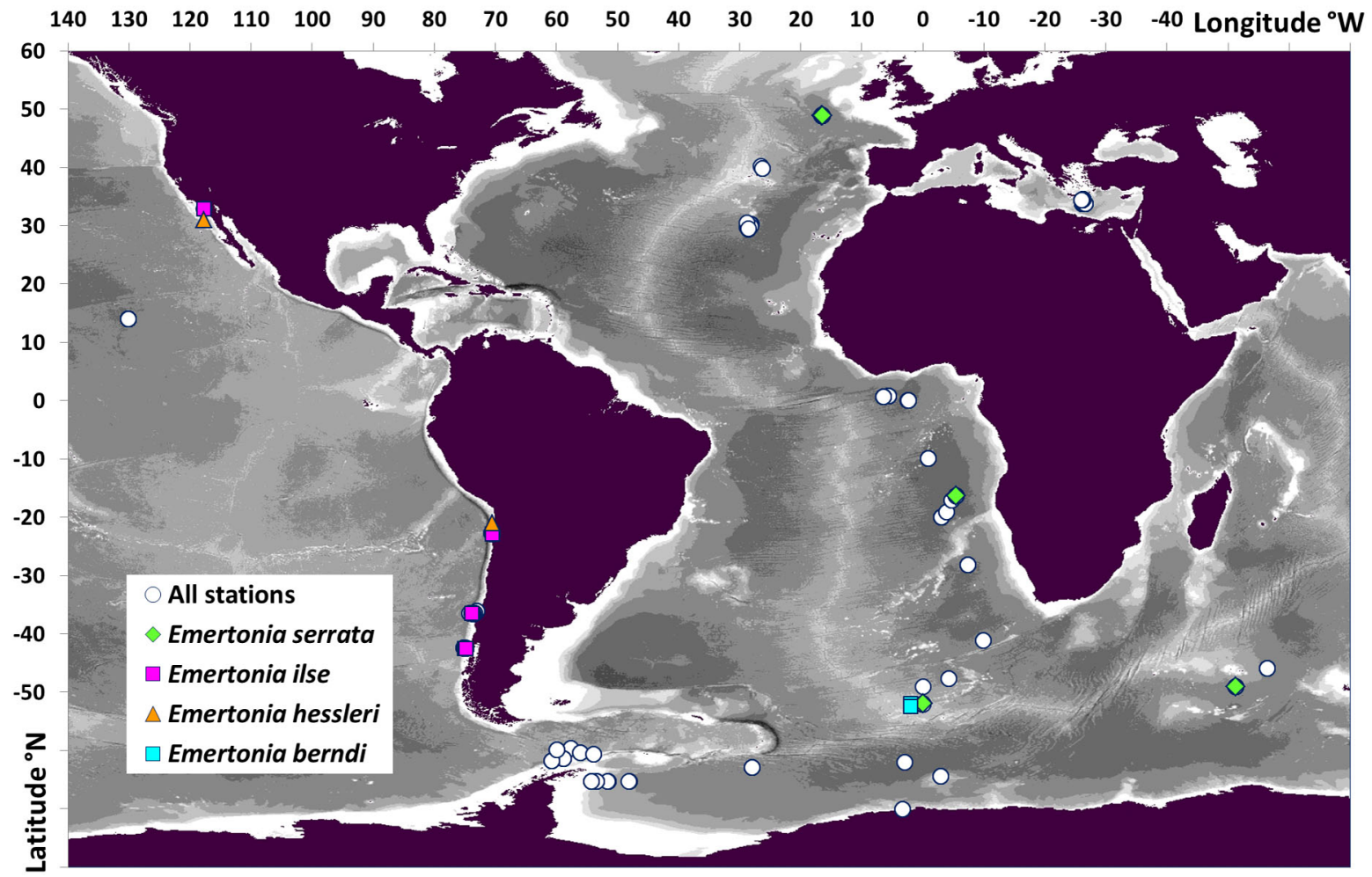

FIGURE 2. Distribution of Emertonia serrata sp. nov., E. ilse sp. nov., E. berndi sp. nov., and E. hessleri sp. nov. in the Pacific, Atlantic, and Southern Oceans (filled symbols, see legend). All stations checked for Paramesochridae in the course of this study are indicated (white circles). Closely situated stations or deployments represented by a single symbol. Isobaths given in 1,000 m contours. Source: General Bathymetric Chart of the Oceans (GEBCO), 30" grid.

Further, all available multicorer and several box corer samples from additional expeditions were checked for the four new species but contained none of them. These samples were collected from the following marine areas (Fig. 2):

Mediterranean: Eastern Mediterranean (RV Meteor M71-2, LEVAR, 2007); Atlantic Ocean: Seine and Sedlo sea mounts (RV Meteor M60-1, OASIS, 2003; cf. Büntzow 2011), Guinea Basin (RV Meteor M63-2, DIVA-2, 2005; cf. Menzel \& George 2012), Cape Basin (RV Polarstern PS67, ANDEEP III, 2005; cf. Rose et al. 2006); Southern Ocean: Weddell and Scotia Sea (RV Polarstern PS61, ANDEEP I and II, 2002, Gutzmann et al. 2004; cf. Rose et al. 2015); Pacific Ocean: nodule province (RV L'Atalante, NODINAUT, 2004; $c f$. Mahatma 2009).

Different methods for taking sediment samples were applied. In the following we list the methods used in the expeditions that revealed specimens of the four new species:

The D.S.V. Alvin gathered tube cores with a $6.6 \mathrm{~cm}$ inner diameter, which were then processed as described by Thistle \& Eckman (1990). First, each tube core was mounted on an extruder and the water overlying the sediment was drawn off. Then, the top $1 \mathrm{~cm}$ of the sediment was extracted and fixed in a sodium-borate-buffered solution of $45-\mu \mathrm{m}$ filtered seawater and formalin (4:1). Using the Barnett (1968) procedure, copepods were concentrated from the sediment (with a mean extraction efficiency of $98.5 \%, n=6$, Thistle \& Eckman 1988), stained with rose bengal, and sorted under a dissecting microscope (Thistle \& Eckman 1990). Meiofauna samples from the other expeditions were taken with a multiple corer (MUC; $c f$. Barnett et al. 1984) although with differing internal diameters of the cores: (PUCK $3.6 \mathrm{~cm}$, PAP $5.7 \mathrm{~cm}$, DIVA-1 $9.6 \mathrm{~cm}$, SYSTCO $9.4 \mathrm{~cm}$, and CROZEX $5.9 \mathrm{~cm}$ ). 


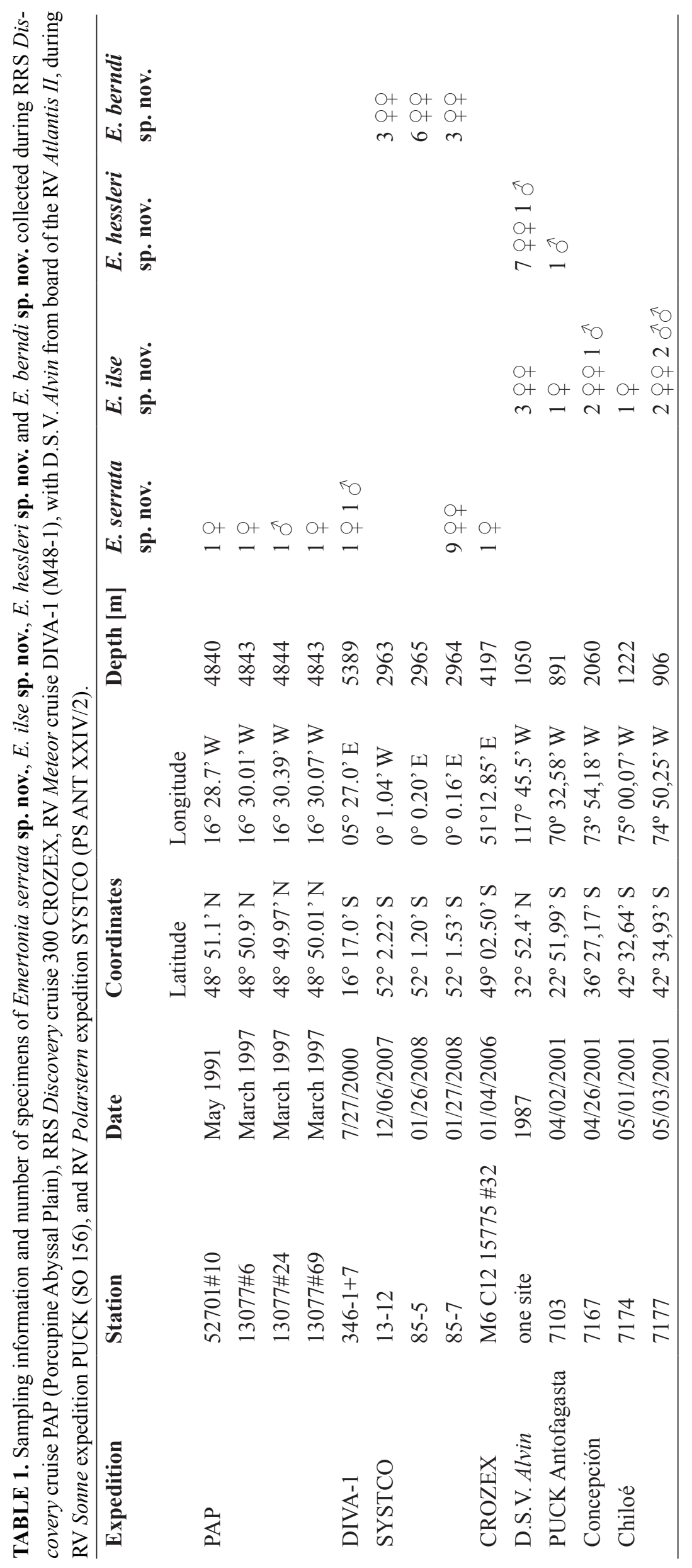


All samples from the latter expeditions were preserved with 5\% buffered formalin. In order to separate the meiofauna from sediment and other particles, the samples were first washed with tap water through a 40- $\mu \mathrm{m}$ (PUCK, DIVA-1, CROZEX) or a 32- $\mu \mathrm{m}$ mesh sieve (PAP, SYSTCO) and then centrifuged (Rose et al. 2005; VeitKöhler et al. 2009, 2013; Kalogeropoulou et al. 2010; CROZEX: unpubl.). A colloidal silica polymer (H.C. Starck, Levasil $200 / 40 \%, \rho=1.17$ ) functioned as a flotation medium, and kaolin held back the heavier particles (McIntyre \& Warwick 1984). After each of three iterations of centrifugation (at 4,000 rpm), the floating matter containing meiofauna organisms was decanted over the respective sieve and rinsed with tap water.

The meiofauna was sorted and counted with a Leica MZ 12.5 stereomicroscope on a higher taxon level (e.g. Annelida, Copepoda, Nematoda). The copepods were transferred to a mixture of glycerin and water (1:1), while all other taxa stayed in the sample and were preserved with 5\% buffered formalin after counting. The Emertonia species were then identified with the aid of a Leica DMR microscope.

Specimens of E. berndi sp. nov., E. hessleri sp. nov., E. ilse sp. nov., and E. serrata sp. nov. were selected, mounted in glycerin on slides and drawn from the dorsal and lateral view. Body parts were drawn after dissection. Illustrations were made using a Leica DMR microscope equipped with differential interference contrast (DIC) at $1000 \mathrm{x}$ magnification and with the aid of a camera lucida. The illustrations were then traced, to ensure a high resolution, using the software Adobe Photoshop CC 2017.

The type specimens of all four species were imaged with a confocal laser scanning microscope. Individuals were stained beforehand with a watery solution of acid fuchsin and Congo red (modified after Michels \& Büntzow 2010). They were then scanned with a Leica CTR 5000 (DZMB, Senckenberg am Meer) equipped with a Leica DM 5000 B microscope (400 x magnification) and two visible light lasers (Argon and DPSS561). Maximum intensity projections were created with the Leica LAS software (Leica Microsystems) using image stacks. The final images were assembled and adjusted for contrast and brightness using the software Adobe Photoshop CC 2017.

The map was created using the mapping tool provided by GEBCO (General Bathymetric Chart of the Oceans, 30 second grid file GEBCO_2014_1D) and the GEBCO bathymetry data sources from IOC, IHO and BDOC (1994).

The descriptive terminology follows Huys et al. (1996). Abbreviations used in this text: aes $=$ aesthetasc, $\exp =$ exopod, enp = endopod, benp $=$ baseoendopod, P1-P6 = swimming legs 1-6, and enp(exp)1,2,3 = the first, second, third segment of the endopod (exopod).

\section{Systematics}

\section{Order Harpacticoida Sars, 1903}

\section{Family Paramesochridae Lang, 1944}

\section{Subfamily Paramesochrinae Lang, 1944}

\section{Genus Emertonia Wilson, 1932}

\section{Emertonia serrata Mathiske \& Veit-Köhler sp. nov.}

http://zoobank.org/urn:lsid:zoobank.org:act:5EFC895C-8621-473C-AAF0-164D3A2D0E1B

Type material. The examined specimens are registered and deposited in the Senckenberg Forschungsinstitut und Naturmuseum Frankfurt (SMF), Germany. All specimens were collected in the Atlantic Ocean and in the Atlantic and Indian Ocean sector of the Southern Ocean. Station numbers indicate "Expedition, station number (plus deployment number for SYSTCO and DIVA-1), depth, core number, sediment horizon".

Female holotype, SMF 37235 (adult female on 1 slide): RV Polarstern PS71—SYSTCO, St. 85-7, 2,964 m, MUC8, 0-1 cm.

Male allotype, SMF 37236 (adult male on 1 slide): RV Meteor 48/1-DIVA-1, St. 346-7, 5,389 m, R7, 0-1 $\mathrm{cm}$.

Female paratype 1, SMF 37237 (adult female on 8 slides): RV Polarstern PS71—SYSTCO, St. 85-7, 2,964 m, MUC8, 0-1 cm. 
Male paratype 2, SMF 37238 (adult male on 3 slides): RRS Discovery 226-PAP, St. 13077\#24, 4,844 m, 0-1 cm.

Etymology. The species name refers to the conspicuous serrations on the spines of the swimming legs P2-P4. Spines of this type are not known from any other species of Paramesochridae.

Description of female. Habitus (Fig. 3A, B). Total body length measured from anterior tip of rostrum to posterior margin of anal somite (holotype) $0.22 \mathrm{~mm}$, including caudal rami $0.24 \mathrm{~mm}$. Body cylindrical, slightly depressed dorsoventrally, with prosome slightly wider than urosome. Pores present in small numbers, distributed dorsally and laterally on cephalothorax and most of free somites. Most sensilla visible on cephalothorax, some on third and fourth pedigerous somite. Entire posterior margin of first urosomal somite ornamented with two rows of microspinules. Genital double-somite ornamented with row of micro- and row of spinules on posterior margin. Third urosomite with row of micro- and row of different sized spinules along posterior margin. Fourth urosomite ventrolaterally with same-sized spinules as anterior urosomite. Fourth urosomite with thin, well developed pseudoperculum. Anal somite short, with minute spinules ventrally and ventrolaterally along posterior margin (Fig. 3B, C).

Caudal rami of adult female (Fig. 3C) cylindrical, approximately two to three times longer than wide, with five setae: seta I absent; seta II slender, dorsally displaced; seta III slender, unipinnate, spine-like, situated dorsolaterally, near posterior end; seta IV shorter, naked, and more slender than III, V long and slender, bipinnate in posterior half; seta VI absent; seta VII slender, on dorsal surface.

Antennule (Fig. 4A, B). Eight-segmented. Armature formula:

$\mathrm{I}(0)$

II (7)

III (3)

$\operatorname{IV}[1+(2+$ aes $)]$

$\mathrm{V}(1)$

VI (0)

VII (3)

VIII $[6+(1+$ aes $)]$ six slender naked setae of different sizes, one seta with three spinules near posterior end three naked setae

three naked setae, two of which situated on small protrusion with one aesthetasc

one slender seta

unarmed

three naked setae, two of which long

seven slender naked setae, one of which fused at base with aesthetasc

Antenna. See male (Fig. 5A).

Mandibular palp (Fig. 5B). Palp biramous. Endopod two-segmented, proximal segment unarmed, distal segment apically with five naked, basally fused, slender setae. Exopod one-third length of endopod, one-segmented, with one dorsally displaced and two apical setae.

Maxillule (Fig. 5C). Praecoxal arthrite with two juxtaposed strong, stout setae on anterior and one seta on anterior surface. Arthrite with one short and flexible, four stout and two spine-like setae. Coxal endite bearing six slender setae. Endite of basis with four slender, naked setae. Endopod one-segmented, bearing two slender naked setae. Exopod with three slender naked setae.

Maxilla (Fig. 5D). Praecoxa and coxa fused forming syncoxa with three endites. No separation with basis visible. Proximal endite with two slender, unipinnate setae. Middle endite with two slender, unipinnate setae. Distal endite with two slender, naked setae. Allobasis with one naked and one unipinnate seta. Endopod with six naked setae, one of which broken off.

Maxilliped (Fig. 5E). Syncoxa with one long, naked seta. Basis with row of spinules. Endopod one-segmented, apically with one long, geniculate seta and one naked seta accompanied by three small spinules.

Swimming legs (Fig. 6; Table 2). With rami characteristic for Emertonia species belonging to the andeepgroup; intercoxal sclerites without ornamentation.

TABLE 2. Setation of swimming legs P1-P4 of Emertonia serrata sp. nov.

\begin{tabular}{lccc}
\hline & Basis & Exopod & Endopod \\
\hline P1 & 1.1 & 0.022 & 0.020 \\
P2 & 0.1 & 0.0 .022 & 010 \\
P3 & 0.1 & 0.0 .022 & 010 \\
P4 & 0.1 & 0.0 .011 & 0.010 \\
\hline
\end{tabular}



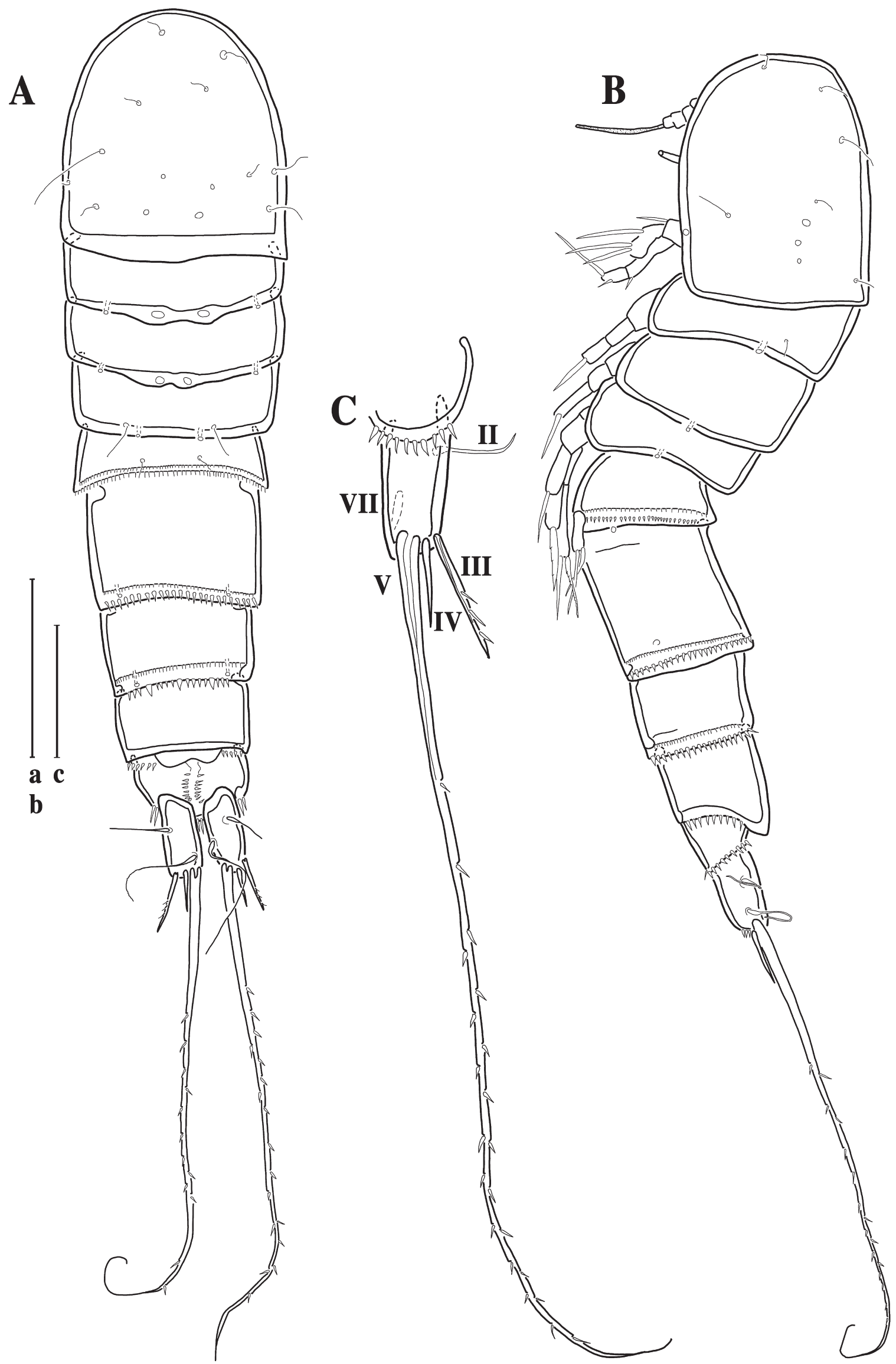

FIGURE 3. Emertonia serrata sp. nov. Female (holotype). A, habitus, dorsal view; B, habitus, lateral view; C. caudal ramus, ventral view. Scale bars $=$ a, b, $0.05 \mathrm{~mm}$; c, $0.02 \mathrm{~mm}$. 

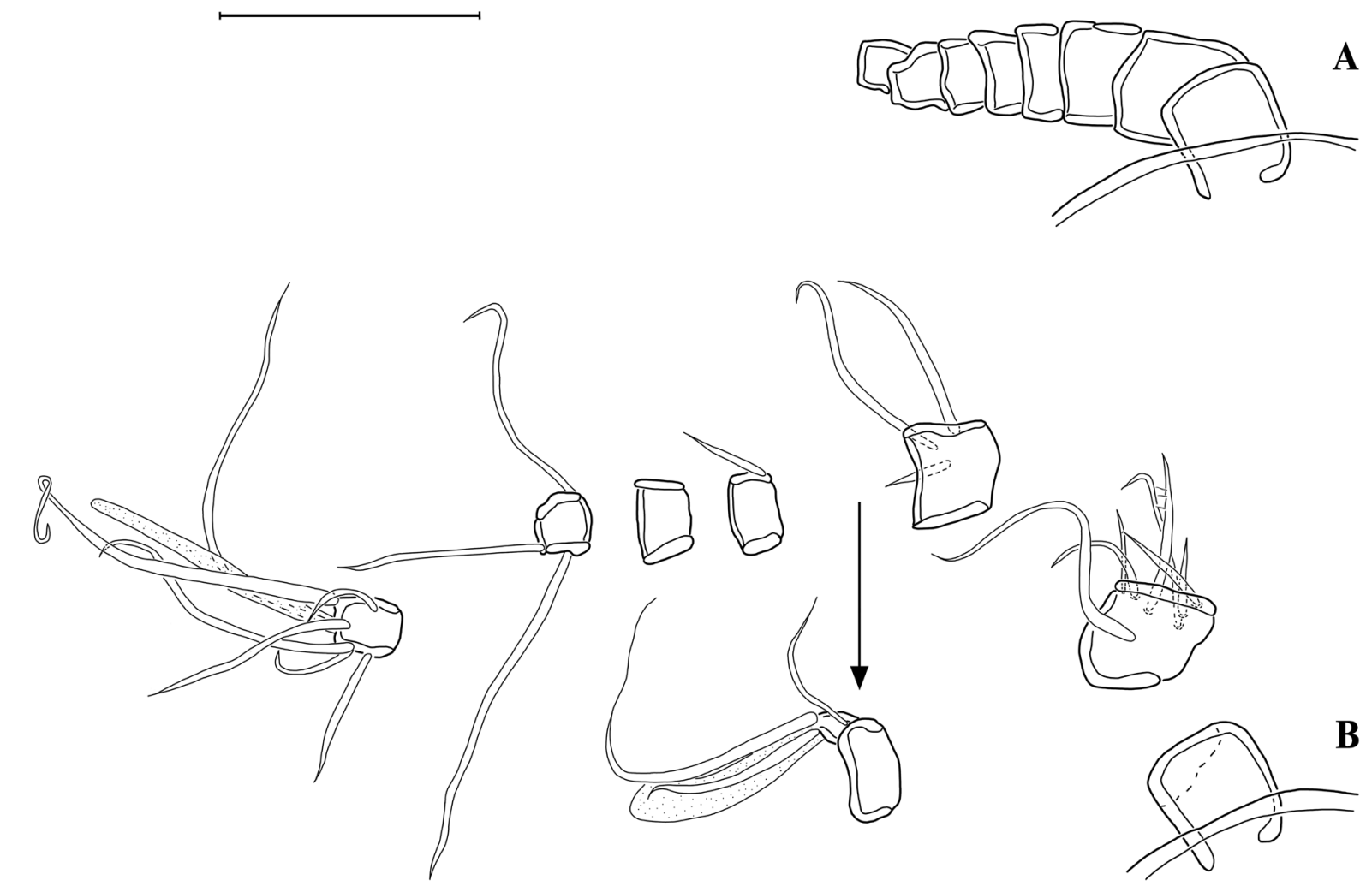

FIGURE 4. Emertonia serrata sp. nov. Female (paratype 1). A, antennule, overview (armature omitted); B, disarticulated antennulary segments showing armature. Scale bar $=0.02 \mathrm{~mm}$.

P1 (Fig. 6A). Basis with one pinnate inner seta and one naked outer seta. Endopod slightly longer than exopod, both rami two-segmented. Enp1 armed with spinules on outer margin and three pinnules near inner distal corner. Enp1 unarmed. Enp2 terminally with one long bipinnate seta, one shorter, naked, slighty displaced outer seta, and one spine-like spinule near inner distal corner. Exp1 with one unipinnate outer spine. Exp2 with all elements arranged around distal margin: one unipinnate and one bipinnate spine, and two setae, the outermost being bipinnate with short outer pinnules, the inner one with pinules on inner margin.

P2-P4 (Fig. 6B-D). Surface of coxae naked. Bases of P2-P4 bearing one naked outer seta accompanied by a short row of spinules. Three-segmented exopods slightly longer than endopods, with spinules along outer margin. P2-P4 exp1 and exp2 with one strong serrated spine; exp2 with one inner spinule situated on pronounced ledge. P2-P3 exp3 with four elements. P2 exp3 with two serrated outer spines, and apically with one long, serrated outer spine and one long inner seta with two long pinnules. P3 exp3 as in P2, but long seta with four long pinnules. P4 exp3 with two serrated spines (outer one short and strongly serrated, inner one long); inner distal corner with few spinules. Endopods P2-P3 one-segmented with spinules along outer margin and an additional terminal spinule row. Endopods P2-P3 bearing two spinules on inner margin, one of which positioned on a ledge; apically with long, rigid, spine-like bipinnate seta. Endopod P4 two-segmented, armed with spinules along outer margin; enp1 apically with one inner spinule, and spinule row on posterior surface; enp2 with a row of inner spinules. P4 enp2 apically with two short spinous processes and one spine-like seta with distally jagged tip.

P5 (Fig. 7A). Baseoendopods fused medially; completely separated from small exopods. Baseoendopod with long outer basal seta (with two pinnules) and short spinule row near outer margin on anterior surface. Endopodal lobes well developed, separated by medial cleft; each with halfmoon-shaped spinule row and two stout setae, the outer unipinnate and the inner one bipinnate. Exopod with several spinules along inner margin and three spinelike setae, the inner one being shortest, the outer one being longest and unipinnate, and the middle one being more flexible, outwardly directed and arising from a minute protrusion. 


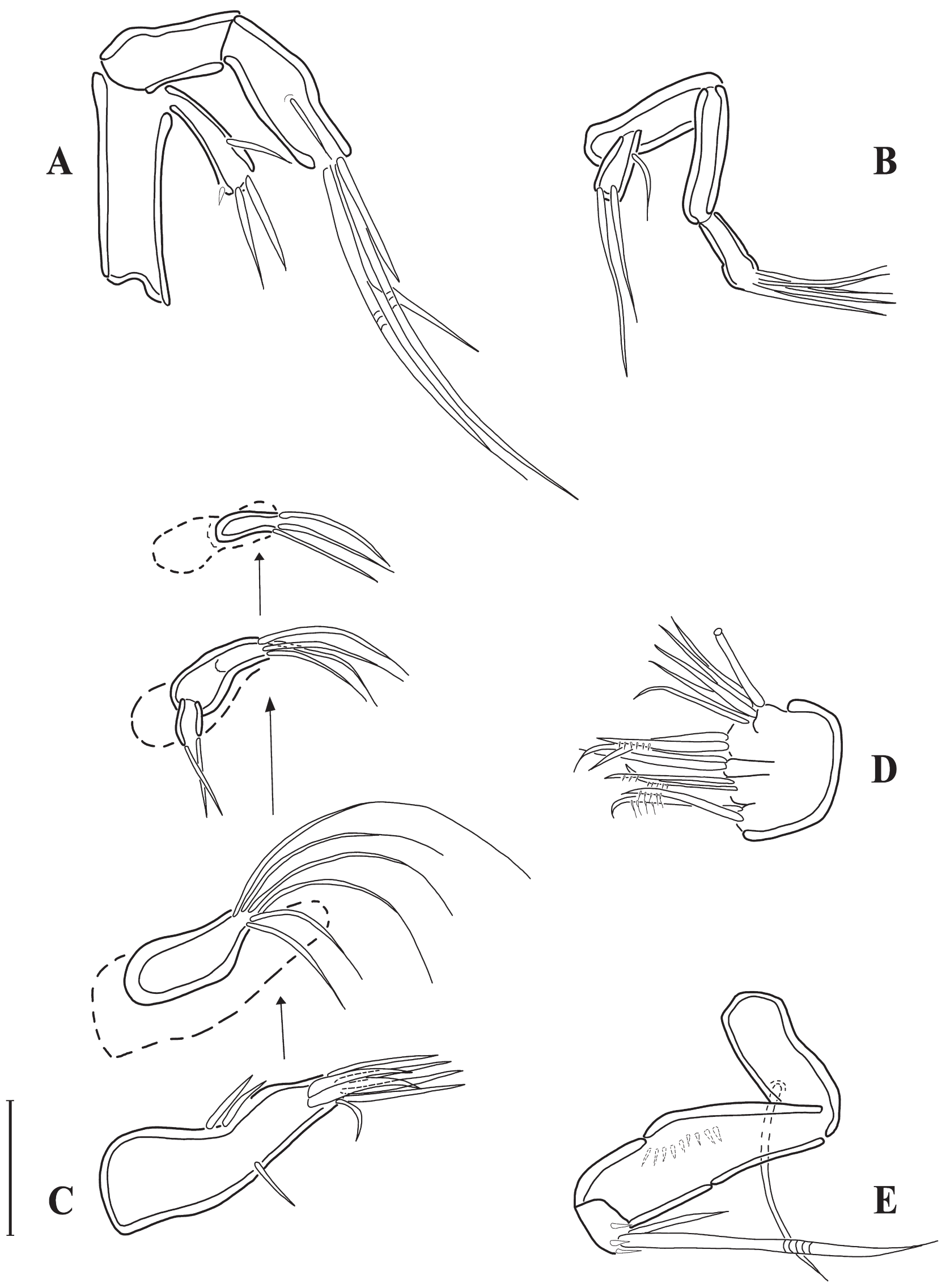

FIGURE 5. Emertonia serrata sp. nov. Male: A, antenna (paratype 2); B, mandibular palp (allotype); C, maxillule, disarticulated (allotype). Female: D, maxilla (paratype 1); E, maxilliped (paratype 1). Scale bar $=0.01 \mathrm{~mm}$. 


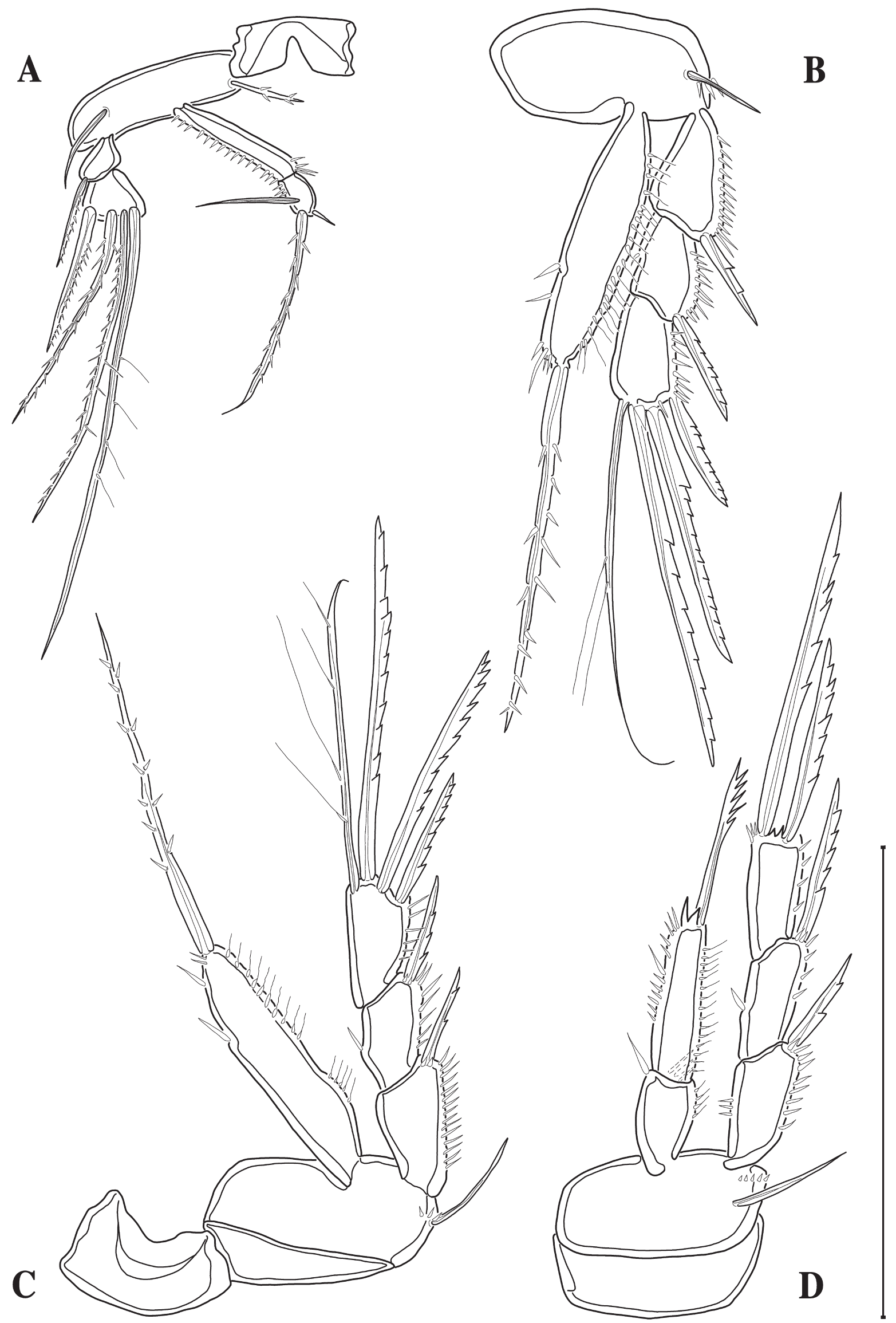

FIGURE 6. Emertonia serrata sp. nov. Female (holotype). A, P1; B, P2; C, P3 with intercoxal sclerite; D, P4. Scale bar $=0.05$ $\mathrm{mm}$. 

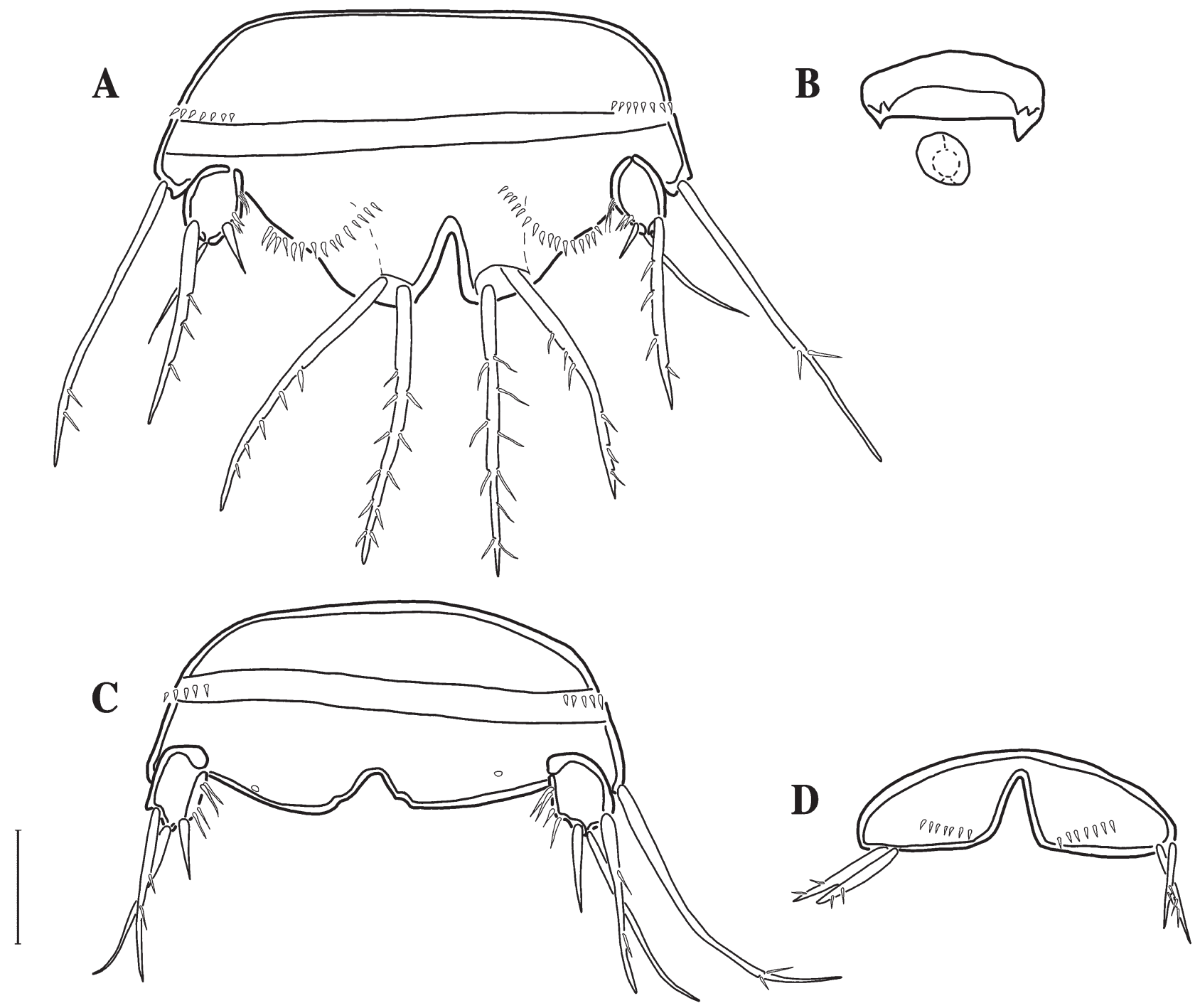

FIGURE 7. Emertonia serrata sp. nov. Female (paratype 1): A, P5; B, P6 and genital field. Male (allotype): C, P5; D, P6. Scale bar $=0.01 \mathrm{~mm}$.

P6 and genital field see Fig. 7B. Sixth pair of legs represented by small fused outgrowths bearing two minute spinous processes.

Description of male. Habitus (Fig. 8A-C). As in female but second and third urosomites not fused. Total body length measured from anterior tip of rostrum to posterior margin of anal somite (allotype) $0.20 \mathrm{~mm}$, including caudal rami $0.22 \mathrm{~mm}$. Mouthparts and swimming legs as in female, sexual dimorphism in antennule, P5, P6 and urosomal segmentation.

Antennule (Fig. 9). Seven-segmented. Segment III small, segment V rounded and bulbous (Fig. 9 A, B). Armature formula:

I (0)

II (5)

III (2)

IV (3)

$\mathrm{V}(6+\mathrm{aes})$

VI (2)

VII $(6+$ aes $)$ five slender naked setae

two naked setae

three slender naked setae

three slender naked setae, three spine-like setae and one aesthetasc

two naked setae

six slender naked setae and one aesthetasc 

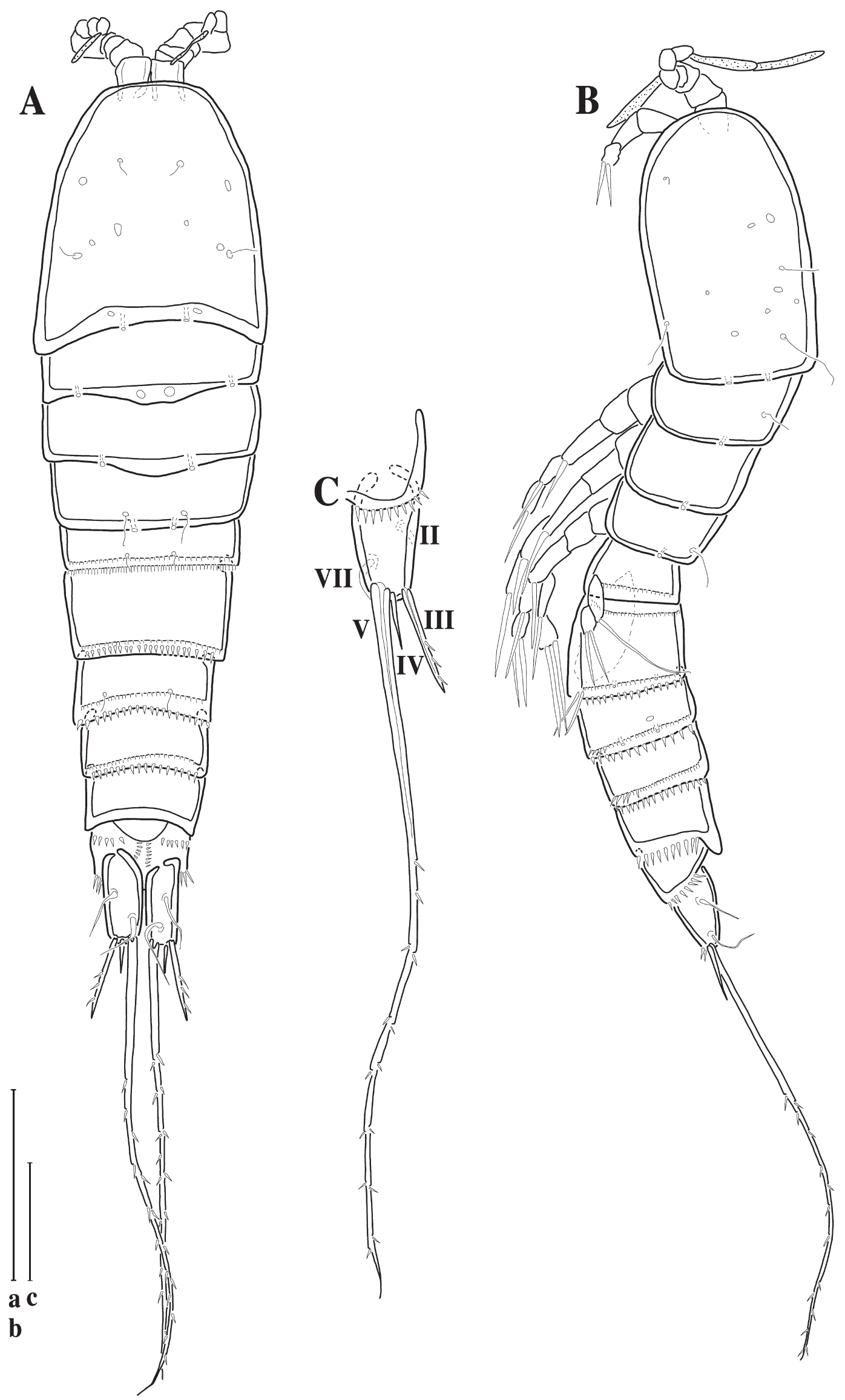

FIGURE 8. Emertonia serrata sp. nov. Male (allotype). A, habitus, dorsal view; B, habitus, lateral view; C, caudal ramus, ventral view. Scale bars $=$ a, b, $0.05 \mathrm{~mm}$; c, $0.02 \mathrm{~mm}$. 
Antenna (Fig. 5A). Endopod two-segmented; enp1 unarmed; enp2 subapically with one seta; apical margin of enp2 with four slender naked setae, two of which geniculate. Exopod one-segmented with one naked inner seta and a small spine adjacent to two naked setae.

P5 (Fig. 7C). Baseoendopods fused medially; with outer basal seta (lost on one side) and short row of spinules near outer margin; endopodal lobes weakly developed, separated medially by indentation. Exopod discrete at base; with several spinules on inner margin; armed with three spine-like setae, the innermost being shortest and naked, the outer being longest and with two pinnules, and the middle one being flexible, naked, originating from a minute protrusion and outwardly directed.

P6 (Fig. 7D). Sixth legs represented by small, medially fused plates separated by deep cleft, each with two small, unipinnate setae and a short row of spinules on anterior surface.

A
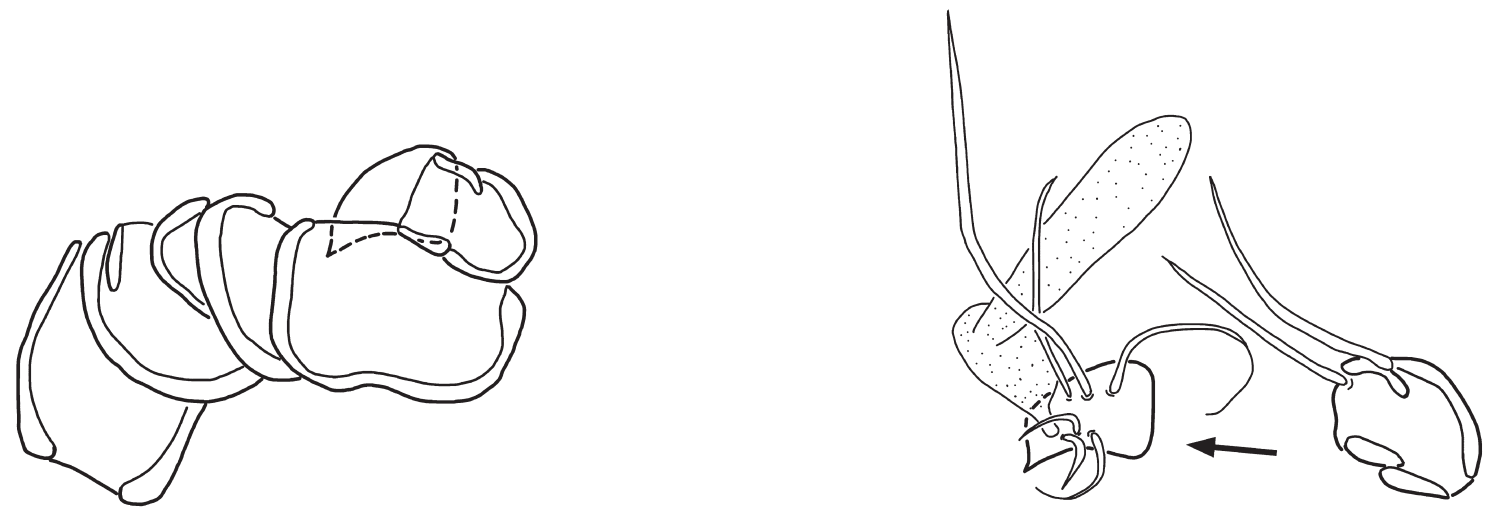

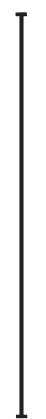

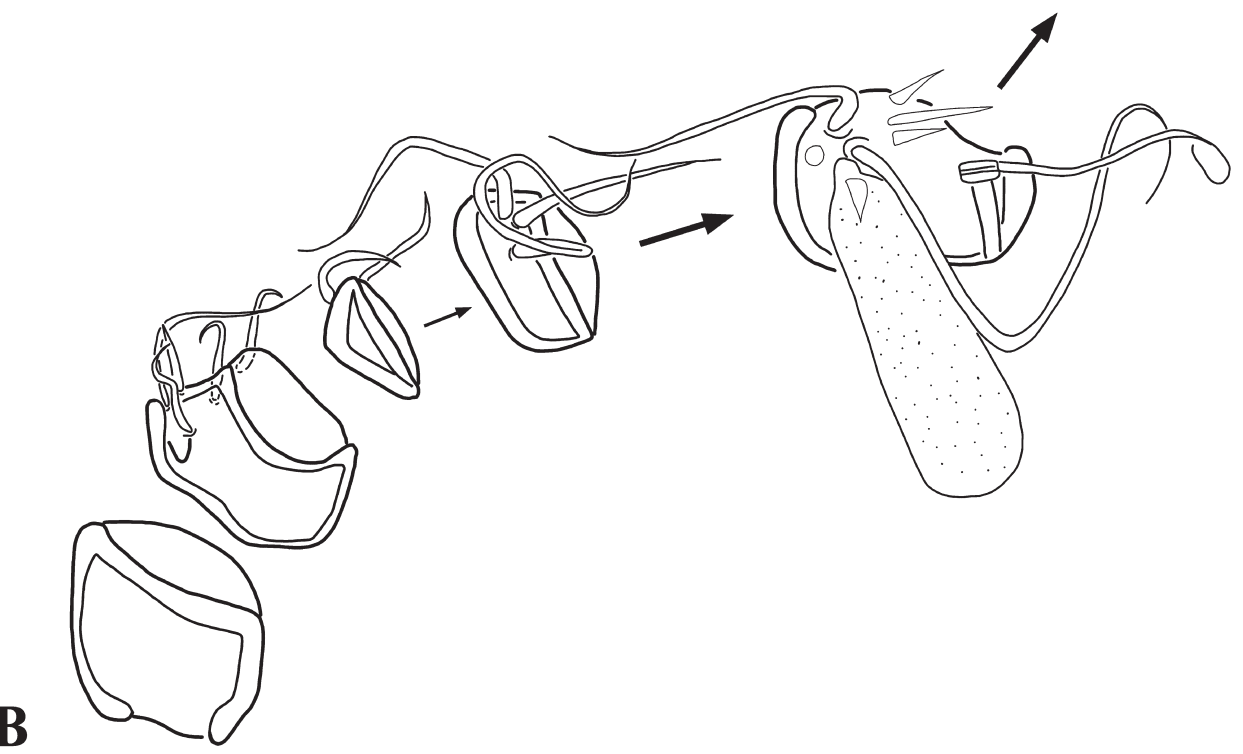

FIGURE 9. Emertonia serrata sp. nov. Male (paratype 1). A, antennule, overview (armature omitted); B, disarticulated antennulary segments showing armature. Scale bar $=0.02 \mathrm{~mm}$.

\section{Emertonia ilse Mathiske \& Veit-Köhler sp. nov.}

http://zoobank.org/urn:lsid:zoobank.org:act:507DF461-3544-4F27-93C4-2E5A4F013E62

Type material. The examined specimens are registered and deposited in the Senckenberg Forschungsinstitut und Naturmuseum Frankfurt, Germany. All specimens of the type material were collected on the continental margin off Chile. Station numbers indicate "Expedition, station number, depth, core number, sediment horizon".

Female holotype, SMF 37239 (adult female on 1 slide): RV Sonne 156 C_PUCK, St. 7174, 1,222 m, R3, 0-1 $\mathrm{cm}$.

Male allotype, SMF 37240 (adult male on 1 slide): RV Sonne 156 B-PUCK, St. 7167, 2,060 m, R1, 0-1 cm.

Female paratype 1, SMF 37241 (adult female on 6 slides): RV Sonne 156 C-PUCK, St. 7177A, 906 m, R4, $0-1 \mathrm{~cm}$. 
Female paratype 2, SMF 37242 (adult female on 2 slides): RV Sonne 156 B-PUCK, St. 7167, 2,060 m, R1C, $0-1 \mathrm{~cm}$.

Male paratype 3, SMF 37243 (adult male on 7 slides): RV Sonne 156 C-PUCK, St. 7177B, 906 m, R3, 0-1 $\mathrm{cm}$.

Female paratype 4, SMF 37244 (adult female on 5 slides): RV Sonne 156 C—PUCK, St. 7177C, 906 m, R4, $0-1 \mathrm{~cm}$.

Male paratype 5, SMF 37245 (adult male on 1 slide): RV Sonne 156 C—PUCK, St. 7177A, 906 m, R3, 0-1 $\mathrm{cm}$.

Etymology. This species is dedicated to Ilse Veit-Köhler, mother of Gritta Veit-Köhler, who always encouraged her daughter's love for nature and animals.

Description of female. Habitus (Fig. 10A, B). Total body length measured from anterior tip of rostrum to posterior margin of anal somite (holotype) $0.21 \mathrm{~mm}$, including caudal rami $0.23 \mathrm{~mm}$. Body cylindrical, slightly depressed dorsoventrally, with prosome slightly wider than urosome. Pedigerous somites bearing P2-P4 with middorsal backwardly directed protrusions arising from posterior margin. Pores present in small numbers, distributed dorsally and laterally on cephalothorax and most of free somites. Sensilla visible on cephalothorax and third pedigerous somite. Second and third prosomal somites dorsally ornamented with short row of microspinules. Entire posterior margin of first three urosomites ornamented with spinules. First urosomite with additional spinule row laterally. Fourth urosomite ventrolaterally with same-sized spinules as in preceding somites and minute spinules along entire posterior margin. Fourth urosomite forming thin, well developed pseudoperculum (Fig. 10A, B). Anal somite short with minute spinules ventrally and ventrolaterally along posterior margin (Fig. 10B, C).

Caudal rami of adult female (Fig. 10C) cylindrical, approximately three times longer than wide, with five setae: seta I absent; seta II slender, dorsally displaced; seta III slender with clearly visible inner structure, spine-like, situated dorsolaterally, near posterior end; seta IV shorter and more slender than III; seta V long and slender with clearly visible internal fracture plane, three pinnules in posterior half; seta VI absent; seta VII slender, arising from dorsal surface. Posterior margin of caudal rami with ventral spinule row.

Rostrum (Fig. 11A). Small, hyaline, not defined at base; not discernible in dorsal or lateral aspect.

Antennule (Fig. 12A, B). Eight-segmented. Armature formula:

I (0)

II (8)

III (4)

IV $(1+2$ aes $)$

$\mathrm{V}(1)$

VI (1)

VII (3)

VIII $[5+(1+$ aes $)+$ aes $]$ eight slender naked setae of different sizes, one of which minute

four naked setae

one naked seta and two aesthetascs

one long slender seta with one pinnule

one slender naked seta

three naked setae, one of which long

six slender setae, two aesthetascs, one of which fused at base with longest

slender naked seta with one spinule

Antenna. See male (Fig. 11B).

Mandible (Fig. 11D, E). Coxa with slender elongate gnathobase (Fig. 11D); cutting edge with two large and four smaller teeth. Palp biramous (Fig. 11E). Basis asetose. Endopod two-segmented; proximal segment asetose, distal segment apically furnished with four naked, basally fused, slender setae. Exopod one-third length of endopod, one-segmented, with three apical setae.

Maxillule (Fig. 11F, G). Praecoxal arthrite with two juxtaposed slender setae on anterior surface. Inner margin of arthrite with five stout spines (two of which shorter than the others) and four additional setae (not all visible in Fig. 11G). Coxal endite bearing three slender setae. Endite of basis armed with three slender naked setae. Endopod one-segmented, with three slender naked setae. Exopod missing.

Maxilla (Fig. 11H). Praecoxa and coxa fused forming syncoxa with three endites. No separation with basis visible. Proximal endite slightly bilobed, with slender, naked seta on either lobe. Middle endite with two slender, naked setae. Distal endite with two slender, naked setae. Allobasis with stout, naked, claw-like spine (no separation from allobasis visible) accompanied by two naked setae. Endopod two-segmented with one naked seta on proximal segment and three naked setae on distal one. 

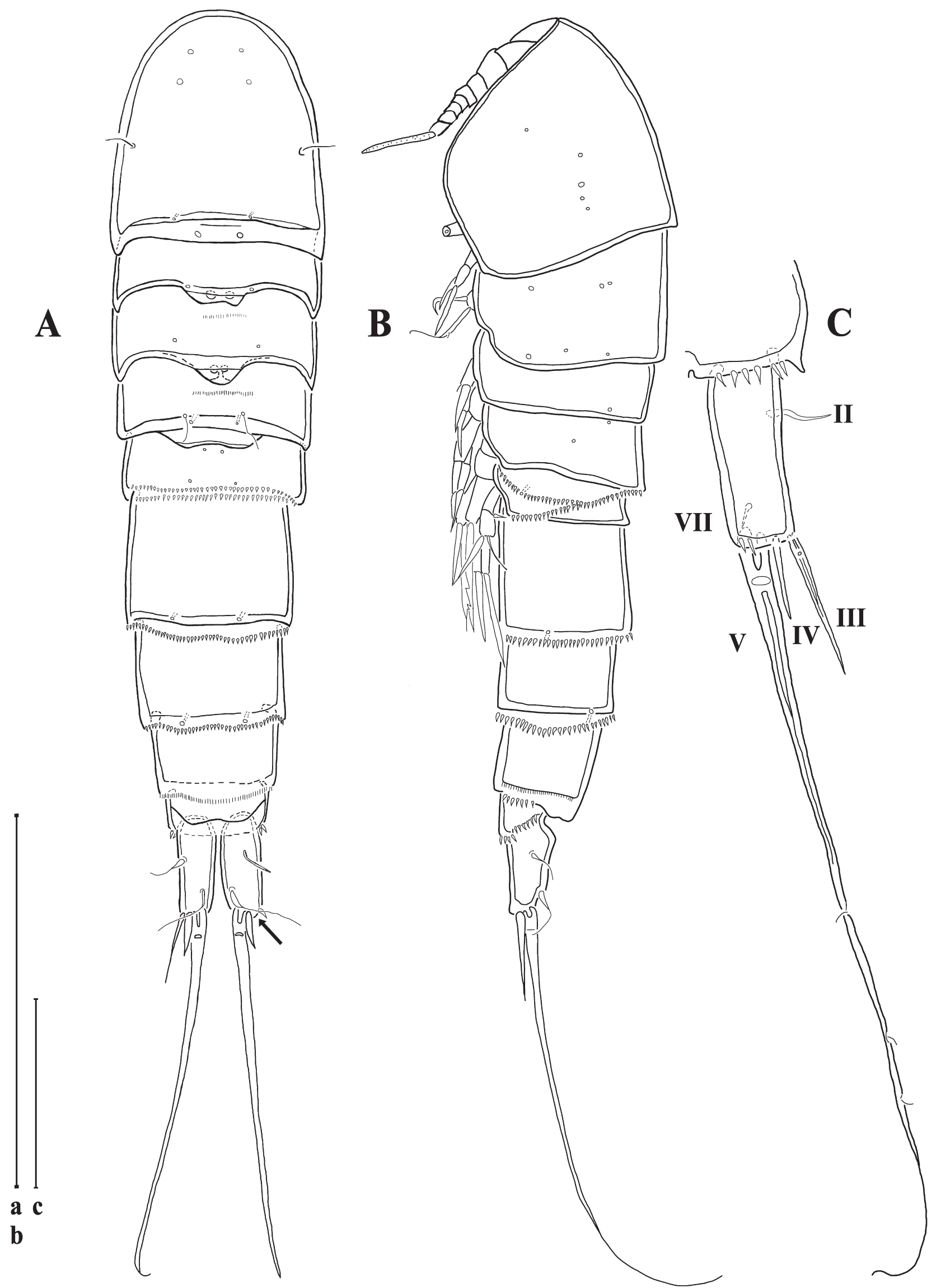

FIGURE 10. Emertonia ilse sp. nov. Female (holotype). A, habitus, dorsal view, arrow indicates inserting point of broken-off seta III; B, habitus, lateral view; C, caudal ramus, ventral view. Scale bars =a, b, $0.1 \mathrm{~mm}$; c, $0.02 \mathrm{~mm}$. 

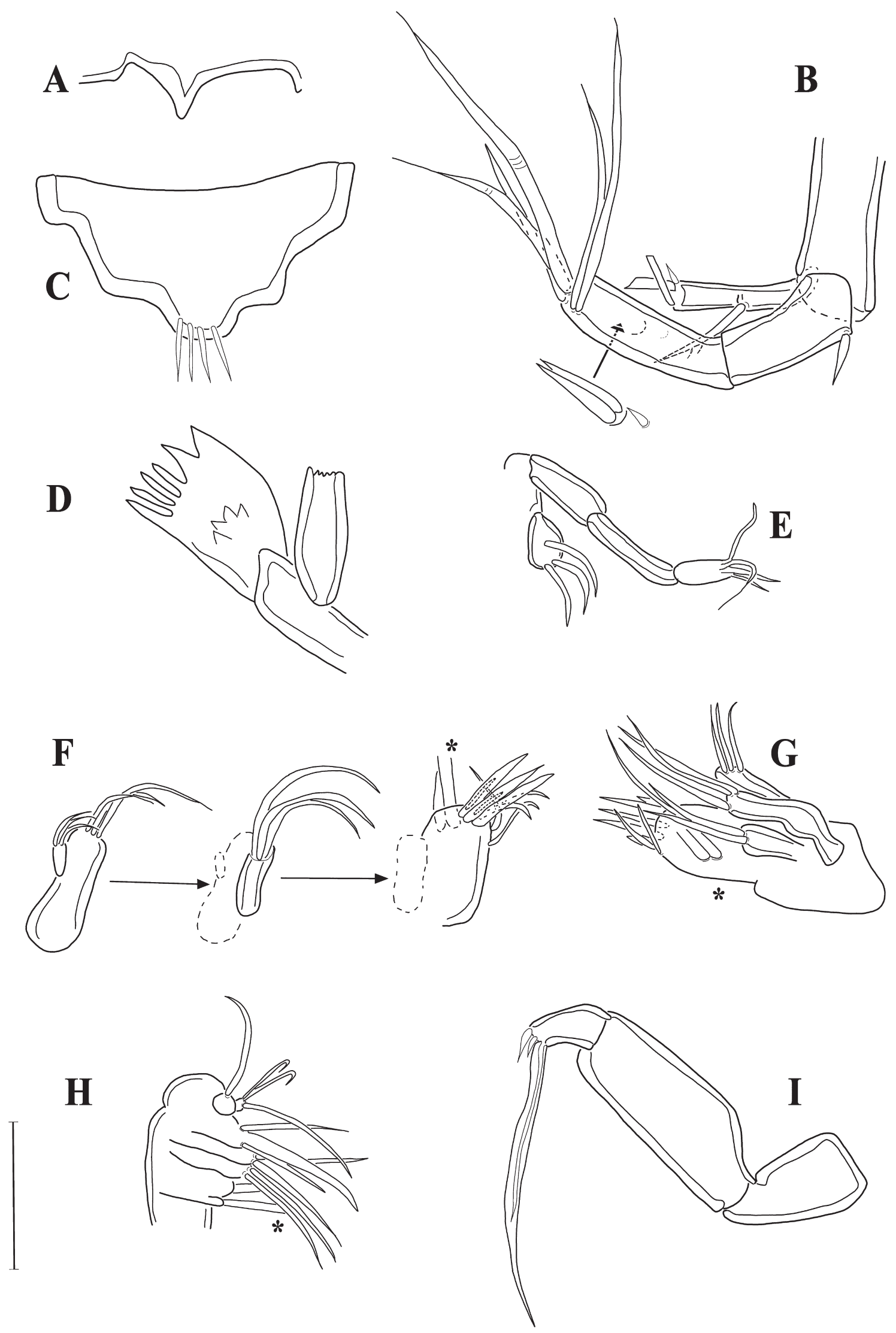

FIGURE 11. Emertonia ilse sp. nov. Female: A, rostrum (paratype 1); C, labrum (paratype 2); D, mandibular gnathobase (paratype 4); E, mandibular palp (paratype 4); F, maxillule, disarticulated (paratype 4); G, maxillule (paratype 4); H, maxilla (paratype 4); I, maxilliped (paratype 2). Male: B, antenna (paratype 3). Scale bar $=0.01 \mathrm{~mm}$. Setae that are not clearly discernible indicated by *. 


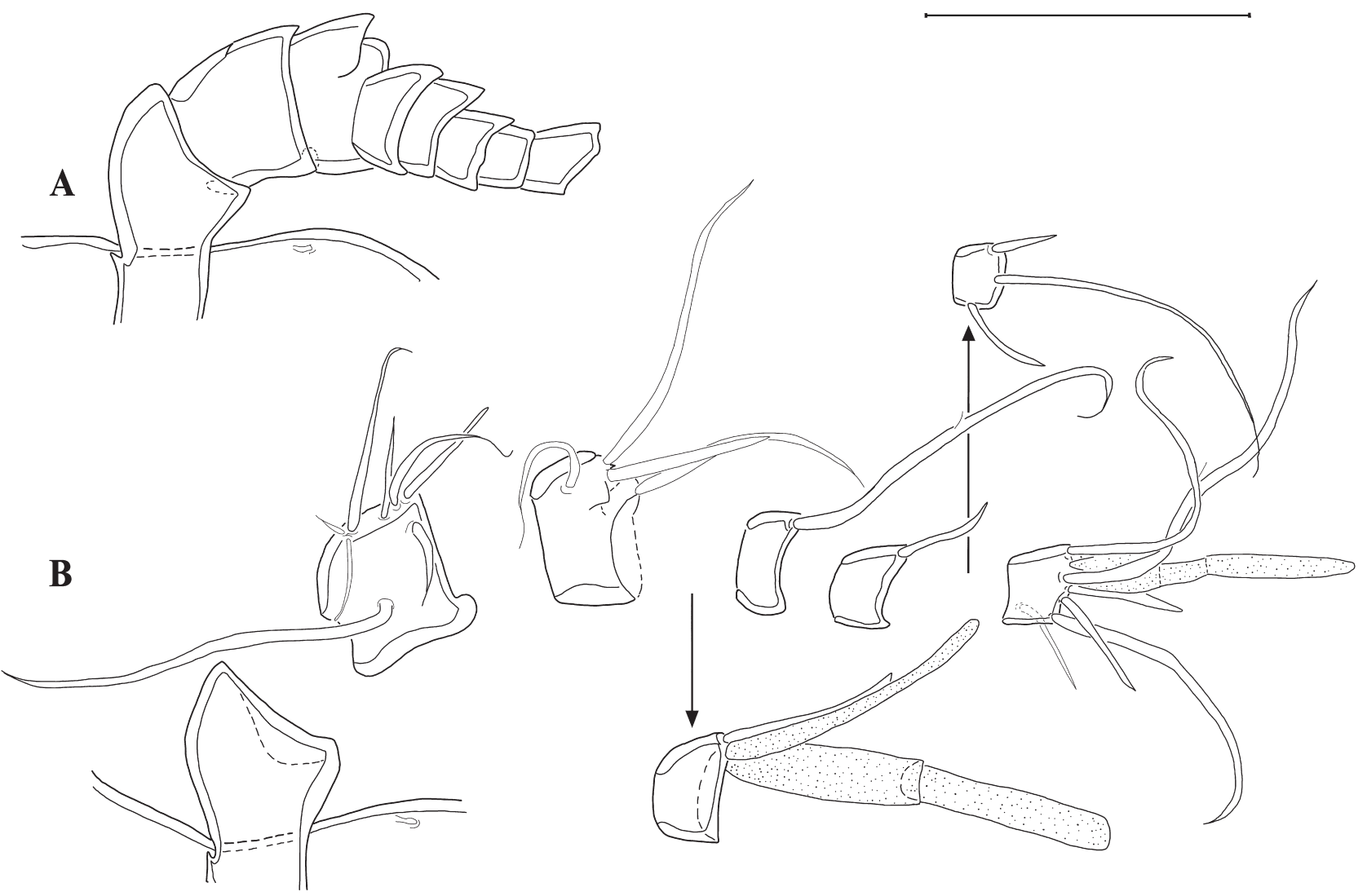

FIGURE 12. Emertonia ilse sp. nov. Female (paratype 1). A, antennule (armature omitted); B, disarticulated antennulary segments showing armature (paratype 1). Scale bar $=0.02 \mathrm{~mm}$.

Maxilliped (Fig. 11I). Syncoxa and basis unarmed. Endopod one-segmented, with two small spines next to one long naked seta.

Swimming legs (Fig. 13; Table 3). With rami characteristic for Emertonia species belonging to the andeepgroup; intercoxal sclerites without ornamentation.

TABLE 3. Setation of swimming legs P1-P4 of Emertonia ilse sp. nov.

\begin{tabular}{lccc}
\hline & Basis & Exopod & Endopod \\
\hline P1 & 1.1 & 0.022 & 0.020 \\
P2 & 0.1 & 0.0 .022 & 010 \\
P3 & 0.1 & 0.0 .022 & 010 \\
P4 & 0.1 & 0.0 .011 & 0.010 \\
\hline
\end{tabular}

P1 (Fig. 13A). Coxa naked. Basis with row of short spinules along inner margin, one pinnate inner seta and one pinnate outer seta. Endopod slightly longer than exopod, both rami two-segmented and, except for exp1, armed with spinules on outer margin. Enp1 unarmed, enp2 terminally with one long inner seta bearing single pinnule, and one shorter, unipinnate, outer seta. Exp1 with one unipinnate outer spine. Exp2 with two unipinnate outer spines and two bipinnate apical setae.

P2-P4 (Fig. 13B-D). Surface of coxae naked. Bases of P2-P4 bearing one naked outer seta (accompanied by two spinules in $\mathrm{P} 4)$. Three-segmented exopods slightly longer than endopods with spinules along outer margin (P2-P4) and terminally (P4). P2-P4 exp1 and exp2 with strong serrated spine; exp2 with two spinules along inner margin in P2, with one spinule situated on pronounced ledge in P3-P4. P2-P3 exp3 with four elements. P2 exp3 with two serrated outer spines and apically one long, naked, spine-like, outer seta and one long, inner seta with one pinnule. $\mathrm{P} 3 \exp 3$ as in P2, but spine-like terminal seta serrated at tip. P4 exp3 with two serrated spines (one short outer and one long terminal). Endopods P2-P3 one-segmented with spinules along outer margin, two short inner 


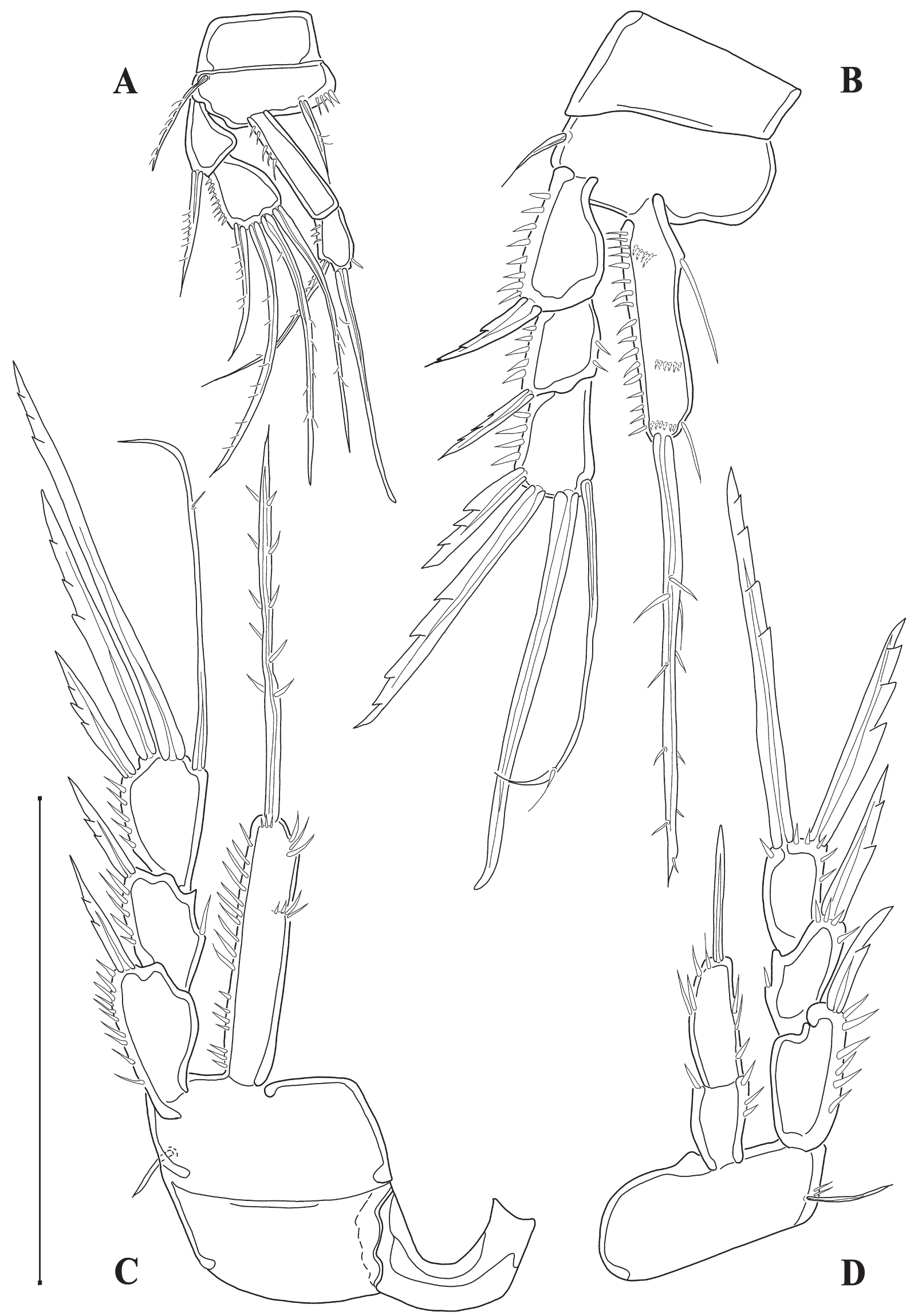

FIGURE 13. Emertonia ilse sp. nov. Female. A, P1 (paratype 3); B, P2 (paratype 1); C, P3 with intercoxal sclerite (paratype 1); D, P4 (paratype 1). Scale bar $=0.05 \mathrm{~mm}$. 
rows of fine spinules and an additional terminal spinule row. Endopod P2 bearing one long spinule, positioned on ledge and one subapically on inner margin. Endopods P2-P3 apically with long, rigid bipinnate seta. Endopod P4 two-segmented; armed with spinules along outer margin, one inner spinule on enp1 and several slender inner spinules on enp2; enp2 apically with one short naked, spine-like seta.

P5 (Fig. 14A). Baseoendopods fused forming medially cleft plate with naked outer basal seta on either side; completely separated from exopods; with slightly curved spinule rows situated near proximal outer margins. Endopodal lobes with paired halfmoon-shaped spinule rows around outer margins; with one large inner and one slightly smaller outer naked seta. Exopod with several spinules along inner margin and three naked spine-like setae, the innermost being shortest and the outer being the longest seta. The middle seta is more flexible, outwardly directed and situated on a protrusion.

P6 and genital field see Fig. 14B. Sixth pair of legs represented by small fused outgrowths bearing a minute spinous process on either side.

Description of male. Habitus (Fig. 15). As in female but slightly larger and second and third urosomites not fused (Fig. 15A, B). Total body length measured from anterior tip of rostrum to posterior margin of anal somite (allotype) $0.23 \mathrm{~mm}$, including caudal rami $0.25 \mathrm{~mm}$. Only third prosomal somite dorsally ornamented with short row of microspinules. Mouthparts and swimming legs as in female, sexual dimorphism in antennule, P5, P6 and urosomal segmentation, in addition to slight differences in armature of caudal rami (Fig. 15C: seta II very tiny on outer margin, no spinules along apical margin).

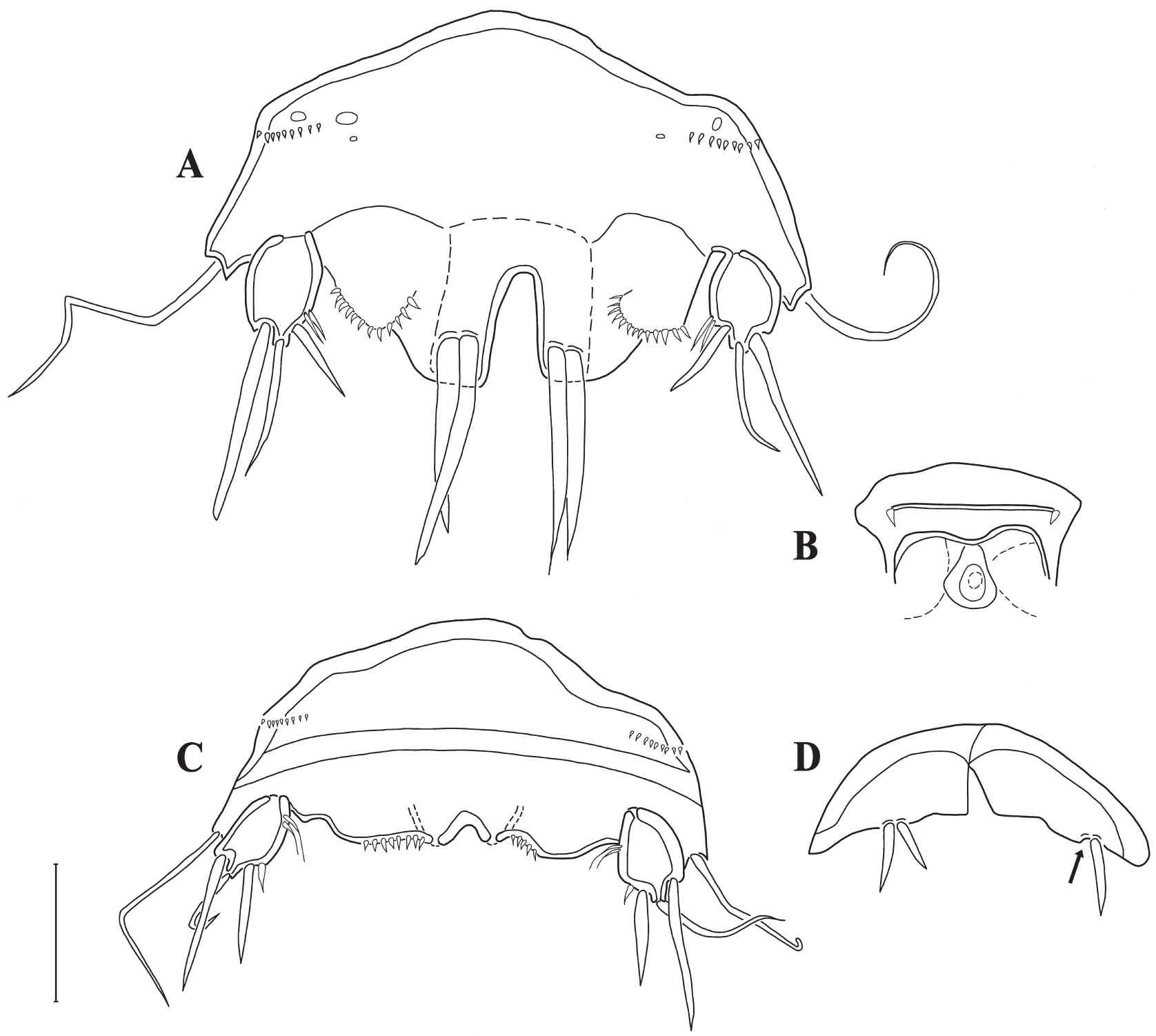

FIGURE 14. Emertonia ilse sp. nov. Female (paratype 1): A, P5; B, P6 and genital field. Male (paratype 3): C, P5; D, P6 (arrow indicates position of broken-off seta). Scale bar $=0.01 \mathrm{~mm}$. 


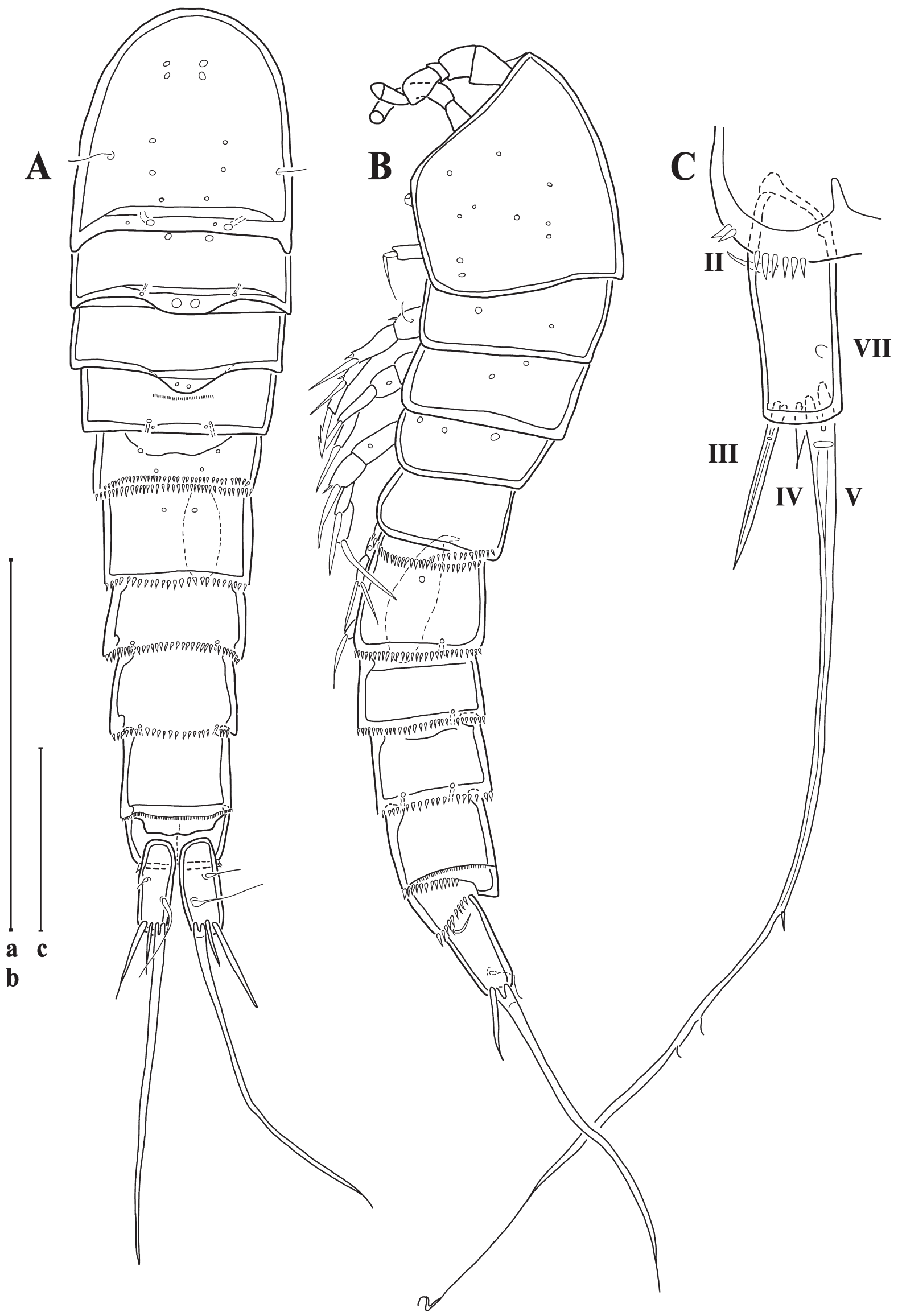

FIGURE 15. Emertonia ilse sp. nov. Male (allotype). A, habitus, dorsal view; B, habitus, lateral view; C, caudal ramus, ventral view. Scale bars $=a, b, 0.1 \mathrm{~mm} ; \mathrm{c}, 0.02 \mathrm{~mm}$. 
Antennule (Fig. 16). Five-segmented. Segment I with spinule row along anterior margin, segment III relatively small, segment IV rounded and bulbous (Fig. 16B, C). Armature formula:

$\mathrm{I}(0)$

III (2)

IV $(5+$ aes $)$

$\mathrm{V}(7+$ aes $)$

four slender naked setae, one of which minute

two naked setae

one slender naked, one minute and three spine-like (Fig. 16C) setae, and one aesthetasc

seven slender naked setae, one of which on anterior margin, and one aesthetasc

Antenna (Fig. 11B). Basis unarmed. Endopod two-segmented; enp1 with one short naked abexopodal seta; enp2 subapically with three spine-like naked setae, one of which small; apical margin of enp2 with five slender naked setae, two of which geniculate. Exopod one-segmented with one inner pinnate seta, apically with a spine adjacent to two setae of different sizes with transversally cut naked tips.

P5 (Fig. 14C). Baseoendopods fused medially; with naked outer basal seta; slightly curved spinule rows situated on either side of basal margin and along posterior margin on endopodal lobes. Exopod discrete at base; with with several spinules along inner margin and three naked setae, two of which spine-like, the innermost being shortest and the outer being the longest seta. The middle seta is flexible, situated on a protrusion and more outwardly directed.

P6 (Fig. 14D). Sixth leg represented by small, medially fused plates, each bearing one small, naked inner seta and one slightly larger, naked outer seta.

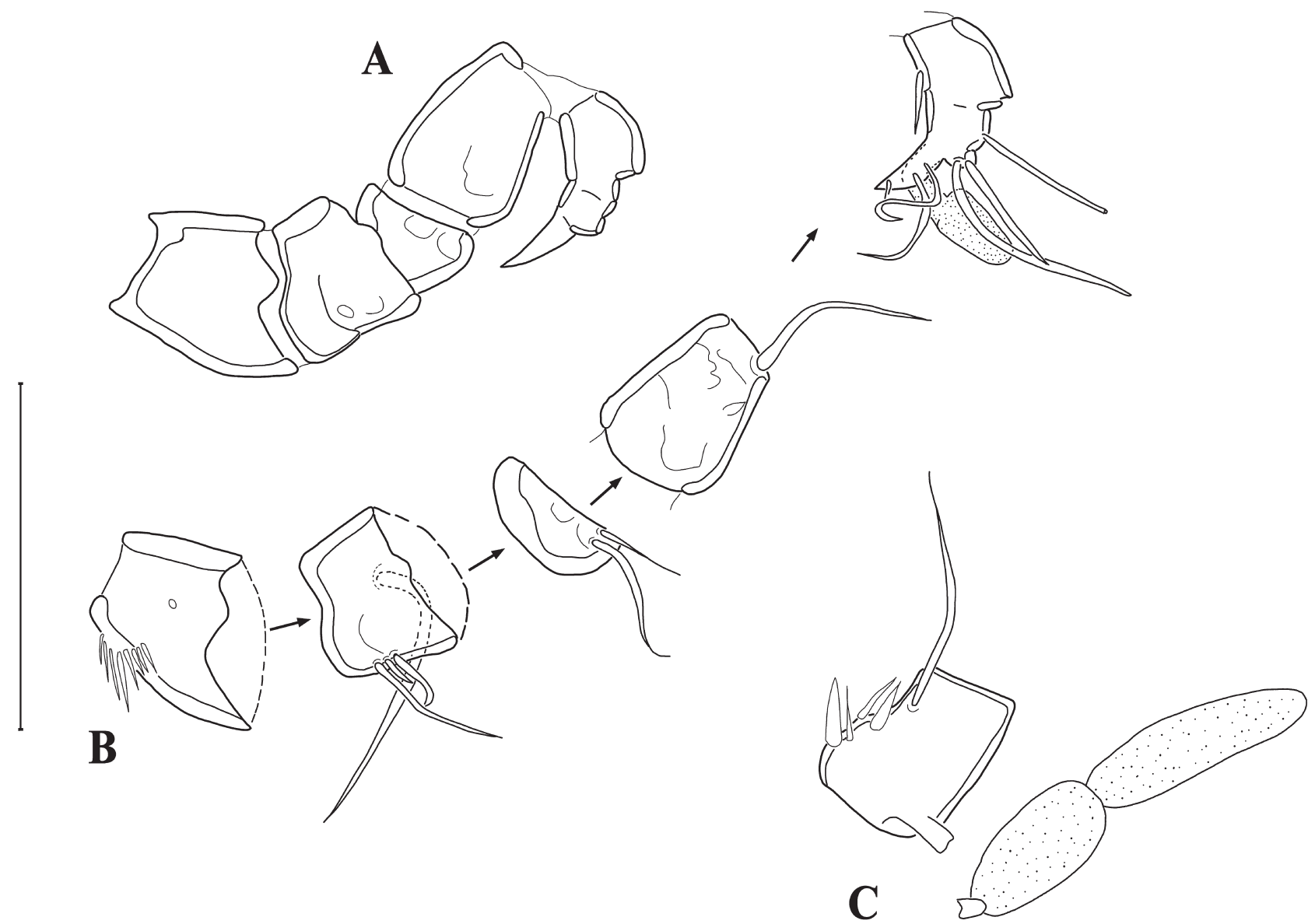

FIGURE 16. Emertonia ilse sp. nov. Male (paratype 1). A, antennule (armature omitted); B, disarticulated antennulary segments showing armature. Scale bar $=0.02 \mathrm{~mm}$.

Emertonia hessleri Mathiske, Thistle \& Veit-Köhler sp. nov.

http://zoobank.org/urn:Isid:zoobank.org:act:28C1DBF5-BF68-47C6-B4F8-4C8FAAD0F5AA

Type material. The examined specimens are registered and deposited in the Senckenberg Forschungsinstitut und 
Naturmuseum Frankfurt, Germany. All specimens of the type material were collected with the D.S.V. Alvin in the San Diego Trough off California (only one station) and during the PUCK expedition off Chile. Station numbers for PUCK indicate "Expedition, station number, depth, core number, sediment horizon". Additionally, for each specimen from the San Diego Trough an identification number assigned by the collector (David Thistle) is given.

Female holotype, SMF 37246 (adult female on 6 slides): D.S.V. Alvin, T3613A, 1,050 m.

Male allotype, SMF 37247 (adult male on 1 slide): RV Sonne 156 A-PUCK, St. 7103, $891 \mathrm{~m}, \mathrm{R} 1,0-1 \mathrm{~cm}$.

Female paratype 1, SMF 37248 (adult female on 3 slides): D.S.V. Alvin, T3649A, 1,050 m.

Female paratype 2, SMF 37249 (adult female on 1 slide): D.S.V. Alvin, T3628, 1,050 m.

Male paratype 3, SMF 37250 (adult male on 4 slides): D.S.V. Alvin, T3649B, 1,050 m.

Female paratype 4, SMF 37251 (adult female on 5 slides): D.S.V. Alvin, T3609, 1,050 m.

Etymology. This species is dedicated to Dr Robert R. Hessler who is a noted deep-sea ecologist.

Description of female. Habitus (Fig. 17). Total body length measured from anterior tip of rostrum to posterior margin of anal somite (holotype) $0.23 \mathrm{~mm}$, including caudal rami $0.25 \mathrm{~mm}$. Body cylindrical (Fig. 17A, B), slightly depressed dorsoventrally, with prosome slightly wider than urosome. Most pores distributed dorsally and laterally on cephalothorax and some on the free body somites. Sensilla visible on cephalothorax and pedigerous somites. First urosomite and genital double-somite dorsolaterally and third and fourth urosomites along entire posterior margin ornamented with spinules (Fig. 17B). Fourth urosomite with thin, well developed pseudoperculum (Fig. 17A). Anal somite short with minute spinules ventrally and ventrolaterally along the posterior margin (Fig. 17B).

Caudal rami (Fig. 17C). Cylindrical, approximately three times longer than wide, with five setae: seta I absent; seta II slender, dorsally displaced; seta III short, slender, spine-like, situated dorsolaterally, near posterior margin; seta IV longer, with clearly visible fracture plane and with flexible end, V long and slender, with clearly visible fracture plane and several pinnules, situated terminally; seta VI absent; seta VII slender, on dorsal surface. Posterior margin of caudal rami with ventral spinule row.

Antennule (Fig. 18). Eight-segmented. No further details visible.

Antenna (Fig. 19A) Basis unarmed. Endopod two-segmented; enp1 with one abexopodal spinule and one short naked inner seta; enp2 with two spinules along inner margin and subapically with four naked dorsal setae; apical margin with six slender naked setae. Exopod one-segmented with one naked flexible seta and a spinule laterally and two naked setae apically.

Mandibular palp (Fig. 19B) biramous. Basis with two spinules. Endopod two-segmented; proximal segment with two naked inner setae, one short and one long; distal segment apically furnished with five naked and slender confluent, basally fused setae. Exopod one-third length of endopod, one-segmented, with one dorsally displaced and two apical setae.

Maxillule (Fig. 19C). Praecoxal arthrite with four naked setae. Coxal endite with four slender naked setae. Endite of basis with four slender naked setae. Endopod one-segmented, with two slender naked setae. Exopod with three slender naked setae, one dorsally displaced.

Maxilla (Fig. 19D). Praecoxa and coxa fused forming syncoxa with three endites. No separation with basis visible. Proximal endite with two slender, naked setae. Middle endite with two slender, naked setae. Distal endite with two slender, naked setae, one of which short. Allobasis with two naked setae. Endopod two-segmented; proximal segment with three naked setae, one of which slightly displaced; distal segment with two naked setae.

Maxilliped (Fig. 19I). Syncoxa with one naked seta. Basis unarmed. Endopod one-segmented with one small spine adjacent to one long naked seta.

Swimming legs (Fig. 20; Table 4). With rami characteristic for Emertonia species belonging to the andeepgroup; intercoxal sclerites without ornamentaion.

TABLE 4. Setation of swimming legs P1-P4 of Emertonia hessleri sp. nov.

\begin{tabular}{lccc}
\hline & Basis & Exopod & Endopod \\
\hline P1 & 1.1 & 0.022 & 0.020 \\
P2 & 0.1 & 0.0 .022 & 010 \\
P3 & 0.0 & 0.0 .022 & 010 \\
P4 & 0.1 & 0.0 .011 & 0.010 \\
\hline
\end{tabular}




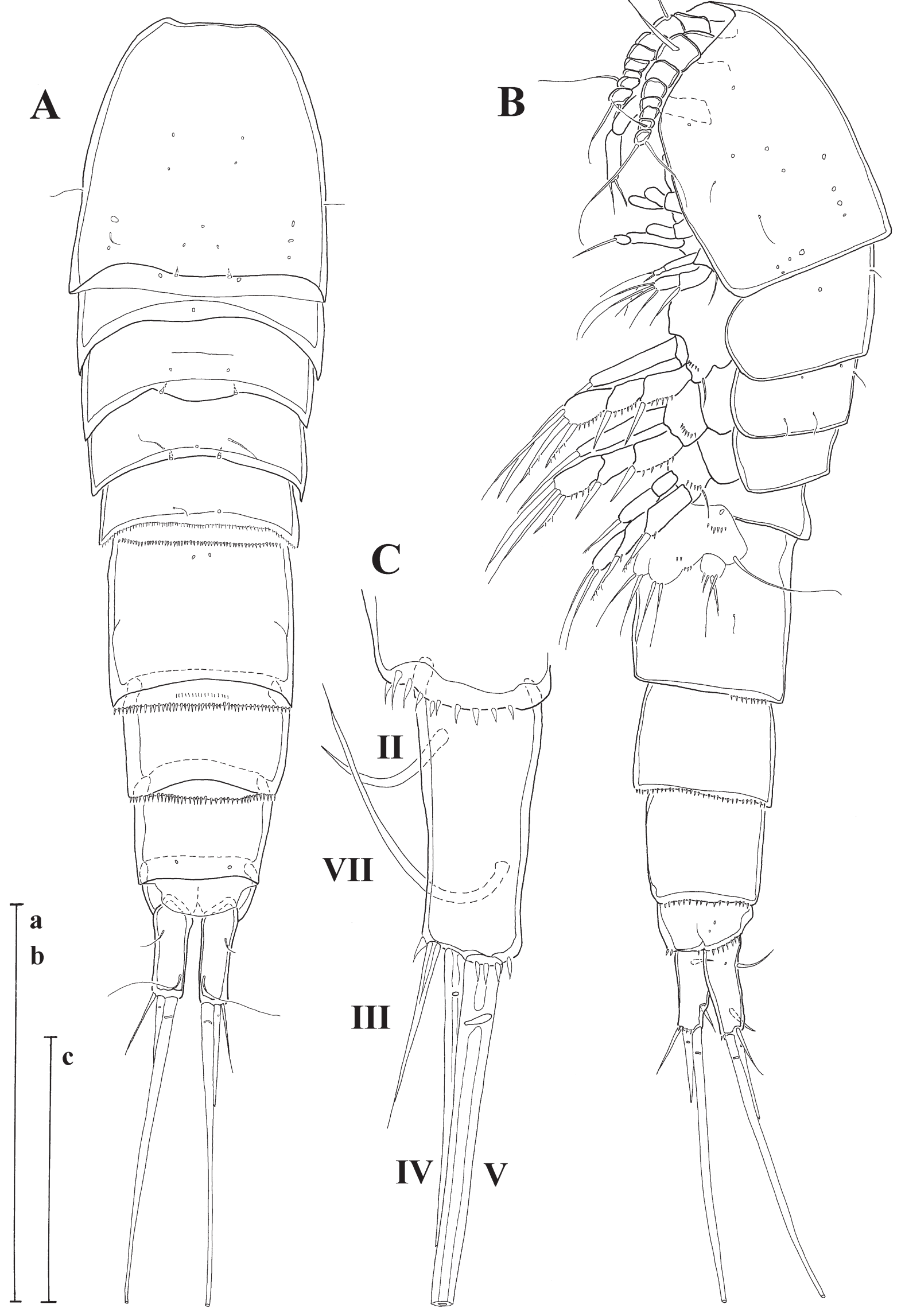

FIGURE 17. Emertonia hessleri sp. nov. Female (holotype). A, habitus, dorsal view; B, habitus, lateral view; C, caudal ramus, ventral view. Scale bars =a,b, $0.1 \mathrm{~mm}$;, $0.02 \mathrm{~mm}$. 
P1 (Fig. 20A). Coxa with several spinules of different sizes along outer margin. Basis with spinules along inner margin, one unipinnate inner and one bipinnate outer seta. Endopod slightly longer than exopod; both rami two-segmented and armed with spinules along outer margin. Enp1 unarmed; with three pinnules along inner apical margin. Enp2 with two equally long unipinnate setae, the inner one slightly stronger and accompanied at base by two long spinules. Exp1 with one unipinnate outer spine. Exp2 with two unipinnate outer spines and terminally with one unipinnate outer and one naked inner seta.

P2-P4 (Fig. 20B-D). Coxae without ornamentation. Basis of P2 with spinule row near naked outer seta. Basis P3 unarmed and basis P4 with naked outer seta. Exopods three-segmented and slightly longer than endopods; all segments with spinules along outer margin in P2 and P3. P4 exp1 sparsely armed and exp2 and exp3 unarmed along outer margin. Spines of P4 exp2 and exp3 accompanied at base by spinules. P2 exp1 and exp2 with strong serrated spine. P3 exp1 with strong naked and exp2 with strong serrated spine. P2-P3 exp2 with spinules along inner margin. P4 exp1 and exp2 with two spinules on small ledges along inner margin. P2-P3 exp3 with four elements. P2 exp3 with two strongly serrated outer spines and two apical setae, the outermost of which long, naked and spine-like and the inner long and flexible with two long pinnules. P3 exp3 as in P2, but inner apical seta more plumose and outer apical spine with bifid tip. P4 exp3 with two serrated spines (a short outer and a very long terminal). P2-P3 endopods one-segmented; with spinules along outer margin, two short rows of fine spinules and an additional terminal spinule row on posterior surface. P2 enp with three long spinules along inner margin, the proximalmost one positioned on a ledge. P2-P3 endopods apically with long rigid seta, being uniplumose in P2 and bipinnate with spine-like pinnules in P3. P4 endopod two-segmented, armed with spinules along outer margin; enp1 with one long inner spinule and a spinule row along apical margin; enp2 with two groups of three spinules arising from small ledges near apical margin and with one short, naked, spine-like distal seta exhibiting two deep serrations at tip.

$P 5$ (Fig. 21A). Baseoendopods fused medially, completely separated from small exopods; with long, naked outer basal seta on either side and short spinule rows on surface near outer margins; anterior surface with one pore near spinule row and several integumental pits. Endopodal lobes moderately developed, separated by medial cleft; each with halfmoon-shaped spinule row and two stout apical setae, the outer being unipinnate with two spinules and the inner bipinnate. Exopod with one small spinule and three naked spine-like setae, the inner one being shortest, the outer longest and the middle one more flexible, and directed outwardly (contrary to the other setae).

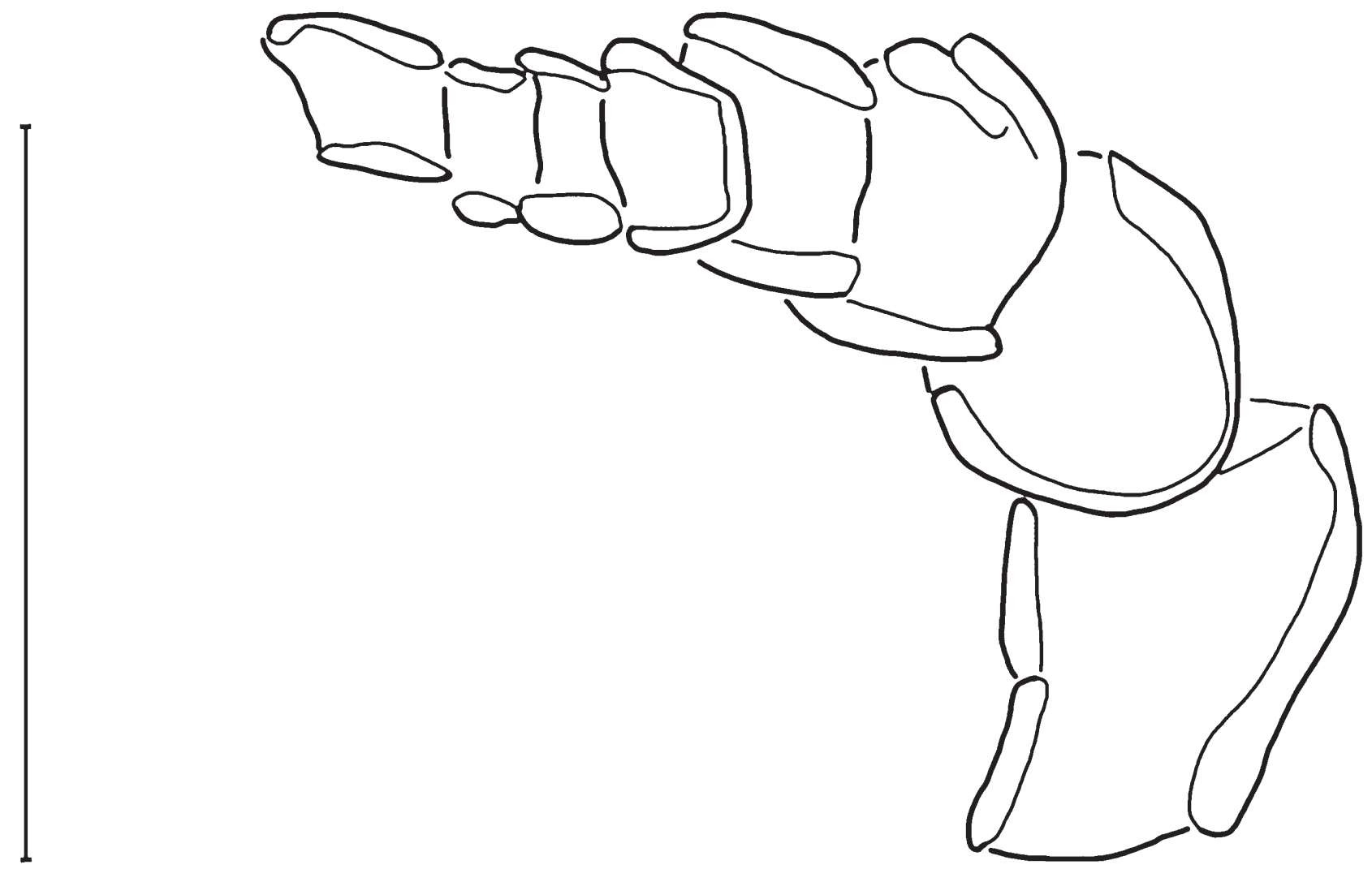

FIGURE 18. Emertonia hessleri sp. nov. Female (paratype 2). Antennule (armature omitted). Scale bar $=0.02 \mathrm{~mm}$. 

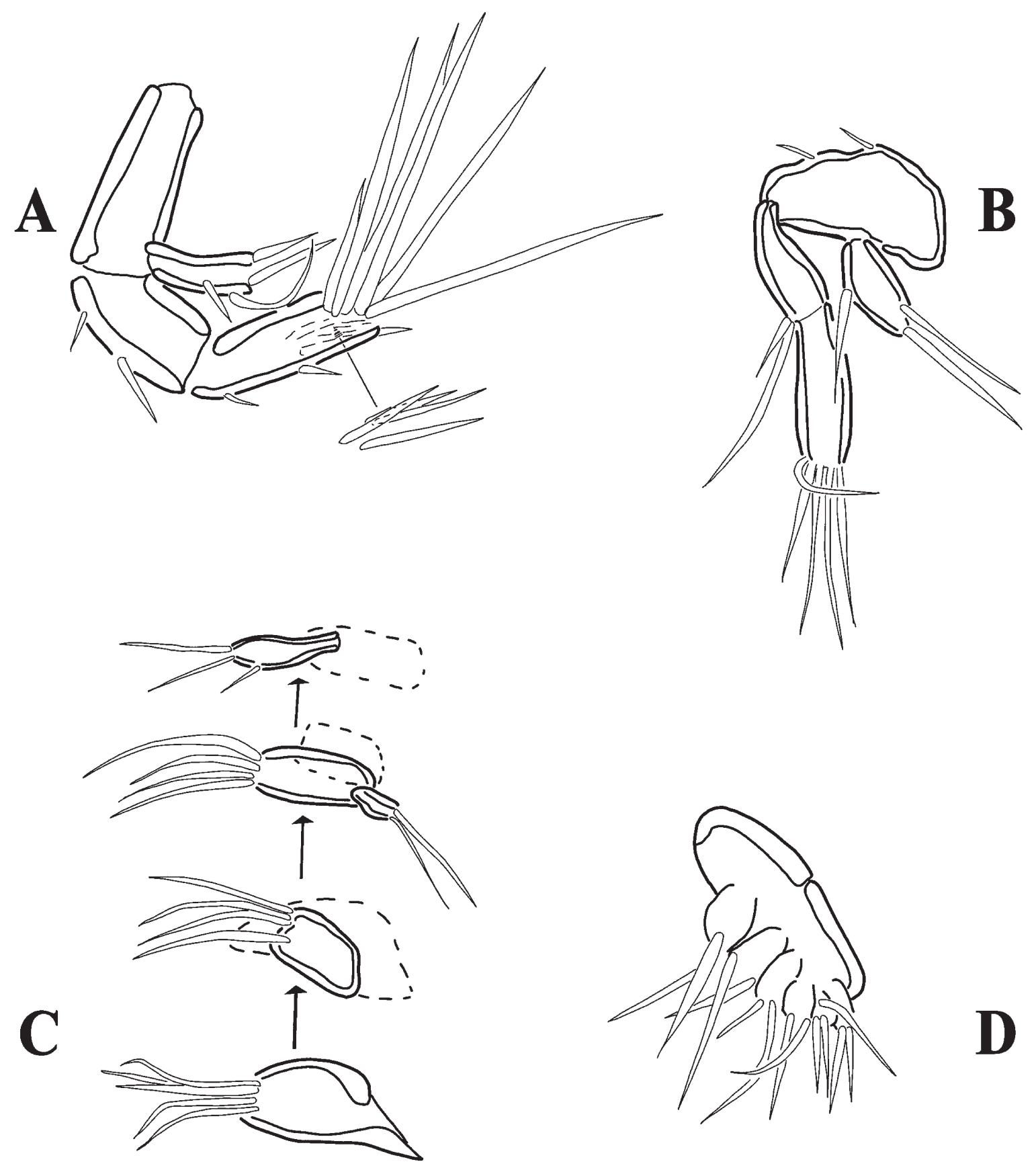

D

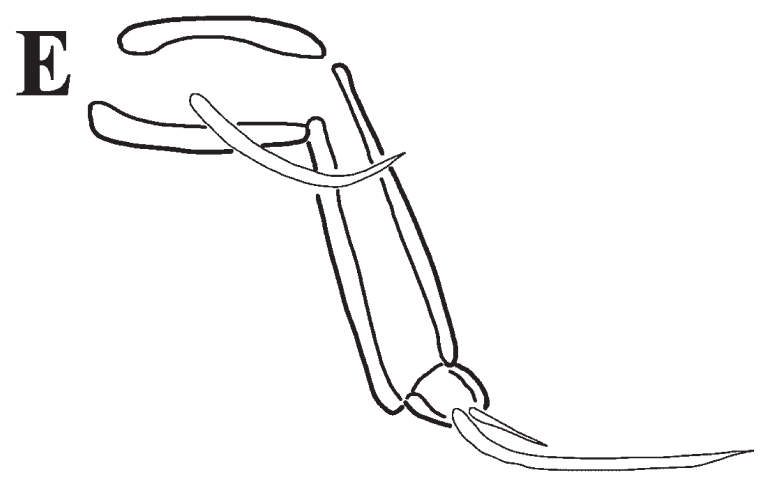

FIGURE 19. Emertonia hessleri sp. nov. Female. A, antenna (paratype 4); B, mandibular palp (paratype 2); C, maxillule, disarticulated (paratype 2); D, maxilla (paratype 4); E, maxilliped (paratype 4). Scale bar $=0.01 \mathrm{~mm}$. 


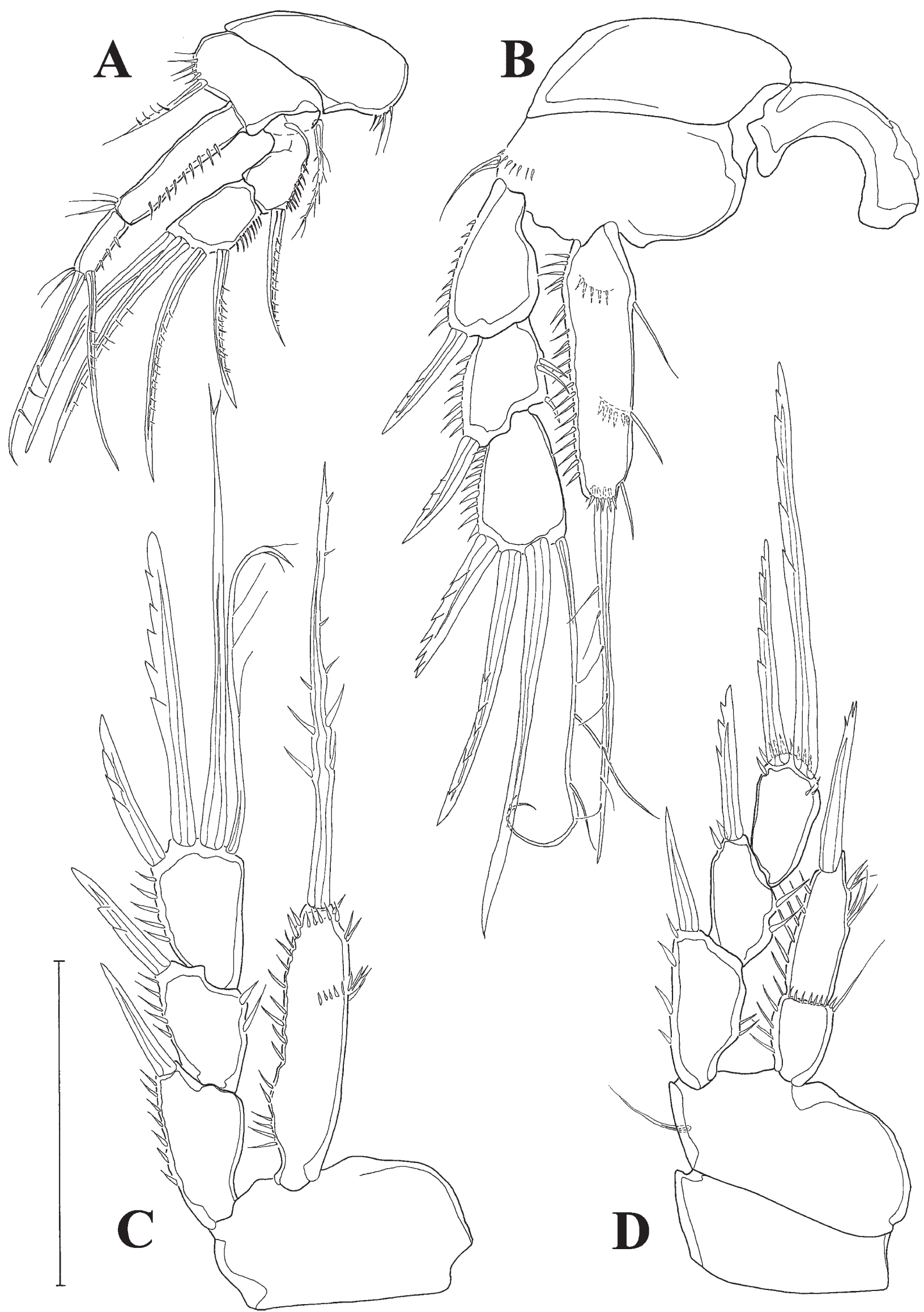

FIGURE 20. Emertonia hessleri sp. nov. Female. A, P1 (paratype 4); B, P2 (holotype); C, P3 with intercoxal sclerite (holotype); D, P4 (holotype). Scale bar $=0.03 \mathrm{~mm}$. 


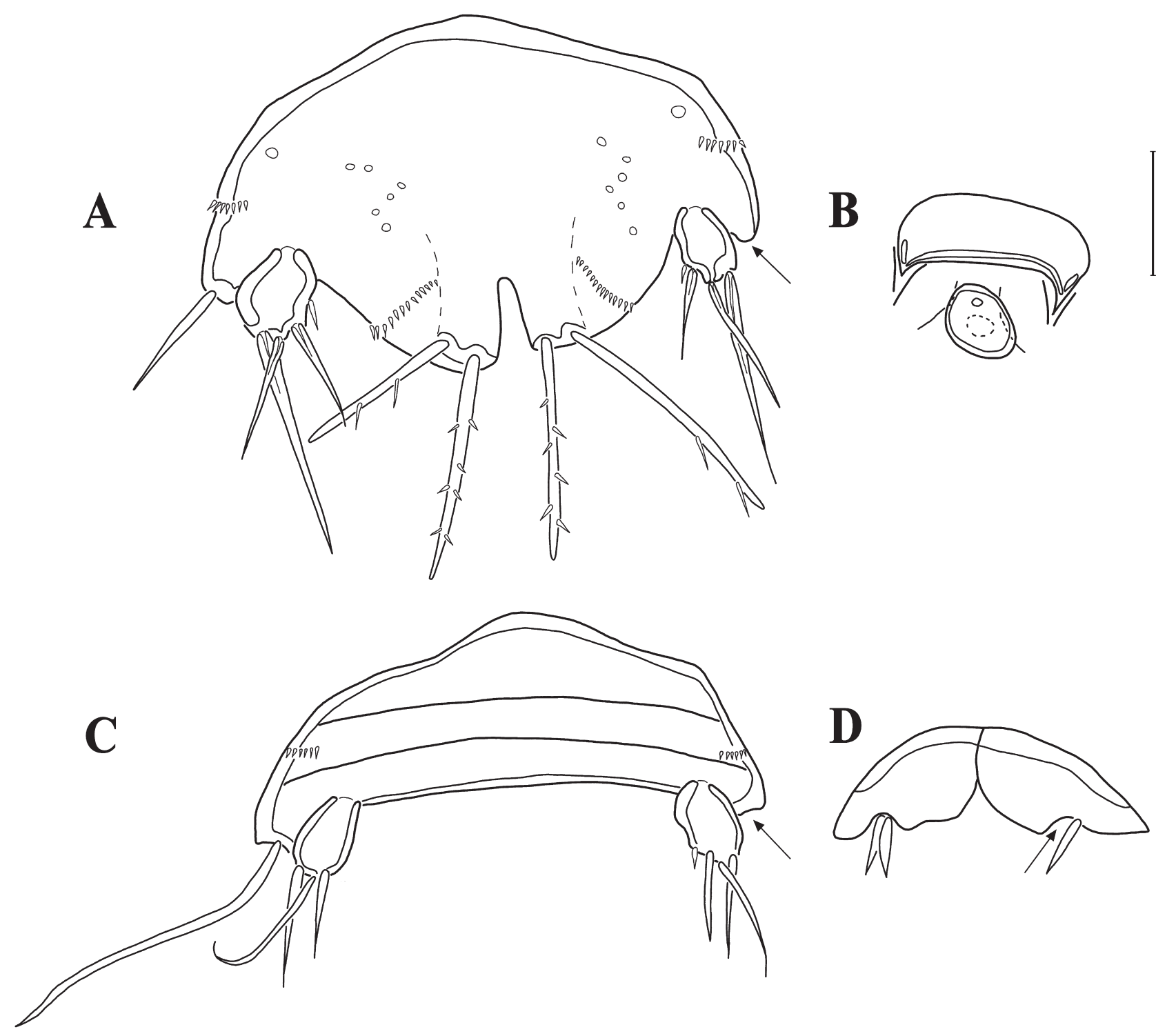

FIGURE 21. Emertonia hessleri sp. nov. Female (holotype): A, P5 (missing outer basal seta indicated by arrow); B, P6 and genital field. Male (allotype): C, P5 (missing outer basal seta indicated by arrow); D, P6. Scale bar $=0.01 \mathrm{~mm}$.

P6 and genital field (Fig. 21B). Sixth pair of legs represented by small fused outgrowths.

Description of male. Habitus (Fig. 22A, B). As in female but slightly smaller and second and third urosomites not fused. Total body length measured from anterior tip of rostrum to posterior margin of anal somite (allotype) $0.18 \mathrm{~mm}$, including caudal rami $0.19 \mathrm{~mm}$. Spermatophore located in right side of the body. Ornamentation of body somites as in female.

Caudal rami (Fig. 22C). For description see female.

Antennule (Fig. 23). Seven-segmented (not all segments visible in Fig. 23B). Segment I with spinule row along outer margin, segment III relatively small, segment IV rounded and bulbous, with two spinules along anterior margin and one stout spinule on apical margin (Fig. 23A). Armature formula:

III (1)

IV $(2+$ aes $)$

$\mathrm{V}$ and $\mathrm{VI}$

VII (3)

eight slender naked setae of different sizes

one naked seta

two slender naked setae and one aesthetasc

no armature discernible

three slender naked setae, one of which minute 


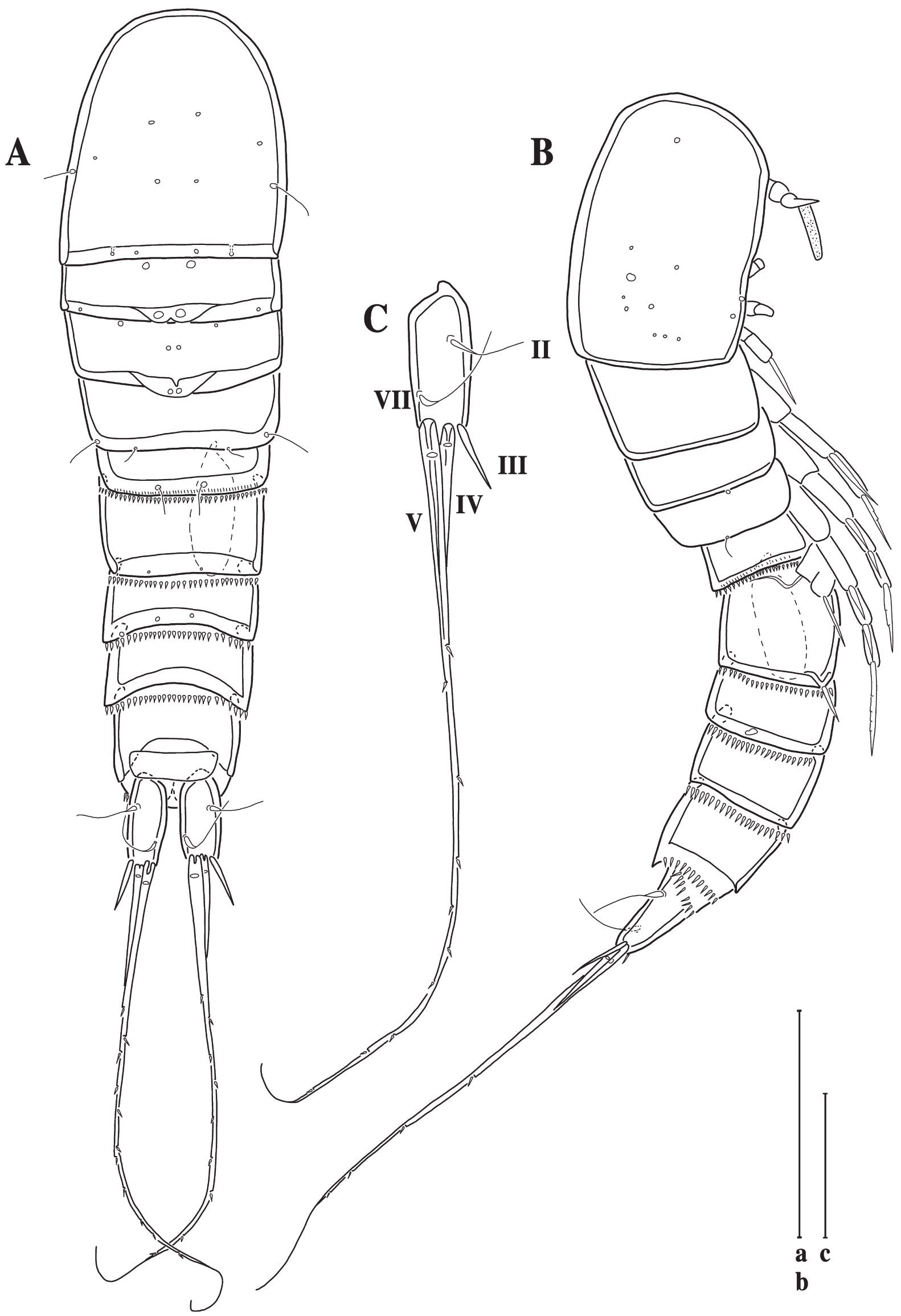

FIGURE 22. Emertonia hessleri sp. nov. Male (allotype). A, habitus, dorsal view; B, habitus, lateral view; C, caudal ramus, dorsal view. Scale bars = a, b, $0.05 \mathrm{~mm}$;, $0.02 \mathrm{~mm}$. 
Swimming legs as in female, sexual dimorphisms only in P5 and P6 (Fig. 21C, D).

P5 (Fig. 21C). Baseoendopods fused medially; with very long, naked outer basal seta on either side and short spinule rows on anterior surface surface near outer margins. Exopod discrete at base; with one small spinule (not visible on one side) and three naked spine-like setae, the middle seta of which being more flexible, longest and outwardly directed.

P6 (Fig. 21D) represented by small, medially fused plates, each bearing two stout setae.

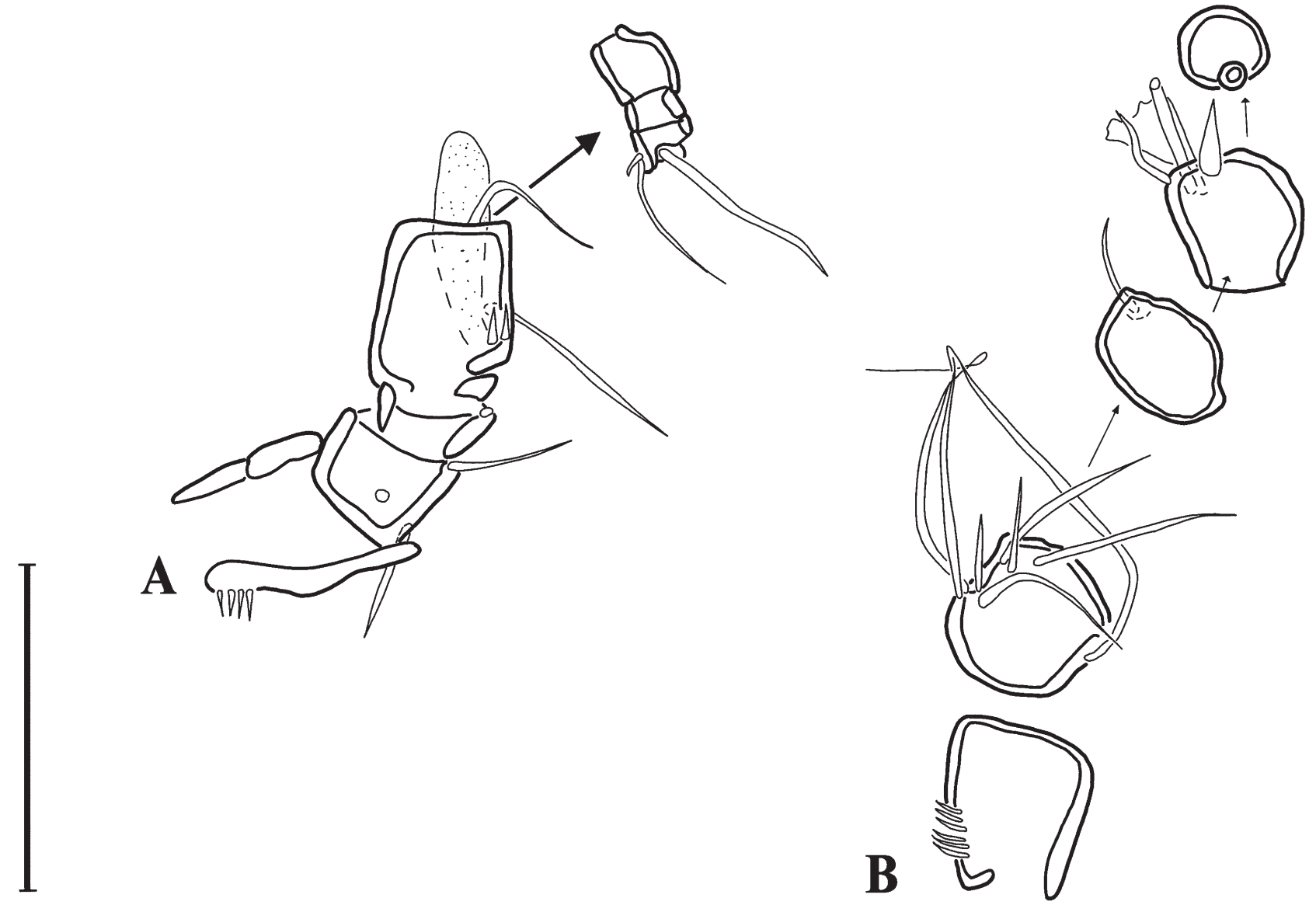

FIGURE 23. Emertonia hessleri sp. nov. Male (paratype 3). A, right antennule, ventral view; B, left antennule (not all segments illustrated). Scale bar $=0.02 \mathrm{~mm}$.

\section{Emertonia berndi Mathiske \& Veit-Köhler sp. nov.}

http://zoobank.org/urn:1sid:zoobank.org:act:4643898D-D226-48A8-88DA-B5DF414BBFE8

Type material. The examined species will be registered and deposited in the Senckenberg Forschungsinstitut und Naturmuseum Frankfurt, Germany. All specimens of the type material were collected in the Southern Ocean, Atlantic Sector. Station numbers indicate "Expedition, station number-deployment number, depth, core-number, sediment horizon".

Female holotype, SMF 37252 (adult female on 1 slide): RV Polarstern PS71—SYSTCO, St. 85-7, 2,964 m, MUC1, 0-1 cm.

Female paratype 1, SMF 37253 (adult female on 1 slide): RV Polarstern PS71-SYSTCO, St. 85-5, 2,965 m, MUC3, 0-1 cm.

Female paratype 2, SMF 37254 (adult female on 3 slides): RV Polarstern PS71-SYSTCO, St. 13-12, 2,963 $\mathrm{m}, \mathrm{MUC2}, 0-1 \mathrm{~cm}$.

Female paratype 3, SMF 37255 (adult female on 1 slide): RV Polarstern PS71-SYSTCO, St. 85-7, 2,964 m, MUC4, 0-1 cm.

Etymology. This species is dedicated to Annabel Mathiske's father, Dr Bernd Mathiske, for always supporting her and for sparking her interest in marine biology. 
Description of female. Habitus (Fig. 24A, B). Total body length measured from anterior tip of rostrum to posterior margin of anal somite (holotype) $0.23 \mathrm{~mm}$, including caudal rami $0.25 \mathrm{~mm}$. Body cylindrical (Fig. 24A, B), slightly depressed dorsoventrally, with prosome slightly wider than urosome. Pores distributed dorsally and laterally on cephalothorax and some on the free somites. Sensilla visible on cephalothorax and somites bearing P2-P5. Second and third prosomites dorsally with short row of microspinules and spinules along entire posterior margin (in third prosomite of minute size). Entire posterior margin of the first three urosomites ornamented with spinules; fourth urosomite ventrolaterally with similar-sized spinules (Fig. 24B) and forming thin, well developed pseudoperculum (Fig. 24A). Anal somite short with minute spinules ventrally and ventrolaterally along posterior margin (Fig. 24A, B).

Caudal rami of adult female (Fig. 24C) cylindrical, approximately three times longer than wide, with five setae: seta I absent; seta II slender, dorsally displaced; seta III short, slender, spine-like, situated dorsolaterally near outer distal corner; seta IV longer, unipinnate, with clearly visible fracture plane and with flexible end; seta V long and slender, bipinnate, with clearly visible fracture plane, situated terminally; seta VI absent; dorsal seta VII slender. Posterior margin of caudal rami ventrally with several spinules (Fig. 24B).

Antennule (Fig. 25). Eight-segmented. Segment I with spinule row along inner margin. Armature formula:

$\mathrm{I}(0)$

II (10)

III (5)

$\operatorname{IV}(2+$ aes $)$

$\mathrm{V}(1)$

VI (1)

VII (3)

VIII $[6+(1+$ aes $)]$ ten slender naked setae of different sizes

four naked setae, one small spine and one scar (possibly from broken-off seta) along anterior margin

one short naked seta on inner margin and one long naked seta on protrusion accompanying aesthetasc

one long, naked slender seta

one long slender seta with one spinule

three naked setae

six slender setae, terminally with one aesthetasc fused at base with one slender naked seta

Antenna (Fig. 26A) Basis unarmed. Endopod two-segmented. Enp1 with one long, naked inner seta. Enp2 subapically with two naked dorsal setae accompanied by a stout spine; apical margin with seven slender naked setae, five of which geniculate. Exopod one-segmented with one naked inner seta, subapically a stout spine and apically a spinule row and two naked setae.

Mandibular palp (Fig. 26B). Palp biramous. Endopod two-segmented; proximal segment with two naked inner setae; distal segment apically with seven naked, slender, basally fused setae of different lengths. Exopod one-third length of endopod, one-segmented, with one dorsally displaced and four apical setae.

Maxillule (Fig. 26C). Praecoxal arthrite apically with four stout and two slender naked setae, two juxtaposed slender setae on anterior surface and one outer spinule. Coxal endite bearing four slender naked setae. Endite of basis armed with four slender naked setae. Enp one-segmented with two slender naked setae. Exp with five slender naked setae.

Maxilla (Fig. 26D). Praecoxa and coxa fused to form a syncoxa bearing three endites. No separation towards basis visible. Proximal endite slightly bilobed, with a slender, naked seta on either lobe. Middle endite with one slender, naked seta. Distal endite armed with two naked setae. Allobasis with stout naked claw-like spine accompanied by three naked setae (one of which with not detectable tip). Enp with four naked setae and one of which slightly displaced.

Maxilliped (Fig. 26E). Syncoxa with a row of spinules accompanying a slender naked seta. Basis asetose. Enp one-segmented with five setae, of which two are slender and naked, two are short slender and naked, and one is stout, long, unipinnate and spine-like.

Swimming legs (Fig. 27; Table 5). With modified rami characteristic for Emertonia species belonging to the andeep-group and naked intercoxal sclerites. 


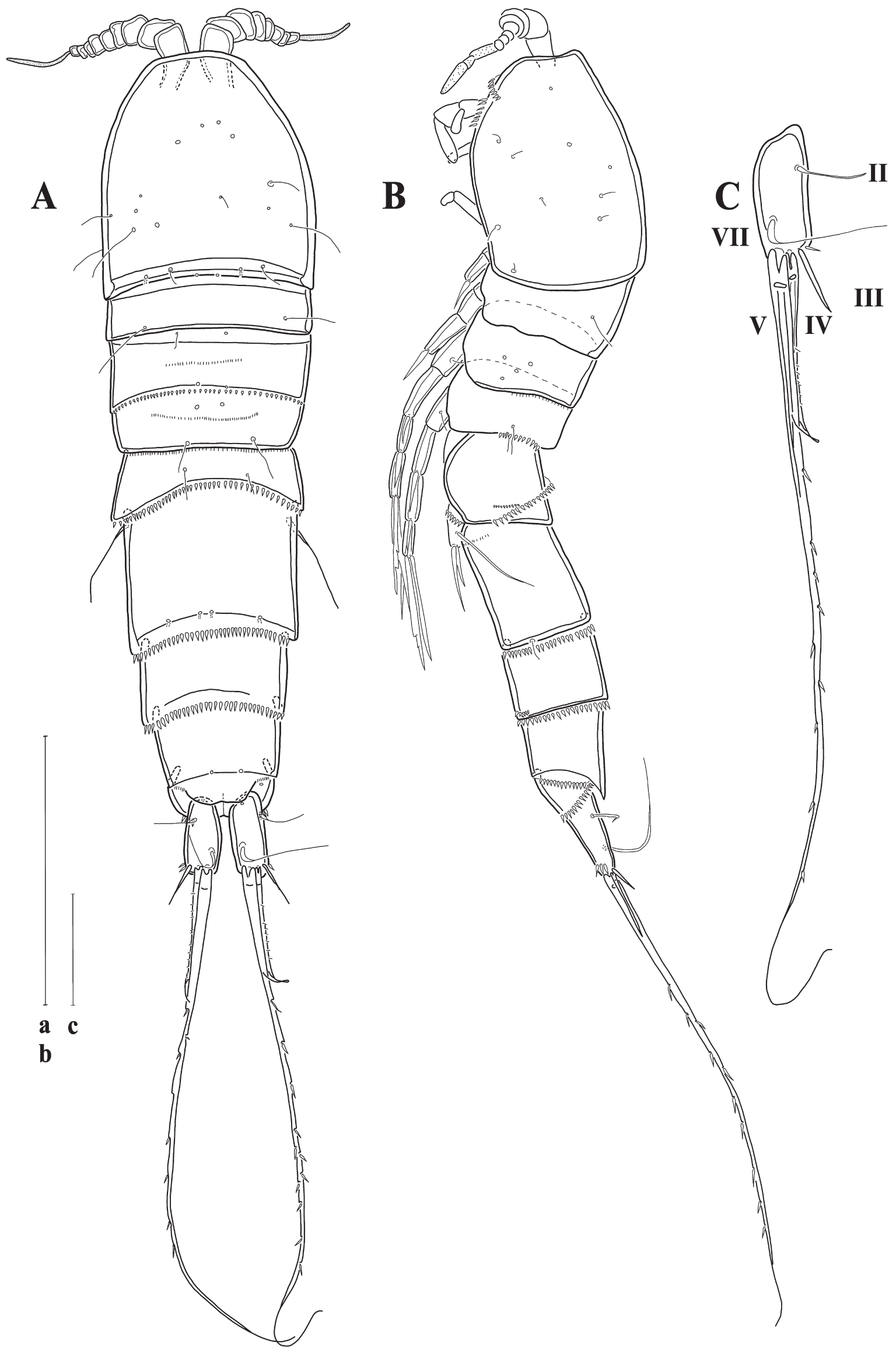

FIGURE 24. Emertonia berndi sp. nov. Female (holotype). A, habitus, dorsal view; B, habitus, lateral view; C, caudal ramus, dorsal view. Scale bars =a, b, $0.1 \mathrm{~mm} ; \mathrm{c}, 0.02 \mathrm{~mm}$. 


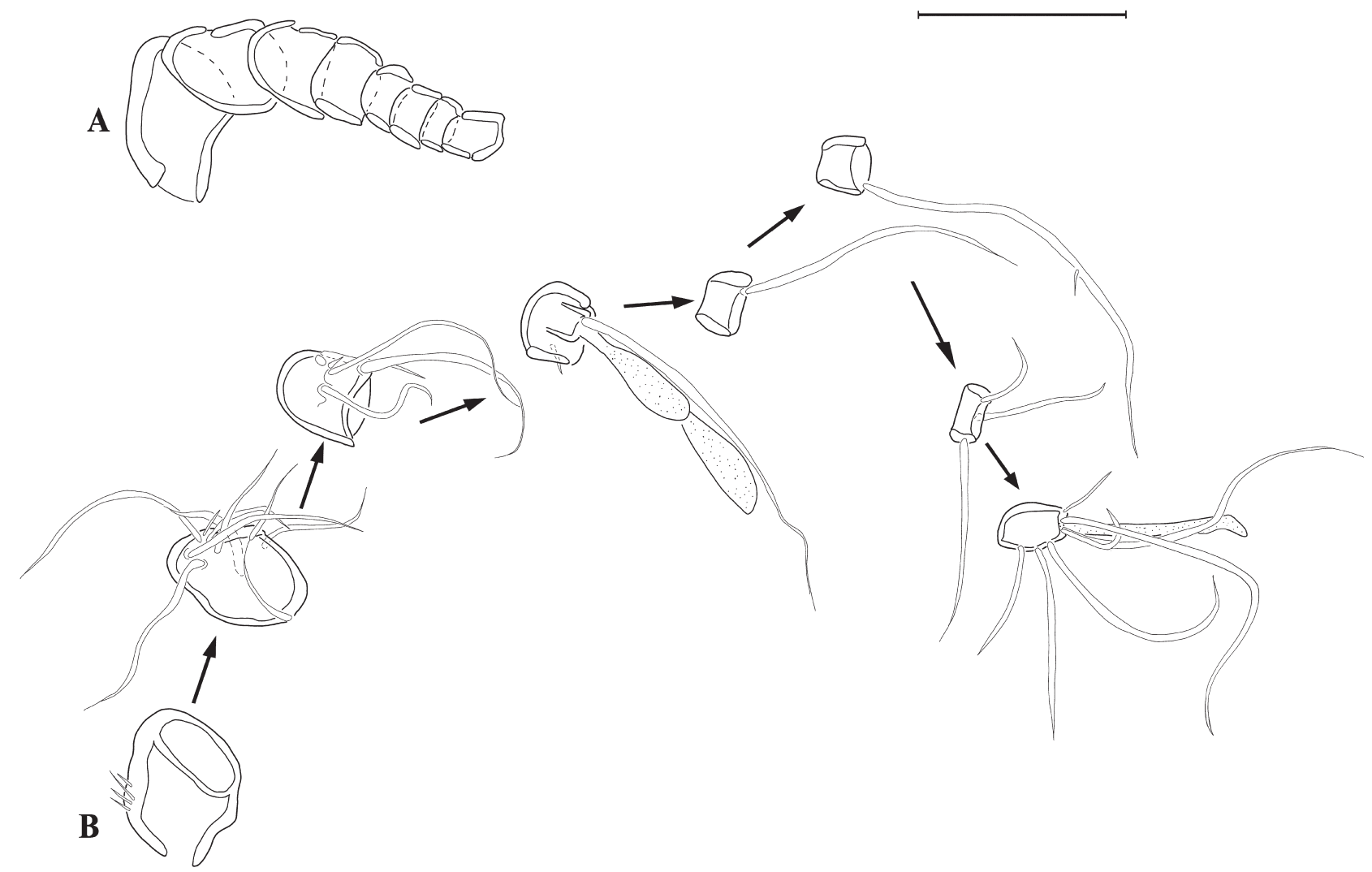

FIGURE 25. Emertonia berndi sp. nov. Female (holotype). A, antennule (armature omitted); B, disarticulated antennulary segments showing armature. Scale bar $=0.02 \mathrm{~mm}$.

TABLE 5. Setation of swimming legs P1-P4 of Emertonia berndi sp. nov.

\begin{tabular}{lccc}
\hline & Basis & Exopod & Endopod \\
\hline P1 & 1.1 & 0.022 & 0.020 \\
P2 & 0.0 & 0.0 .022 & 010 \\
P3 & 0.0 & 0.0 .022 & 010 \\
P4 & 0.1 & 0.0 .011 & 0.010 \\
\hline
\end{tabular}

P1 (Fig. 27A). Coxa not visible. Basis with two spinules at inner margin, one inner and one outer pinnate seta. Enp slightly longer than exp, both rami two-segmented and exp2 and enp1 ornamented with spinules on outer margin. Enp1 unarmed, enp2 terminally with one long unipinnate seta and one shorter naked slighty displaced outer seta. Exp1 with one outer naked spine. Exp2 with two outer unipinnate spines and terminally two unipinnate setae.

P2-P4 (Fig. 27B-D). Coxa anteriorly with short row of outward facing flexible setules. Basis of P2-P4 with a spinule row on outer margin. Basis P4 bearing one naked outer seta. Three-segmented exopods slightly longer than endopods with spinules along outer margin and terminally (P2-P4). Exp1 and exp2 with strong serrated outer spines and spinules at the spine's base. Exp2 P3 with three spinules situated on pronounced ledge on inner margin. Exp2 $\mathrm{P} 4$ with one spinule situated on pronounced ledge and one at apical part of inner margin. Exp3 with spine-like spinules at base of all setae (P2-P4). Exp3 P2 and P3 with four elements. Exp3 P2 with two strongly serrated outer spines and two apical setae, the outermost of which long spine-like and serrated at distal half and the innermost long flexible and naked. Exp3 P3 as in P2, but inner apical seta plumose with pinnules on inner side. Exp3 P4 with two serrated spines (one short outer and one long terminal). Endopods P2 and P3 one-segmented with spinules along the outer margin and an additional terminal spinule row. Spinule row on outer margin of enp P2 ending below apical margin in an inward curve. Enp P2 with additionally two very long spinules at two thirds of the outer margin. Enp P3 with three spinules on a ledge on inner margin. Enps P2 and P3 apically with long, rigid, spine-like bipinnate seta. Endopod P4 two-segmented, armed with spinules along outer margin, one inner spinule on enp1 and three slender inner spinules on a ledge on enp2. Enp2 P4 apically with one spine-like seta jaggedly serrated at tip. 

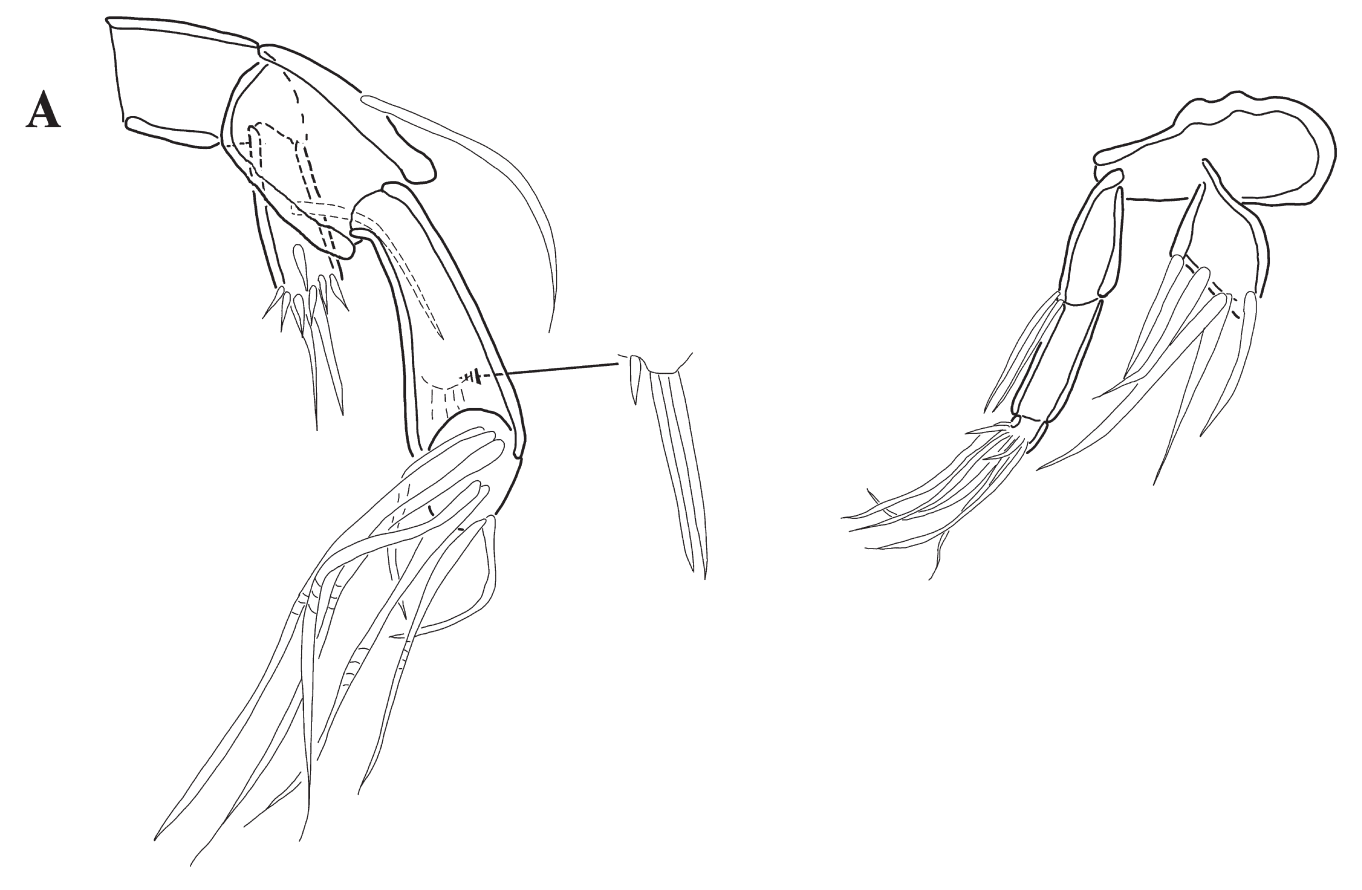

B
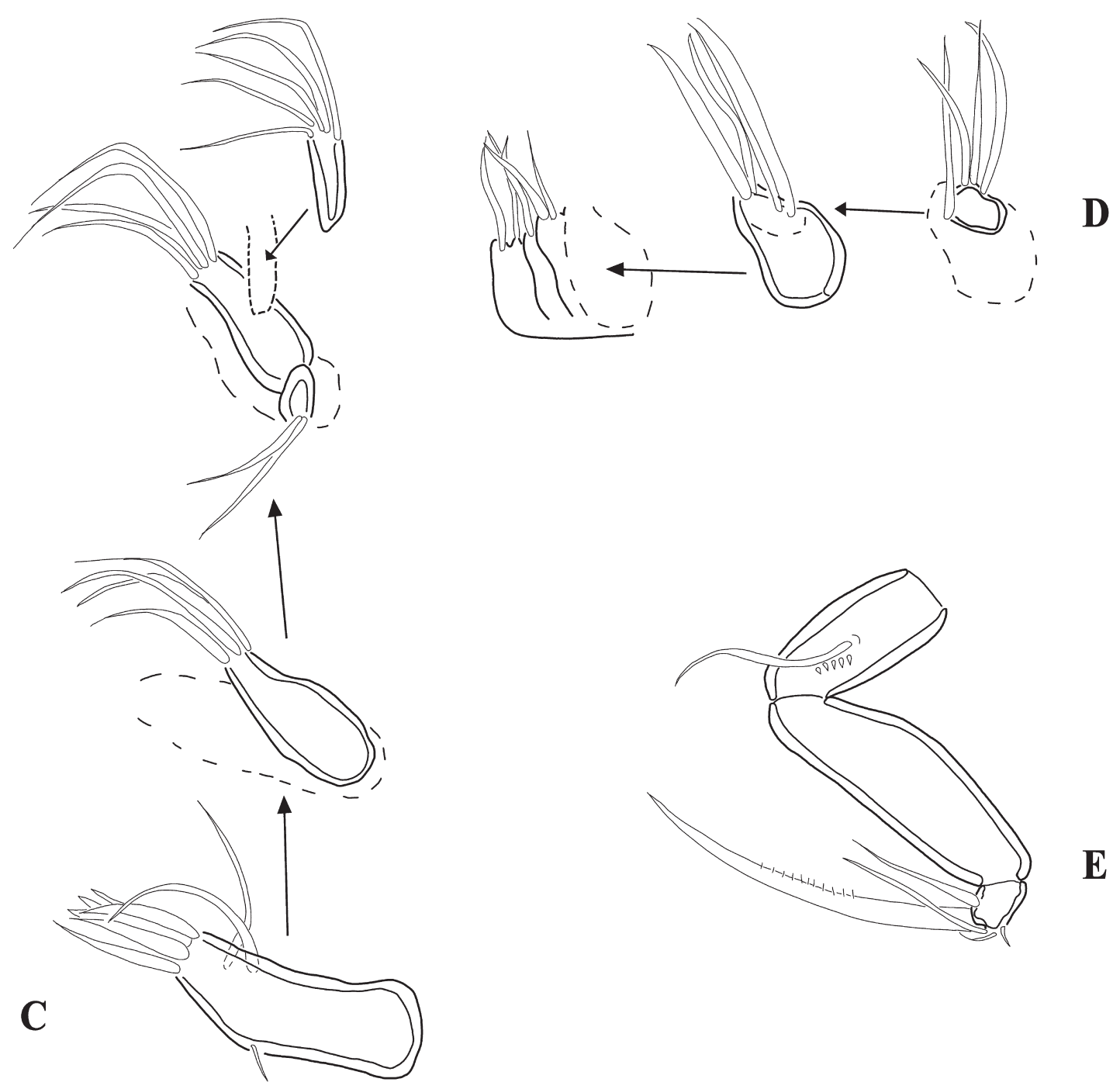

E

FIGURE 26. Emertonia berndi sp. nov. Female. A, antenna (paratype 1); B, mandibular palp (paratype 3); C, maxillule, disarticulated (paratype 2); D, maxilla (paratype 2); E, maxilliped (paratype 1). Scale bar $=0.01 \mathrm{~mm}$. 

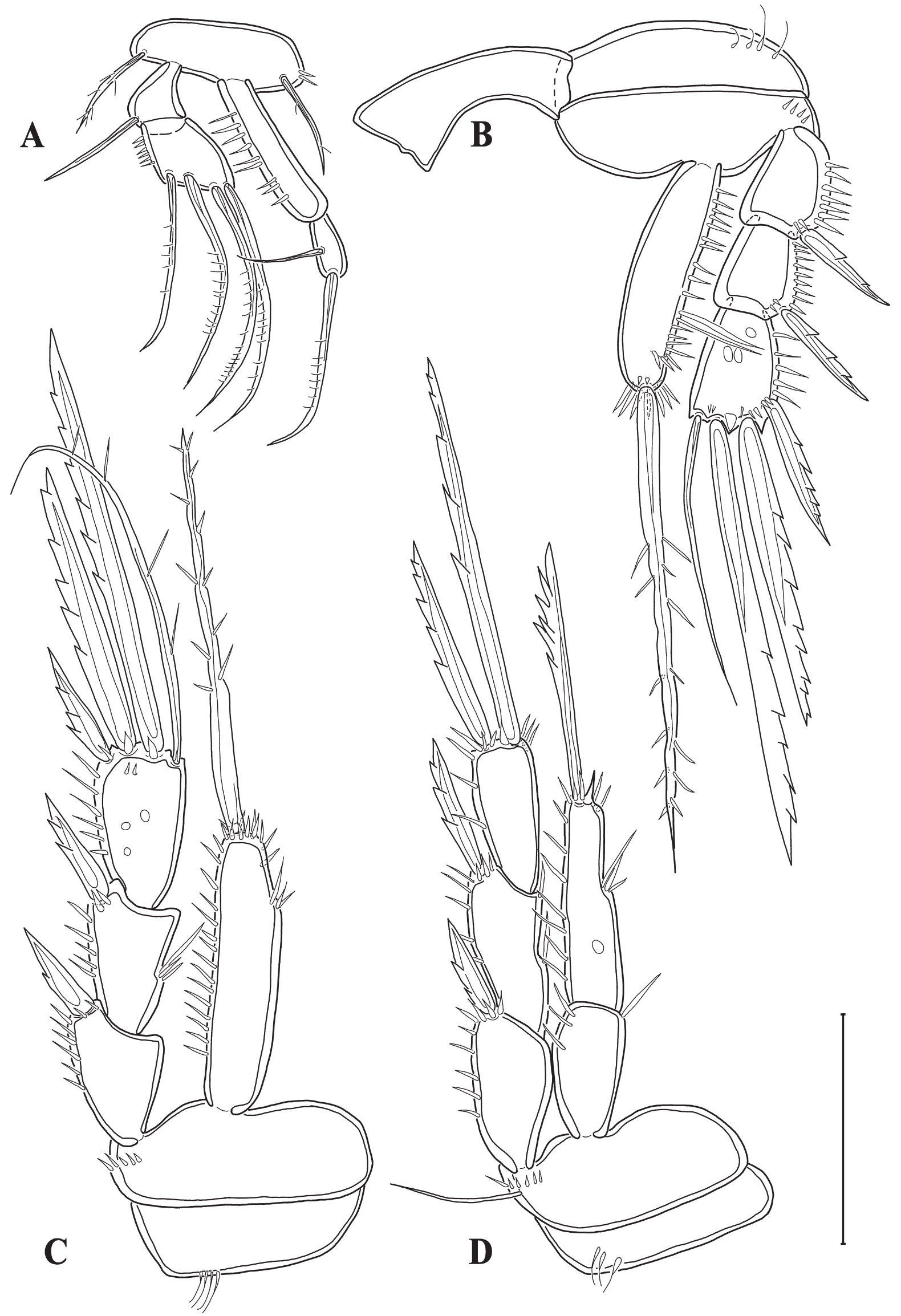

FIGURE 27. Emertonia berndi sp. nov. Female (holotype). A, P1; B, P2 with intercoxal sclerite; C, P3; D, P4. Scale bar = 0.02 $\mathrm{mm}$. 
P5 (Fig. 28A). Legs of P5 fused in the middle. Exopod and baseoendopod fused, forming a non-segmented plate. Benp with outer long basal naked seta and short spinule rows on surface proximally from exp. Endopodal lobes drawn out with medial cleft, each armed with two pinnate setae. Exopodal parts with three naked setae, with the innermost being shortest and the outer being the longest seta. The outer and inner setae are spine-like while the middle seta is more slender, flexible and outwardly oriented. Exopodal part of right body side with a short spinule row near innermost seta.

P6 and genital field see Fig. 28B. Sixth pair of legs represented by small wavily fused outgrowths bearing two small inner thorns on each side.

Male. Unknown.

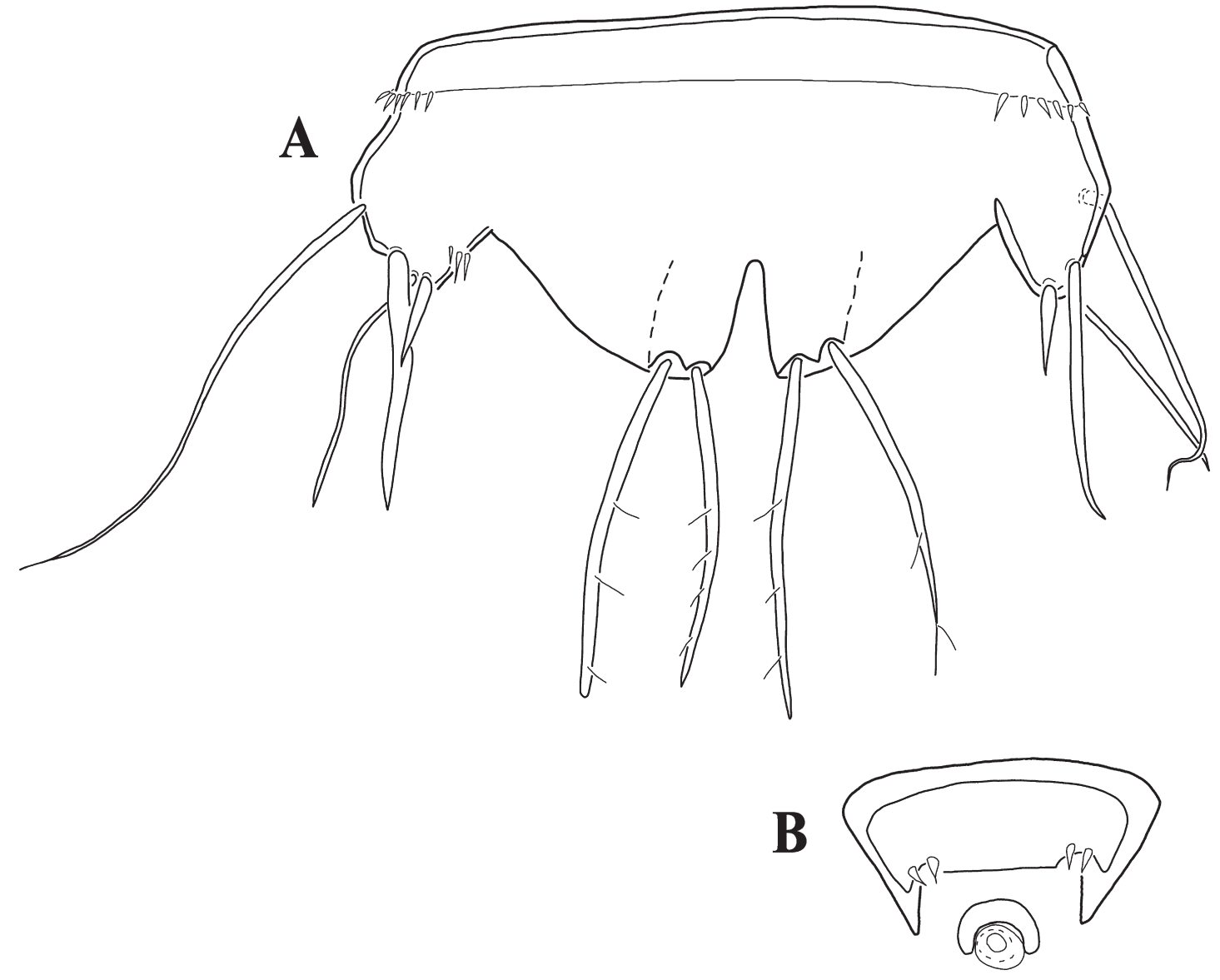

FIGURE 28. Emertonia berndi sp. nov. Female (holotype). A, P5 (holotype); B, P6 and genital field. Scale bar $=0.02 \mathrm{~mm}$.

\section{Discussion}

\section{Taxonomic history of the genus Emertonia}

The genus Emertonia was proposed by Wilson (1932) for the type species Emertonia gracilis Wilson, 1932. Kunz (1962) established the genus Kliopsyllus Kunz, 1962 to accommodate four species from the genera Paramesochra T. Scott, 1892 and Leptopsyllus T. Scott, 1894 (originally described as Leptopsyllus coelebs Monard, 1928, L. constrictus Nicholls, 1935, Paramesochra holsatica Klie, 1929 and P. major Nicholls, 1939) (Monard 1928; Klie 1929; Nicholls 1935, 1939). At that time Kunz (1962) was uncertain whether Emertonia gracilis should be part of the genus Kliopsyllus and therefore regarded it as species incerta.

Huys (2009) re-examined the remaining syntypes of Emertonia gracilis and concluded that they completely matched the diagnosis of Kliopsyllus given by Kunz $(1962,1981)$ and Apostolov \& Marinov (1988). Since the generic name Kliopsyllus became a junior subjective synonym of Emertonia it was replaced by the latter.

Based on WoRMS Editorial Board (2017), the genus Emertonia contains at present 48 species, including the four new species presented herein. The most recently described species are Emertonia clausi and E. ingridae by 
Pointner et al. (2013) and E. koreana Back \& Lee, 2017 and E. simplex Back \& Lee, 2017 by Back \& Lee (2017), in addition to those originally described as Kliopsyllus species: E. andeep (Veit-Köhler, 2004), E. diva (Veit-Köhler, 2005), E. brevicaudata (Kornev \& Chertoprud, 2008), E. schminkei (Veit-Köhler \& Drewes, 2009) and E. minor (Vasconcelos, Veit-Köhler, Drewes \& Parreira dos Santos, 2009) (Veit-Köhler 2004; 2005; Kornev \& Chertoprud 2008; Vasconcelos et al. 2009; Veit-Köhler \& Drewes 2009).

\section{Placement and differentiation of Emertonia berndi sp. nov., E. hessleri sp. nov., E. ilse sp. nov. and E. serrata sp. nov.}

Following the latest classification of the Paramesochridae, the four new species are assigned to the genus Emertonia. According to Easton \& Thistle (2016) morphological and genetic analyses produced the same taxonomic classifications. Therefore, this generic placement is based on the combination of characteristics for Emertonia, as given by Veit-Köhler (2004): the two-segmented rami of P1, the 3-segmented exopod of P2-P4, the presence of two setae on P4 exp3 and the 1-segmented endopod bearing one seta in P2 and P3. Within the genus the four new species are assigned to the "andeep-group" established by Back \& Lee (2017). The species of this group are characterized by the 2-segmented endopod of P4. The six species of the andeep-group can be differentiated by the key below.

\section{Key to species of the Emertonia andeep-group}

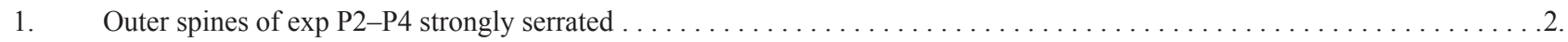

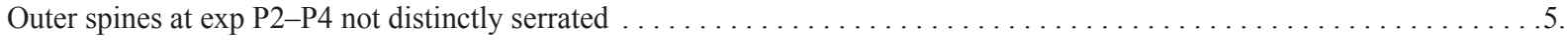

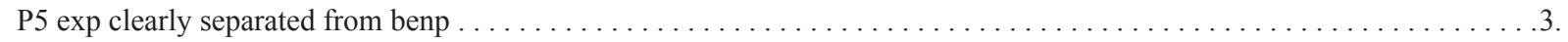

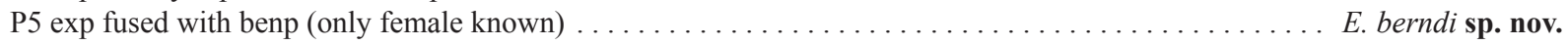

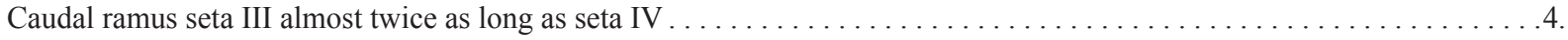

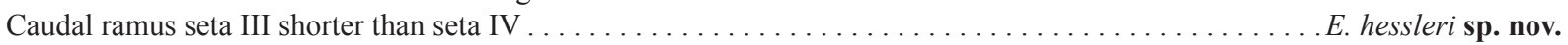

Caudal ramus setae III and V with clearly visible internal structure, seta III naked . . . . . . . . . . E. ilse sp. nov. Caudal ramus setae III and V without clearly visible internal structure, seta III unipinnate . . . . . . . . . E. serrata sp. nov. Anal somite laterally with strong, chitinous, dorsally flexed appendages (distinct hook-like structures) . ............

E. andeep (Veit-Köhler, 2004).

Anal somite without such structures. ......... E. minor (Vasconcelos, Veit-Köhler, Drewes \& Parreira dos Santos, 2009).

Emertonia berndi sp. nov., E. hessleri sp. nov., E. ilse sp. nov., and E. serrata sp. nov. are each unique within the genus. Their characteristics will be compared below to the original descriptions of previously established species. Unfortunately, most of the older descriptions of Emertonia species contain poor illustrative and descriptive information on the mouthparts. Hence, these particular attributes cannot be verified in detail for all species.

Antenna. Emertonia ilse sp. nov., unlike the other new species, bears two setae with transversally cut tips on the antennary exopod. This type of seta can also be found in E. andeep, E. diva and E. schminkei, where the exopod bears four such setae (Veit-Köhler 2004, 2005; Veit-Köhler \& Drewes 2009). Many of the more recently described species also have transformed setae on the antennary exopod. However, they have transversal brushlike tips and not transversally cut, bare tips on the antennary exopod. Emertonia regulexstans (Mielke, 1984a), E. similis (Mielke, 1984a) and E. unguiseta (Mielke, 1984a) from the Galapagos Islands have two, while E. constricta pacifica (Mielke, 1984b), E. panamensis (Mielke, 1984b), and E. chilensis (Mielke, 1985) have only one of these transformed setae (Mielke 1984a, 1984b, 1985). All four new species have subapical setae on the second endopodal segment of the antenna. While E. berndi sp. nov. and E. ilse sp. nov. have one short and two long setae situated in a similar manner as in E. diva, E. hessleri sp. nov. has four very long setae and E. serrata sp. nov. only one.

Maxilliped. The maxilliped of Emertonia ilse sp. nov. bears two short spines and one long naked seta on the endopod which is a unique condition in the genus. In contrast, the maxilliped of E. hessleri sp. nov. (and E. minor) bears one small spine adjacent to the one long naked seta. While E. hessleri sp. nov. and E. ilse sp. nov. do not have spinule rows on their maxilliped, E. serrata sp. nov. has a spinule row on the basis and E. berndi $\mathbf{s p}$. nov. on the syncoxa. Like E. serrata sp. nov., E. andeep has a spinule row on the basis of the maxilliped, however the spinules are much longer. Similar to E. berndi sp. nov., E. schminkei has a row of spinules on the syncoxa of the maxilliped, this row however has longer spinules. In comparison, E. clausi and E. ingridae have two short rows of spinules on the syncoxa of the maxilliped. Emertonia ingridae has spinule rows on the syncoxa and the basis, which makes it unique at least within the lately described Emertonia species, since this characteristic may have been overlooked in the older descriptions. 
Swimming legs. Emertonia berndi sp. nov., E. hessleri sp. nov., E. ilse sp. nov., and E. serrata sp. nov. are the only known species in the genus that show strongly serrated outer spines on the exopods of P2-P4. The closest condition to this is found in E. regulexstans, E. similis and E. unguiseta, which show tooth-like indentations on the same spines (Mielke 1984a). But whereas these indentations are only superficial, the serrations in E. serrata sp. nov., E. ilse sp. nov., E. hessleri sp. nov., and E. berndi sp. nov. are very deep, reaching far into the spines.

Outer spinules are present on most endopods and exopods of P2-P4 in E. berndi sp. nov., E. hessleri sp. nov., E. ilse sp. nov. and E. serrata sp. nov. This characteristic can also be found in other Emertonia species, such as E. andeep, E. clausi, E. diva and E. holsatica varians (Kunz, 1951) (Kunz 1951; Veit-Köhler 2005; Pointner et al. 2013). Emertonia berndi sp. nov. has the additional distinctive feature of two very long spinules in the distal third of the outer margin of the $\mathrm{P} 2$ endopod. Other species, like E. andeep and E. diva, also show variations in the length of the spinules along the outer margin, but they are not restricted to only a few spinules. The P4 of E. hessleri $\mathbf{s p .}$ nov. differs from that of the other new species in having only sparse ornamentaion on exp1 and none along the outer margin of exp2 and 3.

Within the genus Emertonia, E. berndi sp. nov., E. hessleri sp. nov., E. ilse sp. nov., and E. serrata sp. nov. are the only species with spinules that are situated on ledges along the inner margin of the swimming legs. While $E$. ilse sp. nov. has three spinules situated on ledges (one on P3 exp2, P4 exp2 and P2 endopod, respectively), E. berndi sp. nov. has groups of three spinules on three different ledges (on the inner margins of exp2 and endopod of P3 and P4 enp2). Emertonia hessleri sp. nov. and E. serrata sp. nov., however, have less pronounced ledges (E. serrata sp. nov. has one on endopod of $\mathrm{P} 2$, one on endopod and exp2 of $\mathrm{P} 3$ and $\mathrm{P} 4 \mathrm{exp} 3$, while E. hessleri sp. nov. has one on exp1 and two on exp2 of P4, one on endopod of $\mathrm{P} 2$ and one on $\mathrm{P} 4$ enp2). A very conspicuous attribute, which is so far known only in E. berndi sp. nov., is a short row of anteriorly situated, outward facing, flexible setules on the anterior surface of the coxa.

P4. Most Emertonia species have a one-segmented P4 endopod. Emertonia andeep, E. berndi sp. nov., E. hessleri sp. nov., E. ilse sp. nov., E. minor and E. serrata sp. nov., however, show the two-segmented condition for this ramus ("andeep-group" as defined by Back \& Lee 2017). The first endopodal segment carries an inner spinule (E. andeep has a seta) and the second carries one apical seta, as observed in other Emertonia species (Veit-Köhler 2004; Vasconcelos et al. 2009). As mentioned by Veit-Köhler (2004), Paramesochra also has an inner seta on P4 enp1, but two-segmented endopods in P2-P3 and only one seta on P4 enp2. While Wellsopsyllus Kunz, 1981 has the same combination of one-segmented endopods in P2-P3 and a two-segmented P4 endopod, it bears no setae on the endopods of P2-P3 and only one seta on the endopod of P4.

Another unusual character is that E. berndi sp. nov., E. hessleri sp. nov. and E. serrata sp. nov. have deep serrations on the apical seta of $\mathrm{P} 4$ enp2. While E. berndi sp. nov. and E. serrata sp. nov. have more jagged-like serrations, E. hessleri $\mathbf{s p . ~ n o v . ~ h a s ~ s o m e ~ d e e p ~ s e r r a t i o n s ~ a t ~ t h e ~ t i p ~ o f ~ t h i s ~ s e t a . ~ T h e s e ~ c h a r a c t e r i s t i c s ~ c a n ~ a l s o ~ b e ~ f o u n d ~}$ in E. acutifurcata (Mielke, 1985) which, like E. berndi sp. nov. and E. serrata sp. nov., has several outward facing, jagged-like serrations. Conversely, E. chilensis and E. debilis (Kunz, 1981) resemble E. hessleri sp. nov. in having serrations only at the tip of the seta (Mielke 1985), with the former two species showing some additional serrations on this apical seta (Kunz 1981; Mielke 1985). Emertonia ilse sp. nov., contrary to E. berndi sp. nov., E. hessleri sp. nov. and E. serrata sp. nov., has a short, naked, spine-like seta apically on $\mathrm{P} 4$ enp2. This condition can also be found in E. enalia (Krishnaswamy, 1957), E. idiotes (Wells, 1967), E. insularis (Kunz, 1981) and E. longifurcata (Scheibel, 1975) (Krishnaswamy 1957; Wells 1967; Kunz 1981; Scheibel 1975).

P5. In all new species, the second outermost seta on the P5 exopod is more flexible and outwardly directed (contrary to the other spine-like setae). In E. ilse sp. nov., E. hessleri sp. nov. and E. serrata sp. nov. this seta originates from a protrusion, a character not found anywhere else in the genus.

All four new species have spinule rows on the surface of the baseoendopod. Both sexes of $E$. ilse sp. nov., $E$. hessleri sp. nov. and E. serrata sp. nov. and the females of $E$. berndi sp. nov. have short, slightly curved spinule rows on the anterior surface of the baseoendopod, near the outer margin. Females of E. hessleri sp. nov., E. ilse sp. nov. and E. serrata sp. nov. also show halfmoon-shaped spinule rows on the anterior surface of the endopodal lobes of the baseoendopod.

Spinules on the surface of the baseoendopod can also be found in E. andeep and E. diva. Contrary to the newly described species, $E$. andeep has three spinule rows on each of the drawn-out, endopodal lobes and $E$. diva has hedgehog-like arranged spinule rows at the inner margin of the exopod. Other species of Emertonia do not have spinules on the surface of the benp. These could have been overlooked in earlier descriptions since Emertonia species are typically minute and older optical devices offered markedly lower resolution. 
Caudal rami. All four new species have very short caudal rami compared to their width, being only two to three times longer than wide. Many Emertonia species show the same length:width ratio, such as E. capensis Krishnaswamy, 1957, E. panamensis and E. regulexstans (Krishnaswamy 1957; Mielke 1984a, 1984b).

While in E. berndi sp. nov. and Emertonia hessleri sp. nov. seta III is the shortest of the terminal setae on the caudal rami, in E. ilse sp. nov. and E. serrata sp. nov. seta IV is the shortest. In all Emertonia species described so far seta III is short, except in E. spiniger (Wells, Kunz \& Rao, 1975) which has only two terminal setae (Wells et al. 1975). To date, E. ilse sp. nov. and E. serrata sp. nov. are the only species in the genus in which seta IV of the caudal rami is the shortest. The two longest terminal setae in E. berndi and E. hessleri (IV and V), and E. ilse (III and $\mathrm{V})$ are characterized by distinct, clearly visible inner structures. These structures are lacking in the longest terminal setae of E. serrata (III and V).

In conclusion, the strongly serrated spines on the exopods of $\mathrm{P} 2-\mathrm{P} 4$ and the outwardly directed, flexible seta on the exopod of $\mathrm{P} 5$ are the most striking characters of $E$. berndi $\mathbf{s p . ~ n o v . , ~ E . ~ h e s s l e r i ~} \mathbf{s p . ~ n o v . , ~ E . ~ i l s e ~ s p . ~ n o v . ~ a n d ~} E$. serrata sp. nov. They support a close relationship between these four, otherwise distinctly different, species.

\section{Biogeography}

Little is known about large-scale distributional patterns among deep-sea meiofaunal species. First studies addressed the geographical distribution of nematodes (e.g. Lambshead et al. 2003; Brandt et al. 2007). Seifried (2004) summarized the state of knowledge on deep-sea Harpacticoida and called for studies on abundance, distribution, and diversity at species level. Only recently an increasing number of studies provided insight into the diversity and biogeography of certain harpacticoid taxa (Gheerardyn \& Veit-Köhler 2009: Southeastern Atlantic and Southern Ocean; Menzel 2011 and Menzel et al. 2011: Pacific, Atlantic and Southern Ocean, Mediterranean; Menzel \& George 2012: Southeastern Atlantic; Pointner et al. 2013: Pacific, Atlantic and Southern Ocean).

Large-scale distribution surveys on deep-sea Paramesochridae started with the study by Gheerardyn \& VeitKöhler (2009). Pointner et al. (2013) found the same deep-sea paramesochrid species in the Northeast Atlantic, the Southeastern Atlantic and in the Northeastern Pacific Nodule Province. According to these studies the dispersal potential of Paramesochridae in the deep sea is virtually limitless.

Large distribution ranges in harpacticoid species were confirmed by genetic studies carried out by Easton \& Thistle (2016), revealing that $13.3 \%$ of their studied benthic copepod species had ranges greater than $1,000 \mathrm{~km}$. Since benthic copepods have no pelagic larval stages in their life history, these authors stated that deep-sea harpacticoids allow for a conservative test of hypotheses about species' range sizes. The question of how these species maintain genetic continuity over these long distances has remained as yet unanswered.

The species' ranges by far exceed the distances that can be traversed by harpacticoid copepods throughout their individual lifespans (Menzel et al. 2011) which may be compared to their small body size impressively long. The modeled generation time for deep-sea harpacticoid species is around one year (Veit-Köhler, pers. comm.). The four new Emertonia species fit the previously observed pattern of widely distributed and only locally found paramesochrid species (Gheerardyn \& Veit-Köhler 2009; Pointner et al. 2013).

\section{Rareness of Emertonia species}

The new species were found in a small number of stations (11) compared to the total number of 74 investigated stations - most of them sampled during the Census of Abyssal Marine Life (CeDAMar). A total of 875 sediment samples (mainly collected with multicorers) were checked in the course of this study (Fig. 2). The number of copepods examined (adults and copepodids) totalled more than 73,000 individuals. Assuming a percentage of 30\% adults in deep-sea harpacticoid communities (George et al. 2014), the 49 collected adult individuals of the four new species (out of approx. 22,000 inspected adult copepods) show their rareness compared to other, more typical deep-sea taxa (e.g. Argestidae: $c f$. Menzel 2011). However, species such as E. andeep, described from only two specimens found during the ANDEEP II expedition to the Weddell Sea (Veit-Köhler 2004), proved to be extremely wide-spread when samples of other expeditions were taken into account (Gheerardyn \& Veit-Köhler 2009). The same is true for E. serrata sp. nov. which was reported only from the Southeastern Atlantic (Gheerardyn \& VeitKöhler 2009; as their putative species Kliopsyllus sp. 1). Three of the four new species proved to be extremely widespread. Consequently, the rareness of Paramesochridae in the deep sea does not necessarily exclude their 
suitability as model organisms for distribution range studies of benthic copepods. Moreover, their easy-to-assess simple morphology with a reduced segmentation and setation of the swimming legs, and their ubiquity makes biogeography studies on deep-sea Paramesochridae a straightforward and rewarding task.

\section{Wide distribution of shared characters}

Each one of the newly described Emertonia species shows the same new characters that had not previously been observed in the genus Emertonia: serrated spines on the exopods of P2-P4 and an outwardly directed, flexible seta on the exopod of P5. It has become apparent that the presence of these features is very widely spread (Fig. 2; Table 1 ) as the distribution ranges of the new species are large and differ strongly.

Specimens of E. serrata sp. nov. were found in stations in the Atlantic Ocean and the Southern Ocean. The species' range extended from the Porcupine Abyssal Plain in the north and the Angola Basin in the southeast to the sub-Antarctic Crozet Plateau and the Southern Polar Front at $52^{\circ} \mathrm{S}$. Emertonia serrata sp. nov. thus shows the widest distribution range of the four species, spanning more than 11,000 km. Emertonia ilse sp. nov. was first collected in the Pacific Ocean from the San Diego Trough off California in the north in 1987 and later rediscovered in 2001 on the continental margin off the Chilean island Chiloé in the south $(9,500 \mathrm{~km})$. Specimens of E. hessleri sp. nov. were recorded during the same two expeditions but only from the San Diego Trough and the northernmost Chilean station off Antofagasta. Emertonia berndi sp. nov. had the smallest observed distribution range. It was only found in one locality at the Southern Polar Front $\left(52^{\circ} \mathrm{S}\right)$ in the Southern Ocean (Fig. 2; Table 1). Whether this finding is due to a certain degree of endemism expressed by this species, an indication towards local aggregations of these otherwise very rare animals, or the result of undersampling remains to be determined. The actual sampling effort carried out during the respective expeditions can be derived from the original studies and cruise reports (see 2. Material and methods).

\section{Distribution range discrepancies}

The variety in the distribution ranges of the four new species is in line with prior findings. Gheerardyn \& VeitKöhler (2009) and Pointner et al. (2013) found that several species in the genus Emertonia, have a wide distribution range, spanning thousands of kilometers, whereas others are restricted to single regions. Pointner et al. (2013) emphasize that even closely related species may inhabit disjoint areas. Furthermore, such distribution heterogeneity is not restricted to Paramesochridae, but also applies to other Harpacticoida (e.g. Menzel et al. 2011; Easton \& Thistle 2016). Submarine ridges are assumed to have a natural barrier effect, but Gheerardyn \& Veit-Köhler (2009) and Menzel et al. (2011) observed that they may not be limiting the dispersal of benthic harpacticoids.

Land masses such as the Central American Isthmus that separates the Atlantic from the Central Pacific are natural barriers for the dispersal of deep-sea species. However, a study on fossil records from a bitumen clast in Oman shows that modern freshwater copepods have existed since at least late Carboniferous times (c. $303 \mathrm{Ma}$ ) (Selden et al. 2010). Since freshwater harpacticoids originate from marine ancestors, the latter must have existed long before the breakup of Pangaea around 230 million years ago. Therefore, speculations regarding a historical connection can be attempted by assuming great geological ages for the given species, or their recent ancestors. Perhaps the observed distribution patterns originated during the separation of today's ocean regions. The Pacific and Atlantic Oceans diverged in the Miocene (10 Ma) (Scotese et al. 1988). This may have separated the common ancestors of E. serrata sp. nov. (found primarily in Atlantic) and E. ilse sp. nov. and E. hessleri sp. nov. (found in Pacific).

The Drake Passage and Scotia Sea developed around 40 million years ago (Thomson 2004). This possibly permitted E. serrata sp. nov. to disperse to the Southern Ocean. That the Southern Ocean is not a closed system for Paramesochridae is also shown by the distribution patterns of E. andeep and E. diva (Gheerardyn \& Veit-Köhler 2009). Nevertheless, the reason for the restriction to the Antarctic of e.g. Wellsopsyllus (Wellsopsyllus) antarcticus Kottmann \& Veit-Köhler in Kottman et al., 2013, W. (Scottopsyllus) praecipuus (Veit-Köhler, 2000), E. berndi sp. nov., and several other as yet undescribed Paramesochridae remains to be explained (Veit-Köhler 2000; Gheerardyn \& Veit-Köhler 2009; Kottmann et al. 2013). A plausible cause may be the Antarctic Circumpolar Current, which has often been described as a possible barrier for the dispersal of species (Thomson 2004). Maldonado et al. (1998) assume that the full Antarctic Circumpolar Current has begun around the Middle Miocene. 


\section{Means of dispersal}

In general, one would expect that taxa with high dispersal capabilities have stronger links to multiple oceans than groups with reduced dispersal capabilities (such as isopods, ostracods, and nematodes). This is documented in a discussion about the biodiversity and biogeography of macro- and meiobenthic groups in the deep sea of the Southern Ocean presented by Brandt et al. (2007). In particular, they made a link between dispersal capacities and biogeographic patterns in the Antarctic plausible.

The dispersal capabilities of sediment-dwelling harpacticoids are limited due to their non-planktonic larval stages. Many groups, such as Paramesochridae, are additionally restricted in their mobility due to reduced pereiopods and their elongate body shape (Thistle \& Sedlacek 2004).

A possible explanation for the wide distribution in spite of limited mobility are benthic currents (Thistle 1988; Gheerardyn \& Veit-Köhler 2009). This implies that copepods must somehow leave the sediment. However, most sediment-bound harpacticoids are not considered emergers, species defined as capable of actively leaving the sediment. Emergers are identifiable by their pronounced pereiopodal setation (Thistle \& Sedlacek 2004). This does not apply to Paramesochridae. To date only one species of Paramesochridae has been reported to emerge from the sediment (K. Walters pers. comm.). Individuals of Wellsopsyllus intermedius (Scott \& Scott, 1895) (former Intermedopsyllus intermedius) originating from intertidal sediments were observed in the water column (Armonies 1989). Whether these individuals emerged actively or were passively resuspended is not clear.

For the deep sea Thistle (1988) has found that resuspension of meiofauna occurs due to perturbations caused by benthic storms followed by passive transport in benthic currents, which can lead to large-scale dispersal. Menzel et al. (2011) confirmed that whereas the morphology of copepods influences their individual mobility and vertical distribution, it ultimately does not determine their overall geographical range.

\section{Acknowledgements}

We are grateful to Bernd Mathiske for proof-reading an earlier version of the manuscript and Anja Rüten-Budde who-at the age of 14-drew the female habitus and swimming legs of Emertonia hessleri sp. nov. (Figs 17, 20). Leon Hoffman is acknowledged for creating the distribution map (Fig. 2). We are grateful to Rony Huys for thoroughly reviewing and editing the manuscript. Thanks also to the crews and captains of the respective expeditions carried out with D.S.V. Alvin (from board of the RV Atlantis II), RV Polarstern, RV Sonne, and RV Meteor. The Census of Marine Life projects CeDAMar and CAML as well as Senckenberg am Meer-DZMB and Alfred-Wegener-Institute of Polar and Marine Research, Germany are thanked for financial and logistic support. Prof. Pedro Martínez Arbizu provided access to the deep-sea samples collected during the course of CeDAMar and facilitated the participation of GV-K in the SYSTCO expedition. At the DZMB Jutta Heitfeld, Annika Hellmann, Marco Bruhn, Katharina Bruch, Daniela Hugo, Jan Knott, Johanna Kottmann, Christoph Plum, Karin Pointner, and Markus Schulz sorted the meiofauna. This is ANDEEP publication number 220 and publication number 50 that uses data from the Senckenberg am Meer Confocal Laserscanning Microscope Facility.

\section{References}

Apostolov, A. \& Marinov, T.M. (1988) Copepoda Harpacticoida (morski kharpaktikoidi). [Copepoda, Harpacticoida (marine harpacticoids)]. Fauna Bolgarii [Fauna Bulgarica], 18, 1-384. [in Bulgarian]

Armonies, W. (1989) Meiofaunal emergence from intertidal sediment measured in the field: significant contribution to nocturnal planktonic biomass in shallow waters. Helgoländer Meeresuntersuchungen, 43, 29-43. https://doi.org/10.1007/bf02365548

Back, J. \& Lee, W. (2017) Two new species of the genus Emertonia Wilson, 1932 from Korean waters (Copepoda, Harpacticoida, Paramesochridae). ZooKeys, 718, 35-64. https://doi.org/10.3897/zookeys.718.19959

Barnett, P.R.O. (1968) Distribution and ecology of harpacticoid copepods of an intertidal mud flat. Internationale Revue der gesamten Hydrobiologie, 53, 177-209. https://doi.org/10.1002/iroh.19680530202

Barnett, P.R.O., Watson, J. \& Connelly, D. (1984) A multiple corer for taking virtually undisturbed samples from shelf, bathyal and abyssal sediments. Oceanologica Acta, 7, 399-408. 
https://doi.org/10.1017/s0269727000014846

Boxshall, G.A. \& Halsey, S.H. (2004) An Introduction to Copepod Diversity. Ray Society, London, xv +966 pp.

Brandt, A., Gooday, A.J., Brandão, S.N., Brix, S., Brökeland, W., Cedhagen, T., Choudhury, M., Cornelius, N., Danis, B., De Mesel, I., Diaz, R.J., Gillan, D.C., Ebbe, B., Howe, J.A., Janussen, D., Kaiser, S., Linse, K., Malyutina, M., Pawlowski, J., Raupach, M. \& Vanreusel, A. (2007) First insights into the biodiversity and biogeography of the Southern Ocean deep sea. Nature, 447, 307-311. https://doi.org/10.1038/nature05827

Büntzow, M. (2011) Vergleichende gemeinschaftsanalytische und taxonomische Untersuchungen der Harpacticoidenfauna der Seeberge „Sedlo“ und „Seine“ (nördlicher Mittelatlantik). Ph.D. dissertation, Carl von Ossietzky Universität Oldenburg, Oldenburg, Lower Saxony, viii + 128 pp., unpaginated tables A1-A30.

Chertoprud, E.S., Garlitska, L.A. \& Azovsky, A.I. (2010) Large-scale patterns in marine harpacticoid (Crustacea, Copepoda) diversity and distribution. Marine Biodiversity, 40, 301-315. https://doi.org/10.1007/s12526-010-0054-z

Easton, E.E. \& Thistle, D. (2016) Do some deep-sea, sediment-dwelling species of harpacticoid copepods have $1000 \square \mathrm{km} \square \mathrm{scale}$ range sizes? Molecular Ecology, 25, 4301-4318. https://doi.org/10.1111/mec.13744

GEBCO (2014) GEBCO_2014 Grid. Version 20150318. Available from: http://www.gebco.net (accessed April 2019)

George, K.H., Veit-Köhler, G., Martínez Arbizu, P., Seifried, S., Rose, A., Willen, E., Bröhldick, K., Corgosinho, P.H., Drewes, J., Menzel, L., Moura, G. \& Schminke, H.K. (2014) Community structure and species diversity of Harpacticoida (Crustacea: Copepoda) at two sites in the deep sea of the Angola Basin (Southeast Atlantic). Organisms, Diversity and Evolution, 14, $57-73$. https://doi.org/10.1007/s13127-013-0154-2

Gheerardyn, H. \& Veit-Köhler, G. (2009) Diversity and large-scale biogeography of Paramesochridae (Copepoda, Harpacticoida) in South Atlantic abyssal plains and the deep Southern Ocean. Deep-Sea Research I, 56, 1804-1815. https://doi.org/10.1016/j.dsr.2009.05.002

Gutzmann, E., Martínez Arbizu, P., Rose, A. \& Veit-Köhler, G (2004) Meiofauna communities along an abyssal depth gradient in the Drake Passage. Deep-Sea Research II, 51, 1617-1628. https://doi.org/10.1016/j.dsr2.2004.06.026

Huys, R. (2009) Unresolved cases of type fixation, synonymy and homonymy in harpacticoid copepod nomenclature (Crustacea: Copepoda). Zootaxa, 2183 (1), 1-99. https://doi.org/10.11646/zootaxa.2183.1.1

Huys, R., Gee, J.M., Moore, C.G. \& Hamond, R. (1996) Marine and Brackish Water Harpacticoid Copepods. Part 1. In: Barnes, R.S.K. \& Crothers, J.H. (Eds.), Synopses of the British Fauna. New Series. Vol. 51. Field Studies Council, Shrewsbury, pp. i-viii + 1-352.

IOC, IHO \& BODC (2003) Centenary Edition of the GEBCO Digital Atlas. Published on CD-Rom on behalf of the Intergovernmental Oceanographic Commission and the International Hydrographic Organization as part of the General Bathymetric Chart of the Oceans; British Oceanographic Data Centre, Liverpool. [CD-Rom]

Kalogeropoulou, V., Bett, B.J., Gooday, A.J., Lampadariou, N., Martínez Arbizu, P. \& Vanreusel, A. (2010) Temporal changes (1989-1999) in deep-sea metazoan meiofaunal assemblages on the Porcupine Abyssal Plain, NE Atlantic. Deep Sea Research II, 57, 1383-1395. https://doi.org/10.1016/j.dsr2.2009.02.002

Klie, W. (1929) Die Copepoda Harpacticoida der südlichen und westlichen Ostsee mit besonderer Berücksichtigung der Sandfauna der Kieler Bucht. Zoologische Jahrbücher, Systematik, 57, 329-386.

Kornev, P.N. \& Chertoprud, E.C. (2008) Copepod Crustaceans of the order Harpacticoida of the White Sea: Morphology, Systematics, Ecology. KMK Scientific Press Ltd, Moscow, 379 pp.

Kottmann, J., Kihara, T.C., Glatzel, T. \& Veit-Köhler, G. (2013) A new species of Wellsopsyllus (Copepoda, Harpacticoida, Paramesochridae) from the deep Southern Ocean and remarks on its biogeography. Helgoland marine Research, 67, 3348. https://doi.org/10.1007/s10152-012-0302-7

Krishnaswamy, S. (1957) Studies on the Copepoda of Madras. Ph.D. Thesis, University of Madras, Chennai, Tamil Nadu, 168 $\mathrm{pp}$.

Kunz, H. (1951) Marine Harpacticoiden aus dem Küstensand von Südafrika. Kieler Meeresforschungen, 8, 76-81.

Kunz, H. (1962) Revision der Paramesochridae (Crustacea Copepoda). Kieler Meeresforschungen, 18, $245-257$. https://doi.org/10.1016/0011-7471(64)90100-7

Kunz, H. (1981) Beitrag zur Systematik der Paramesochridae (Copepoda, Harpacticoida) mit Beschreibung einiger neuen Arten. Mitteilungen des Zoologischen Museums der Universität Kiel, 1, 2-33.

Lambshead, P.J.D., Brown, C.J., Ferrero, T.J., Hawkins, L.E., Smith, C.R. \& Mitchell, N.J. (2003) Biodiversity of nematode assemblages from the region of the Clarion-Clipperton Fracture Zone, an area of commercial mining. BMC Ecology, 3, $1-12$. https://doi.org/10.1186/1472-6785-3-1

McIntyre, A.D. \& Warwick, R.M. (1984) Meiofauna techniques. In: Holme, N.A. \& McIntyre, A.D. (Eds.), Methods for the 
Study of Marine Benthos. $2^{\text {nd }}$ Edition. Blackwell Publishing Ltd, London, pp. 217-244.

Mahatma, R. (2009) Meiofauna Communities of the Pacific Nodule Province: Abundance, Diversity and Community Structure. Ph.D. dissertation, Carl von Ossietzky Universität Oldenburg, Oldenburg, Lower Saxony, 143 pp.

Maldonado, A., Zitellini, N., Leitchenkov, G., Balanyá, J.C., Coren, F., Galindo-Zaldívar, J., Lodolo, E., Jabaloy, A., Zanolla, C., Rodríguez-Fernández, J. \& Vinnikovskaya, O. (1998) Small ocean basin development along the Scotia-Antarctica plate boundary and in the northern Weddell Sea. Tectonophysics, 296, 371-402. https://doi.org/10.1016/S0040-1951(98)00153-X

Menzel, L. (2011) First descriptions of copepodid stages, sexual dimorphism and intraspecific variability of Mesocletodes Sars, 1909 (Copepoda, Harpacticoida, Argestidae), including the description of a new species with broad abyssal distribution. ZooKeys, 96, 39-80. https://doi.org/10.3897/zookeys.96.1496

Menzel, L. \& George, K.H. (2009) Description of four new species of Mesocletodes Sars, 1909 (Copepoda, Harpacticoida, Argestidae) and redescription of Mesocletodes robustus Por, 1965 from the South Atlantic, including remarks on the Mesocletodes abyssicola-group. Zootaxa, 2096 (1), 214-256. https://doi.org/10.11646/zootaxa.2096.1.14

Menzel, L. \& George, K.H. (2012) Copepodid and adult Argestidae Por, 1986 (Copepoda: Harpacticoida) in the southeastern Atlantic deep sea: diversity and community structure at the species level. Marine Biology, 159, 1223-1238. https://doi.org/10.1007/s00227-012-1903-z

Menzel, L., George, K.H. \& Martínez Arbizu, P. (2011) Submarine ridges do not prevent large-scale dispersal of abyssal fauna: A case study of Mesocletodes (Crustacea, Copepoda, Harpacticoida). Deep Sea Research I, 58, 839-864. https://doi.org/10.1016/j.dsr.2011.05.008

Michels, J. \& Büntzow, M. (2010) Assessment of Congo red as a fluorescence marker for the exoskeleton of small crustaceans and the cuticle of polychaetes. Journal of Microscopy, 238, 95-101. https://doi.org/10.1111/j.1365-2818.2009.03360.x

Mielke, W. (1984a) Interstitielle Fauna von Galapagos. XXXI. Paramesochridae (Harpacticoida). Microfauna marina, 1, 63147.

Mielke, W. (1984b) Einige Paramesochridae (Copepoda) von Panamá. Spixiana, 7, 217-243.

Mielke, W. (1985) Zwei neue Kliopsyllus Arten (Copepoda) aus Chile. Studies on neotropical Fauna and Environment, 20, 97-105. https://doi.org/10.1080/01650528509360677

Monard, A. (1928) Les Harpacticoïdes marins de Banyuls. Archives de Zoologie expérimentale et générale, 67, $259-443$.

Nicholls, A.G. (1935) Copepods from the interstitial fauna of a sandy beach. Journal of the marine biological Association of the United Kingdom, New Series, 20, 379-405. https://doi.org/10.1017/s0025315400045306

Nicholls, A.G. (1939) Some new sand-dwelling copepods. Journal of the marine biological Association of the United Kingdom, New Series, 23, 327-341. https://doi.org/10.1017/S0025315400013928

Pointner, K., Kihara, T.C., Glatzel, T. \& Veit-Köhler, G. (2013) Two new closely related deep-sea species of Paramesochridae (Copepoda, Harpacticoida) with extremely differing geographical range sizes. Marine Biodiversity, 43, 293-319. https://doi.org/10.1007/s12526-013-0158-3

Rose, A., Ingels, J., Raes, M., Vanreusel, A. \& Martínez Arbizu, P. (2015) Long-term iceshelf-covered meiobenthic communities of the Antarctic continental shelf resemble those of the deep sea. Marine Biodiversity, 45, 743-762. https://doi.org/10.1007/s12526-014-0284-6

Rose, A., Cornelius, N., DeMesel, I., Doner, S., Gooday, A.J., Henche, A., Howe, J.A., Ingels, J. \& Narayanaswamy, B.E. (2006) Meiobenthos. Introduction to work at sea: Multicorer sampling during ANDEEP III. Berichte zur Polar- und Meeresforschung, 533, 85-87.

Rose, A., Seifried, S., Willen, E., George, K.H., Veit-Köhler, G., Bröhldick, K., Drewes, J., Moura, G., Martínez Arbizu, P. \& Schminke, H.K. (2005) A method for comparing within-core alpha diversity values from repeated multicorer samplings, shown for abyssal Harpacticoida (Crustacea: Copepoda) from the Angola Basin. Organisms, Diversity and Evolution, 5 (S1), 3-17. https://doi.org/10.1016/j.ode.2004.10.001

Scheibel, W. (1975) Kliopsyllus longifurcatus n. sp., ein sandbewohnender Harpacticoide (Copepoda) der Kieler Bucht. Crustaceana, 29, 235-240. https://doi.org/10.1163/156854075x00270

Scotese, C.R., Gahagan, L.M. \& Larson, R.L. (1988) Plate tectonic reconstructions of the Cretaceous and Cenozoic ocean basins. Tectonophysics, 155, 27-48. https://doi.org/10.1016/0040-1951(88)90259-4

Scott, T. (1892) Additions to the fauna of the Firth of Forth. Part IV. Reports of the Fishery Board for Scotland, Edinburgh, 10 (3), 244-272.

Scott, T. (1894) Additions to the fauna of the Firth of Forth. Part VI. Reports of the Fishery Board for Scotland, Edinburgh, 12 (3), 231-271. 
Scott, T. \& Scott, A. (1895) On some new and rare Crustacea from Scotland. Annals and Magazine of natural History, Series 6, 15 (85), 50-59. https://doi.org/10.1080/00222939508677847

Seifried, S., (2004) The importance of a phylogenetic system for the study of deep-sea harpacticoid diversity. Zoological Studies, 43, 435-445.

http://zoolstud.sinica.edu.tw/Journals/43.2/435.pdf

Seifried, S. \& Martínez Arbizu, P. (2008) A new and exceptional species of Bradya Boeck, 1873 (Copepoda: Harpacticoida: Ectinosomatidae) from the abyssal plain of the Angola Basin and the variability of deep-sea Harpacticoida. Zootaxa, 1866 (1), 303-322. https://doi.org/10.11646/zootaxa.1866.1.15

Selden, P.A., Huys, R., Stephenson, M.H., Heward, A.P. \& Taylor, P.N. (2010) Crustaceans from bitumen clast in Carboniferous glacial diamictite extend fossil record of copepods. Nature Communications, 1 (50), 1-6. https://doi.org/10.1038/ncomms 1049

Thistle, D. (1988) A temporal difference in harpacticoid-copepod abundance at a deep-sea site: caused by benthic storms? DeepSea Research, 35, 1015-1020. https://doi.org/10.1016/0198-0149(88)90073-8

Thistle, D. \& Eckman, J.E. (1988) Response of harpacticoid copepods to habitat structure at a deep-sea site. In: Boxshall, G.A. \& Schminke, H.K. (Eds.), Biology of Copepods. Proceedings of the Third International Conference on Copepoda. Hydrobiologia, 167/168, 143-149. https://doi.org/10.1007/bf00026300

Thistle, D. \& Eckman, J.E. (1990) The effect of a biologically produced structure on the benthic copepods of a deep-sea site. Deep-Sea Research, 37, 541-554. https://doi.org/10.1016/0198-0149(90)90089-e

Thistle, D. \& Sedlacek, L. (2004) Emergent and non-emergent species of harpacticoid copepods can be recognized morphologically. Marine Ecology Progress Series, 266, 195-200. https://doi.org/10.3354/meps266195

Thomson, M.R.A. (2004) Geological and palaeoenvironmental history of the Scotia Sea region as a basis for biological interpretation. Deep-Sea Research II, 51, 1467-1487. https://doi.org/10.1016/j.dsr2.2004.06.021

Vasconcelos, D.M., Veit-Köhler, G., Drewes, J. \& Santos, P.J.P. (2009) First record of the genus Kliopsyllus Kunz, 1962 (Copepoda Harpacticoida, Paramesochridae) from Northeastern Brazil with description of the deep-sea species Kliopsyllus minor sp. nov. Zootaxa, 2096 (1), 327-337. https://doi.org/10.11646/zootaxa.2096.1.19

Veit-Köhler, G. (2000) Habitat preference and sexual dimorphism in species of Scottopsyllus (Copepoda, Harpacticoida) with the description of Scottopsyllus (S.) praecipuus sp. n. from the Antarctic. Vie et Milieu, 50, 1-17.

Veit-Köhler, G. (2004) Kliopsyllus andeep sp. n. (Copepoda: Harpacticoida) from the Antarctic deep sea-a copepod closely related to certain shallow-water species. Deep-Sea Research II, 51, 1629-1641. https://doi.org/10.1016/j.dsr2.2004.06.027

Veit-Köhler, G. (2005) First deep-sea record of the genus Kliopsyllus Kunz, 1962 (Copepoda: Harpacticoida) with the description of Kliopsyllus diva sp. n. - the most abundant member of Paramesochridae at two different sites of the Angola Basin. Organisms, Diversity and Evolution, 5, 29-41.

https://doi.org/10.1016/j.ode.2004.10.003

Veit-Köhler, G., De Troch, M., Grego, M., Bezerra, T.N., Bonne, W., De Smet, G., Folkers, C., George, K.H., Guotong, C., Herman, R., Huys, R., Lampadariou, N., Laudien, J., Martínez Arbizu, P., Rose, A., Schratzberger, M., Seifried, S., Somerfield, P., Vanaverbeke, J., Vanden Berghe, E., Vincx, M., Vriser, B. \& Vandepitte, L. (2010) Large-scale diversity and biogeography of benthic copepods in European waters. Marine Biology, 157, 1819-1835. https://doi.org/10.1007/s00227-010-1454-0

Veit-Köhler, G. \& Drewes, J. (2009) Kliopsyllus schminkei sp. n. (Copepoda, Harpacticoida, Paramesochridae) —a new copepod from the southeast Atlantic deep sea (Angola Basin). Zootaxa, 2096 (1), 313-326.

https://doi.org/10.11646/zootaxa.2096.1.18

Veit-Köhler, G., Gerdes, D., Quiroga, E., Hebbeln, D. \& Sellanes, J. (2009) Metazoan meiofauna within the oxygen-minimum zone off Chile: Results of the 2001-PUCK expedition. Deep-Sea Research II, 56, 1105-1111. https://doi.org/10.1016/j.dsr2.2008.09.013

Veit-Köhler, G., Guilini, K., Peeken, I., Quillfeldt, P. \& Mayr, C. (2013) Carbon and nitrogen stable isotope signatures of deepsea meiofauna follow oceanographical gradients across the Southern Ocean. Progress in Oceanography, 110, 69-79. https://doi.org/10.1016/j.pocean.2013.01.001

Wells, J.B.J. (1967) The littoral Copepoda (Crustacea) of Inhaca Island, Mozambique. Transactions of the Royal Society of Edinburgh, 67 (7), 189-358. https://doi.org/10.1017/s0080456800024017

Wells, J.B.J., Kunz, H. \& Rao, G.C. (1975) A review of the mechanisms for movement of the caudal furca in the family Paramesochridae (Copepoda Harpacticoida), with a de scription of a new species of Kliopsyllus Kunz. Mikrofauna des 
Meeresbodens, 53, 1-16.

Wilson, C.B. (1932) The copepods of the Woods Hole region, Massachusetts. Bulletin United States National Museum, 158, $1-635$.

https://doi.org/10.5479/si.03629236.158.i

Wolff, G. (2006) Initial Cruise Report. D300 Benthic CROZET, 1 December 2005-14 January 2006, 1-139.

WoRMS Editorial Board (2017) World Register of Marine Species. VLIZ. Available from http://www.marinespecies.org (accessed 15 June 2017) 